University of Louisville ThinkIR: The University of Louisville's Institutional Repository

Electronic Theses and Dissertations

5-2019

\title{
An evaluation of the supply and demand of radiation oncology medical physicists in the United States.
}

Christine Marie Swanson

University of Louisville

Follow this and additional works at: https://ir.library.louisville.edu/etd

Part of the Health and Medical Physics Commons, and the Radiation Medicine Commons

\section{Recommended Citation}

Swanson, Christine Marie, "An evaluation of the supply and demand of radiation oncology medical physicists in the United States." (2019). Electronic Theses and Dissertations. Paper 3224.

https://doi.org/10.18297/etd/3224

This Doctoral Dissertation is brought to you for free and open access by ThinkIR: The University of Louisville's Institutional Repository. It has been accepted for inclusion in Electronic Theses and Dissertations by an authorized administrator of ThinkIR: The University of Louisville's Institutional Repository. This title appears here courtesy of the author, who has retained all other copyrights. For more information, please contact thinkir@louisville.edu. 


\title{
AN EVALUATION OF THE SUPPLY AND DEMAND OF RADIATION ONCOLOGY MEDICAL PHYSICISTS IN THE UNITED STATES
}

\author{
By \\ Christine Marie Swanson \\ B.A., Transylvania University, 2009 \\ M.S., University of Kentucky, 2011
}

\begin{abstract}
A Dissertation
Submitted to the Faculty of the

School of Public Health and Information Sciences

of the University of Louisville

in Partial Fulfillment of the Requirements

for the Degree of
\end{abstract}

Doctor of Philosophy in Public Health Sciences

Department of Health Management and Systems Sciences

University of Louisville

Louisville, Kentucky

May 2019 
Copyright 2019 by Christine Marie Swanson

All rights reserved 



\title{
AN EVALUATION OF THE SUPPLY AND DEMAND OF RADIATION ONCOLOGY MEDICAL PHYSICISTS IN THE UNITED STATES
}

\author{
By \\ Christine Marie Swanson \\ B.A., Transylvania University, 2009 \\ M.S., University of Kentucky, 2011 \\ A Dissertation Approved on
}

April 12, 2019

By the following Dissertation Committee:

Robert J. Esterhay, M.D.

Michael D. Mills, Ph.D.

Douglas J. Lorenz, Ph.D.

P. Jeffrey Potash, Ph.D. 


\section{DEDICATION}

This dissertation is dedicated in memory of my mother

Mrs. Ginger Laurie Luerman

who always supported and believed in me. 


\section{ACKNOWLEDGEMENTS}

I would like to thank my committee chair and advisor, Dr. Robert Esterhay, for his never-ending patience and wisdom. I would also like to thank Dr. Michael Mills for going above and beyond as a committee member in his guidance of this project and for encouraging me to pursue this degree. Also, thank you to Drs. Potash and Lorenz for their continual comments and assistance throughout this project. Additionally, I would like to thank my family for the never-ending support and encouragement. Specifically, thank you to my husband, Zach, for making my life outside of work and school as stress

free as possible and being my constant rock. Also, many thanks to my father and brother for their persistence in driving me to reach my goals despite obstacles. I would like to thank my friends and co-workers who gave me the extra encouragement to finish.

Finally, thank you to my mother who gave me the confidence to always push myself to pursue more in life. 


\title{
ABSTRACT \\ AN EVALUATION OF THE SUPPLY AND DEMAND OF RADIATION ONCOLOGY MEDICAL PHYSICS IN THE UNITED STATES
}

\author{
Christine M. Swanson
}

April 12, 2019

Background: This dissertation is a mixed methods evaluation of the radiation oncology medical physics workforce in the United States. Radiation oncology medical physicists serve a vital role in the safe treatment of patients with radiation therapy. While cancer incidence continues to rise, the pathways to board certification in radiation oncology medical physics continue to narrow causing a potential shortage of radiation oncology physicists in the United States. While there is no lack of data about the medical physics community it has scarcely been used to evaluate the current state of the workforce. In order to ensure patient safety, appropriate physics to patient staffing ratios are important and cannot be sustained without an adequate supply of qualified physicists entering the profession annually.

Purpose: The purpose of this dissertation is to determine the current supply of medical physicists, develop a model to predict the future supply and demand, and evaluate the current job market based on the perceptions of recent graduates. The primary question to be addressed is that based on current data and development of a new supply and demand model, will there be enough Radiation Oncology Physicists to keep up with the supply and demand through 2030 ? 
Secondary questions include: Do the perceptions of recent Masters and $\mathrm{PhD}$ graduates of medical physics support the new model findings of the residency shortage?

Are graduates of residency programs in high demand because of the now single pathway into the field?

Methods: Quantitative methods include standard distributive methods; minimum, maximum, quartiles, mean and medians of data ranges. Qualitative methods include a five-point Likert psychometric scale and open-ended question surveys with radiation oncology medical physics graduate students, residents, and recent retirees. Mixed methods procedures include the use of Stella modeling software used for supply and demand analysis. The anonymized list of potential survey respondents was supplied and coded by the American Association of Physicists in Medicine. Subjects with personal emails for follow up responses obtained institutional Review Board approval due to potential self-identifying information.

Results: Based on modeling results approximately 250 residency positions for radiation oncology medical physicists are needed. This is a growth by almost 100 positions needed urgently to meet the rising demand. Perceptions of recent graduates and residents support the modeling results that limited residency positions are leading to a surplus of graduates with no pathway to board eligibility and thus creating a limitation on the workforce making it difficult to meet the rising demand.

Conclusions: While the medical physics profession is a rewarding career, there are immediate and urgent risks to the future of the medical physics workforce. The lack of residencies will lead to a deficit of almost fifteen percent by 2030 if nothing changes. 
There is an urgent need for a widespread evaluation of the medical physics education pathways to ensure a proper workforce moving forward while meeting the ethical obligation to students to have a pathway to certification in the profession. 
TABLE OF CONTENTS

PAGE

ACKNOWLEDGEMENTS iv

ABSTRACT V v

LIST OF TABLES $\quad$ ix

LIST OF FIGURES $\quad x$

CHAPTER I Ï INTRODUCTION 1

CHAPTER II Ï METHODS

CHAPTER III Ï RESULTS 23

CHAPTER IV Ï DISCUSSION 58

REFERENCES $\quad 64$

APPENDIX 1 ï ACRONYMS $\quad 68$

APPENDIX 2 Ï TERMINOLOGY 69

$\begin{array}{ll}\text { APPENDIX 3- STELLA MODEL } & 73\end{array}$

APPENDIX 4- STUDENT JUNIOR MEMBER SURVEY QUESTIONS 76

APPENDIX 5- STUDENT JUNIOR MEMBER SURVEY RESPONSES 82

APPENDIX 6- FOLLOW UP SURVEY STUDENT JUNIOR MEMBERS 107

APPENDIX 7- EMERITUS MEMBER SURVEY QUESTIONS 130

APPENDIX 8- EMERITUS MEMBER SURVEY RESPONSES 133

APPENDIX 9- FOLLOW UP SURVEY EMERITUS MEMBERS 142

$\begin{array}{ll}\text { APPENDIX- IRB APPROVAL } & 150\end{array}$

CURRICULUM VITA 152 


\section{LIST OF TABLES}

TABLE

PAGE

1. Degree Type by Respondents 34

2. Training and Education Completed by Respondents 35

3. Number of years for applicants have applied for a residency position $\quad 35$

4. Responses to questions about graduate program experience and residency 37 availability

5. Responses from employed physicists post residency 39

6. Responses from unemployed physicists post residency 39 


\section{LIST OF FIGURES}

FIGURE

1. 1. Illustration of modern Linear Accelerator

PAGE

2. Forteôs supply and demand model

3. Millôs 2010 Supply and Demand Model

4. Supply Side of Model Version 1

5. Demand side of Model Version 1

$\begin{array}{ll}\text { 6. Final Model } & 14\end{array}$

7. Sector 1- Supply of Graduates in Residency 23

8. Sector 2- Number of Cancer Patients 26

9. Sector 3- Number of New ROPs Needed Annually 26

10. Sector 4- Current Working ROPs 27

11. Sector 5- Difference between current ROPs and ROPs needed 29

12. Sector 6- Working ROP Impact 29

13. Annual and Cumulative gap in ROPs 30

14. Projected Graduates without Residency 31

15. Cumulative Gap with Ideal Growth in Residency 31

16. Annual gap in ROPs with Realistic Residency Growth 32

17. Cumulative gap in ROPs with Realistic Residency Growth 33

18. Employment type post residency 38

19. Number of years in medical physics profession prior to retirement 52 
20. Reasons for leaving medical physics profession

21. How time spent after leaving profession

22. Education Pathways in medical physics 


\section{CHAPTER 1- INTRODUCTION}

\subsection{Overview}

Medical physics is a career that is unknown to most people. Radiation oncology medical physicists are often hidden behind the scenes in radiation oncology departments ensuring patient safety throughout the entire treatment process in radiation therapy. With only about 3,500 full time equivalent (FTE) radiation oncology medical physicists actively working in the United States, it is not surprising that there is little research on the staffing levels. Over the last fifteen years, new certification and training requirements have been implemented to add credibility to the field and restrict entry pathways. One of the major changes is the implementation of a residency requirement for board certification starting in 2014. With restricted entry pathways comes the inherent risk of not being able to keep pace with the current supply and demand model to maintain adequate staffing levels. The most recent studies done in 2010, project that in order to maintain the current demand between 170 and 200 new American Board of Radiology certified Radiation Therapy physicists will need to enter the field annually (M. Mills, Thornewill, J., and Esterhay, R., 2010). With approximately 150 residency positions currently available, there will be a shortage of board-certified radiation oncology physicists by 2025 and a severe shortage by 2030 . The purpose of this study is to determine the current supply of medical physicists, develop a model to predict the future 
supply and demand, and evaluate the current job market based on the perceptions of recent graduates, residents, and retirees.

\subsection{Background}

To appreciate the importance of the radiation oncology physics workforce it is important first to understand cancer prevalence and the role radiation therapy plays in the treatment of cancer. Cancer is a group of diseases that are characterized by uncontrolled growth and spread of abnormal cells. There are over one hundred known types of cancer and over 1.5 million new cases are diagnosed annually in the United States alone (ASTRO, 2015). Approximately two out of every five Americans will be diagnosed with cancer at some point in their lifetime and it is estimated that a little over 600,000 Americans died in 2017 from cancer (Jemal et al., 2017). The difficult part about cancer is that it is hard to diagnose, treat and cure because it can start in almost any part of the body and can affect people of any age, gender, or race. Every cancer behaves slightly differently and no two people are the same. As a result, cancers are treated in an individualized personal way in which each treatment must be customized to each patient dependent on the type of cancer, the stage of the disease, and other comorbidities. The three major ways to treat cancer are surgery, chemotherapy, and radiation therapy. For the purposes of this study, the focus will be exclusively on those patients receiving radiation therapy.

Nearly fifty percent of all cancer patients will receive radiation therapy at some point during their illness (Gelband, Jha, Sankaranarayanan, Horton, \& Banque internationale pour la reconstruction et le, 2015). For some people radiation will be their 
only treatment, while for others it will be done in conjunction with chemotherapy, surgery, or both. In this study, it is not important to differentiate those who are treated with radiation alone or with combined modalities rather that they are all receiving some type of radiation. Radiation therapy is used for localized focused treatments most commonly in the lungs, breast, head and neck, brain, and prostate. While these are the most common sites of treatment, radiation can be used anywhere in the body and for medical conditions other than cancer such as keloids. Radiation therapy at its core is the use of high energy photons, protons or electrons that are accelerated to megavoltage energies focused preferentially using secondary and tertiary collimation devices to deliver a dose to the tumor volume while blocking critical structures to reduce the dose to healthy tissues. As radiation enters the body it delivers dose by causing double stranded breaks to DNA that then causes cells to die (ASTRO, 2015). Since cancer cells have a faster doubling time than healthy cells, the radiation is more lethal in tumor cells then healthy tissues resulting in effective radiation treatments. Radiation therapy is most frequently done using a standard linear accelerator as shown in Figure 1, although specialized treatments can be done on a variety of treatment units.

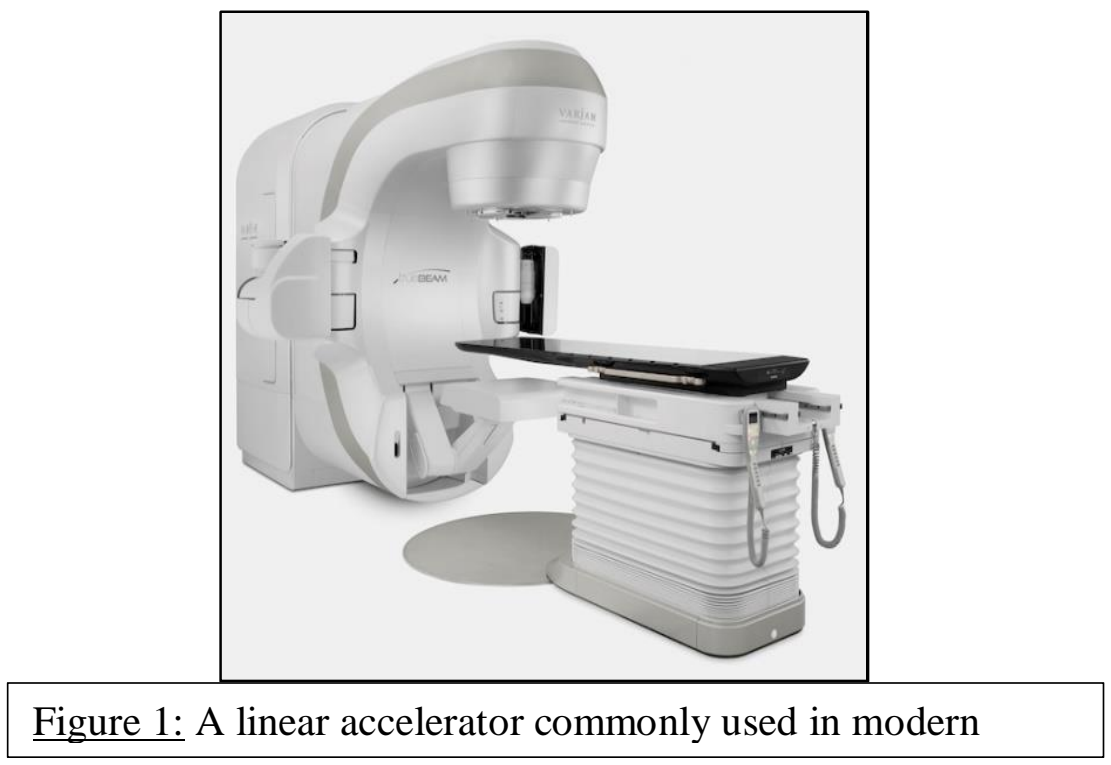


Historically radiation therapy was done with very basic open fields, meaning no modulation of the beam and minimal shaping of the field shape. Because of the basic technology, planning and quality assurance was a relatively simple process. Evolving newer technology has caused radiation therapy to become a highly complex process with several components being modulated simultaneously. Treatments are now composed of multiple beams each with a rotating gantry while multileaf collimators move and dose rates fluctuate all while patients are immobilized with complex patient positioning systems (Paliwal \& Tewatia, 2009). Furthermore, there are complex imaging, respiratory motion management, and implantable fiducials to track and localize the tumor in real time. With the increased precision and ability to control dose delivery, a new treatment regimen called stereotactic radiation therapy has evolved and become more predominant in radiation therapy (Paliwal \& Tewatia, 2009). Stereotactic treatments involve submillimeter precision to deliver much larger doses in a fewer number of treatments. While the nuances in the technology and fractionation schemes are not important to understand, the increased complexity of radiation therapy has increased the need for specialized and qualified medical physicists in radiation therapy.

Radiation oncology medical physicists (ROPs) play an important role in radiation oncology departments. ROPs are primarily responsible for the safety and technical issues associated with radiation therapy treatments. The list of responsibilities for ROPs includes but is not limited to radiation therapy vault shielding calculations, commissioning and accepting new linear accelerators, machine quality assurance (QA), imaging QA, patient dosimetry, patient specific QA, plan QA, chart QA, brachytherapy, and radiation safety (LaPointe, 2011). ROPs work is comprised of two primary 
categories. The first is machine quality assurance, which involves running tests on the imaging and treatment machines on daily, monthly, quarterly, and annual basis. The other primary responsibility is treatment planning and verification that consists of optimizing beams to increase tumor dose while protecting critical structures and checking that the plans are being delivered safely and accurately (Lee et al., 2015).

To become a radiation oncology physicist, the first step is to get a bachelorô degree in physics or similar field such as nuclear engineering. Along with a general BS in physics, or a related field, it is also important to have certain prerequisites such as anatomy and physiology, biology, and electronics. After a bachelorôs degree and prerequisites have been fulfilled, one must complete a masters, professional doctorate $(\mathrm{DMP})$, traditional doctorate $(\mathrm{PhD})$, or a related field $\mathrm{PhD}$ and a certificate program approved by the Commission on Accreditation of Medical Physics Education Programs (CAMPEP). After the program has been completed students are eligible to sit for part one of the board exams administered by the American Board of Radiology (ABR). The board exam is a three-part exam consisting of the written general physics exam (part 1), the written medical physics exam (part 2), and an oral exam (part 3). Part one can be taken if a student is enrolled and in good standing or has graduated from a CAMPEP program. Upon passing part one candidates are eligible to sit for part two upon the completion of a two-year residency at a CAMPEP accredited program by August 31 of the year the test is to be taken. After passing part two of the exam candidates are eligible to take part 3 the next time it is offered (M. Mills, 2014). The residency restriction was implemented in 2014 in order to assure standardization in the training of ROPs. Prior to 2014, a physicist could have three years of work experience and then sit for the Boards in place of a 
residency program. Board certification is necessary in order to be considered a qualified medical physicist (QMP) as defined by the American Association of Physicists in Medicine (AAPM) and receive a license to practice medical physics in states that require licensure. To maintain board certification, continuing education requirements through the ABR must also be met on an annual basis.

As of 2016 there are 6,800 practicing medical physicists in the United States, of which only $75 \%$ work fully or primarily in radiation therapy and only $70 \%$ are certified by the ABR, (or the American Board of Medical Physics, the Canadian College of Physicists in Medicine, or another Board) and of those working in Radiation Oncology, $69 \%$ report working in a primarily clinical role (Frey \& Ibott, 2016). Based off those numbers there are currently estimated to be 3,550 FTE ROPs practicing in the United States. Historically around two hundred new physicists have entered the profession annually to replace the growing demand as well as those physicists reaching retirement age. On average each ROP is expected to be able treat approximately 225 new cancer patients annually (Associates, 2015). It is estimated that a working clinical ROP spends seventy five percent of their time on clinical work so the ratio of working ROP to clinical FTE is 1.333 (M. Mills, Thornewill, J., and Esterhay, R., 2010). Based on a study done by the American Association of Medical Colleges on forecasting supply and demand for oncologists, they found that the number of new cancer patients will continue to rise around two percent annually (AAMC, 2007). Considering there are currently around 1.7 million cancer patients; if that increases by $2 \%$ there are 34,000 new patients. At 225 patients per physicist and 75\% working FTE rate, approximately 120 new physicists would be needed annually assuming no retirement or attrition from the field. When you 
consider the average $1.5 \%$ retirement rate and $1.5 \%$ attrition rate this is an additional 50 to 60 physicists needed totaling 170 to 180 new physicists annually.

Currently in the United States there are 90 accredited radiation oncology physics residency programs and 4 DMP (doctorate of medical physics) programs that include a residency component (CAMPEP, 2015). In 2015, there were 158 total open residency positions (this includes therapy and diagnostic) for new graduates, 145 positions were offered, 134 positions filled and approximately 140 students completed their residency training with around 122 of those in radiation therapy. These 122 graduates fall well short of the 170 predicted to meet current demand. More alarmingly, academic programs are graduating significantly more students than residency positions available, creating an excessive number of students with no pathway to clinical employment. In 2015, alone 209 students applied for the match for 111 possible positions (Clark, 2015). With the lack of CAMPEP accredited residency programs as well as the low passing rates on the oral board exam (67\% average pass rate from 2014-2016 according to the 2017 ABR annual report), it is expected that there will not be enough ROPs in the United States to keep pace with the current supply and demand model (ABR, 2018). Appropriate ROP to patient level is important for patient safety since the key role of the ROP is to provide quality assurance and patient safety measures throughout the entire treatment process. Safety is the primary focus from checks on imaging, planning systems, plan quality, treatment delivery, and machine checks. Deficiencies in staffing levels can lead not only to safety issues but also financial strains on the healthcare industry since it will inflate physics salaries and potentially magnify the current issue by increasing early attrition from the field due to provider burnout. 


\section{CHAPTER 2- METHODS}

\subsection{Stella Modeling}

In order to evaluate the supply and demand of radiation oncology physicists in the United States, non-sequential explanatory mixed methods were used. The project is divided into two major components. The first component is a STELLA model, which depicts the supply and demand of the United States Medical Physics workforce from 2016 to 2030. STELLA is software produced by ISEE Systems that provides visualization for the way dynamic systems function using stock and flow systems with complex equations connecting variables in complicated scenarios (Systems, 2015). The

first step to building the STELLA model is to review the most recent supply and demand models that had been built circa 2010. The two models used as a basis for this model are the model developed by the University of Albany as commissioned by the AAPM in 2010 and the model built by Michael Mills et. al. in 2010 (Forte, 2010; M. Mills, Thornewill, J., and Esterhay, R., 2010).

In 2009 and 2010 the AAPM partnered with the Center for Health Workforce Studies out of the University at Albany School of Public Health in New York to evaluate whether the supply of qualified medical physicists available over the next decade will be sufficient to meet the anticipated demand. In 2010, Langelier and Forte presented their 
findings in a two-part talk at the annual AAPM meeting. Based on their presentations they found that the field was going through standardization with the ABR residency requirement expected to be implemented and had concern about a bottleneck effect once the requirement was implemented (Langelier, 2010). Also, Langelier discussed the challenges associated with predicting technological changes and how that would influence future demand for ROPs. In Fortê̂ talk he developed a simple supply and demand model using STELLA software but with limited influencing factors. In the model he predicted several outcomes based on the number of anticipated residency programs to be developed but all of the data and modeling occurred before the requirement was

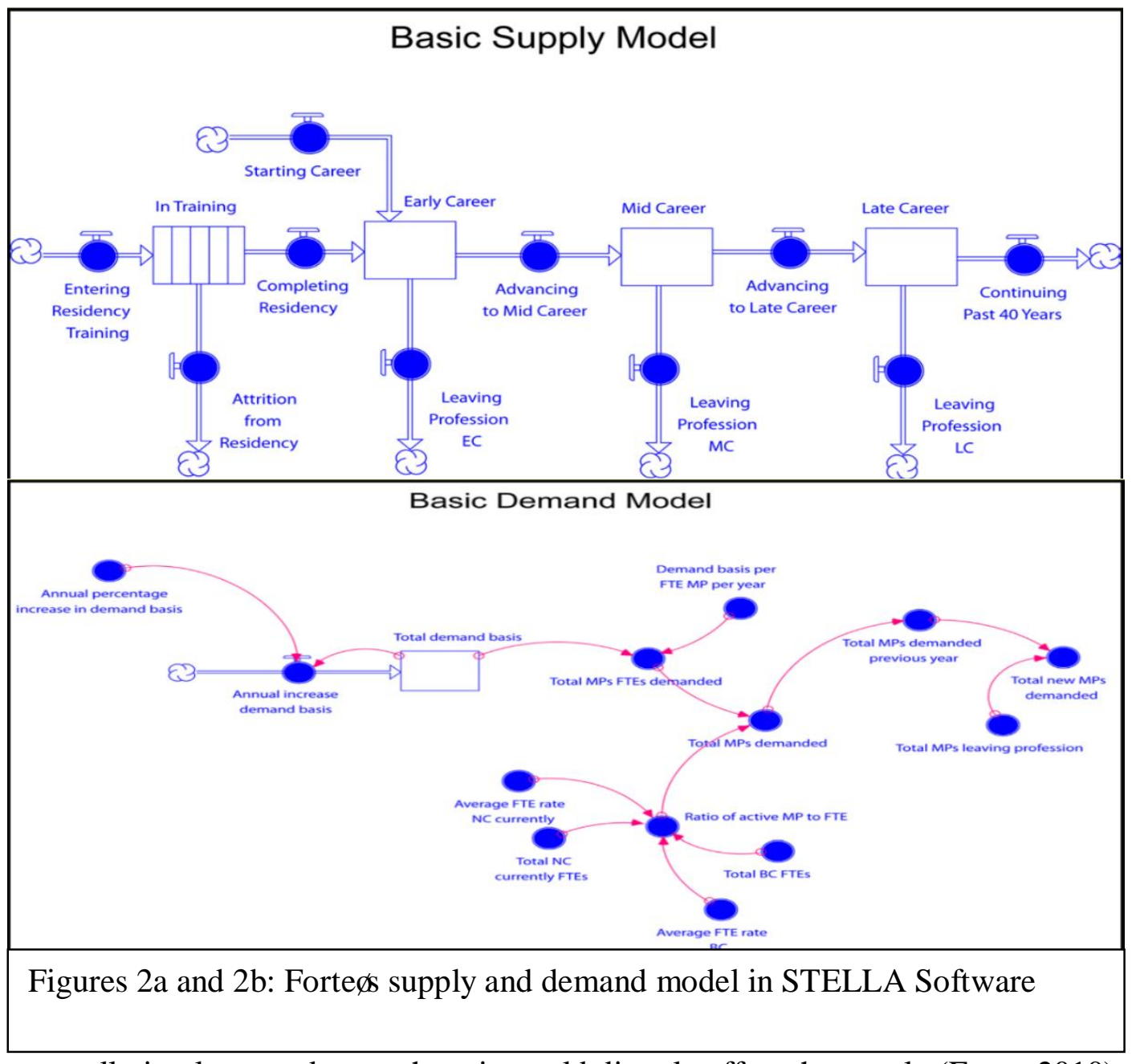

actually implemented to see how it would directly affect the supply (Forte, 2010). 
The other significant medical physics workforce study done on supply and demand in the last 10 years is done by Michael Mills. In that paper he evaluated whether the supply of physicists would meet the demand by 2020 with a varying number of residency positions available. In his paper he estimated 150-175 residency positions would be adequate to meet the current demand as shown in figure 3. (M. Mills, Thornewill, J., and Esterhay, R., 2010). While both models are robust and good

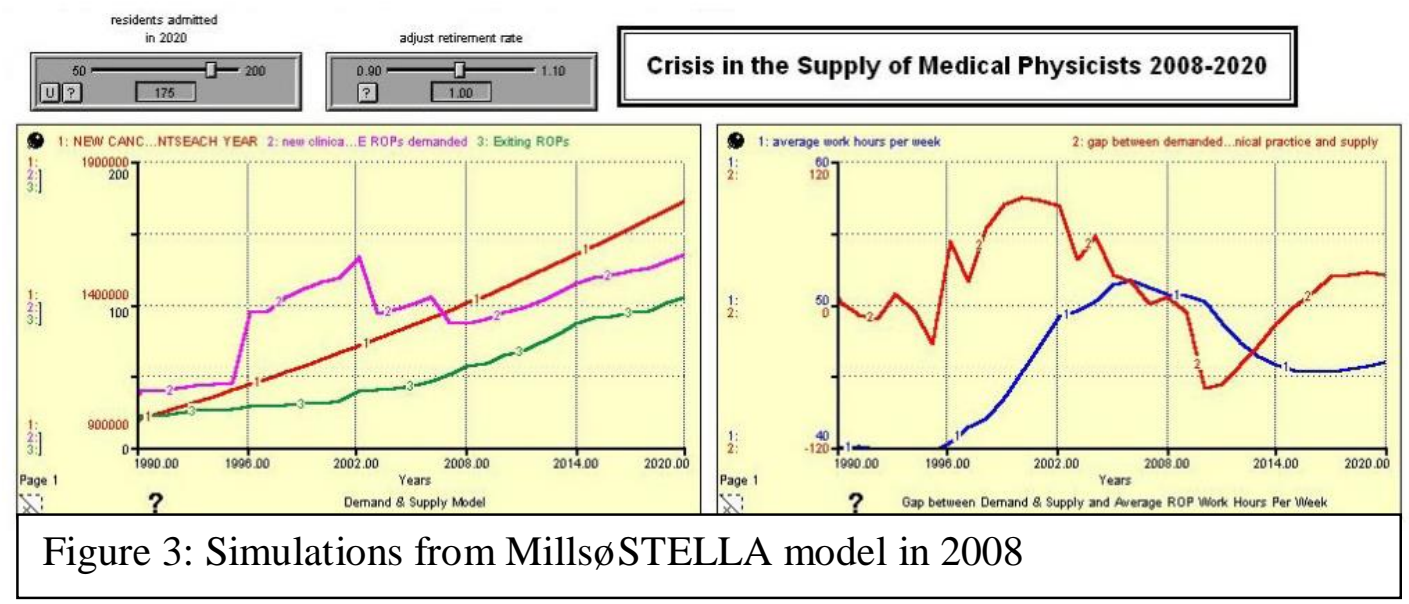

predictors of the trends in the medical physics workforce, neither has been re-evaluated since the implementation of the residency requirement and no further evaluation of the supply and demand of medical physicists has been done since 2010 . This study will reevaluate and modify the existing models in order to predict the future demand now that the implications of the residency requirement can be analyzed with current data.

Post residency implementation, there is now more data to develop trends and show the influence of the residency requirement on the pathway to board certification and thus the pathway to the workforce. To develop the model, it was broken into two separate components. The first was the pathway from graduate student to retired physicist and the second was the components that drive demand. With the influences of the previous models, the first step was to draw out the pathway that a student must take from 
graduating to residency completion. In previous models, they start with students entering residency, which does not account for the variability in acceptance rates from differing types of graduate programs nor does it address the excess of students that will not find a residency position. To become a radiation oncology physicist, the first step is to get a bachelorôs degree in physics or similar field such as nuclear engineering. Along with a general BS in physics, it is also important to have certain prerequisites such as anatomy and physiology, biology, and electronics. After a bachelorô degree and prerequisites have been fulfilled, four types of graduate programs or certifications will allow someone to enter a CAMPEP residency program in clinical medical physics. The four pathways are a masterôs degree, a Ph.D. degree, a DMP, or a certificate program approved by Commission on Accreditation of Medical Physics Education Programs (CAMPEP). After one of the four programs are completed ROPs are eligible to sit for part one of the board exams administered by the American Board of Radiology (ABR). The board exam is a three-part exam consisting of the written general physics exam (part 1), the written medical physics exam (part 2), and an oral exam (part 3). Part one can be taken at the end of graduate school, part two cannot be taken until the completion of a two year residency at a CAMPEP accredited program, and part 3 is one year after passing part two (M. Mills, 2014). The residency restriction was implemented in 2014 in order to assure standardization in the training of ROPs. Prior to 2014 a physicist could have three years of work experience and then sit for the boards in place of a residency program. Board certification is necessary in order to be considered a qualified medical physicist (QMP) as defined by the American Association of Physicists in Medicine (AAPM), and receive a license to practice medical physics in states that require licensure. 
To understand the next stage in the development, it is important first to establish the main components of the model. This Stella model is composed of stocks, flows, converters, connectors, and sectors. The stocks are containers to accumulate groups of people, the flows fill or drain the stocks, the converters can be constants, graphs, formulas, that convert the input into a given output, the connectors connect all of the variables and the sectors group different components into sub sections of the overall model (Systems, 2016). To build the model values and units must be given to all of the stocks and converters then connected by flows and connectors. Once all of the values are added and connections are made, formulas are applied to make the model run. With these components in mind and using the influence of the University of Albany model, the very first part of the supply model was developed:

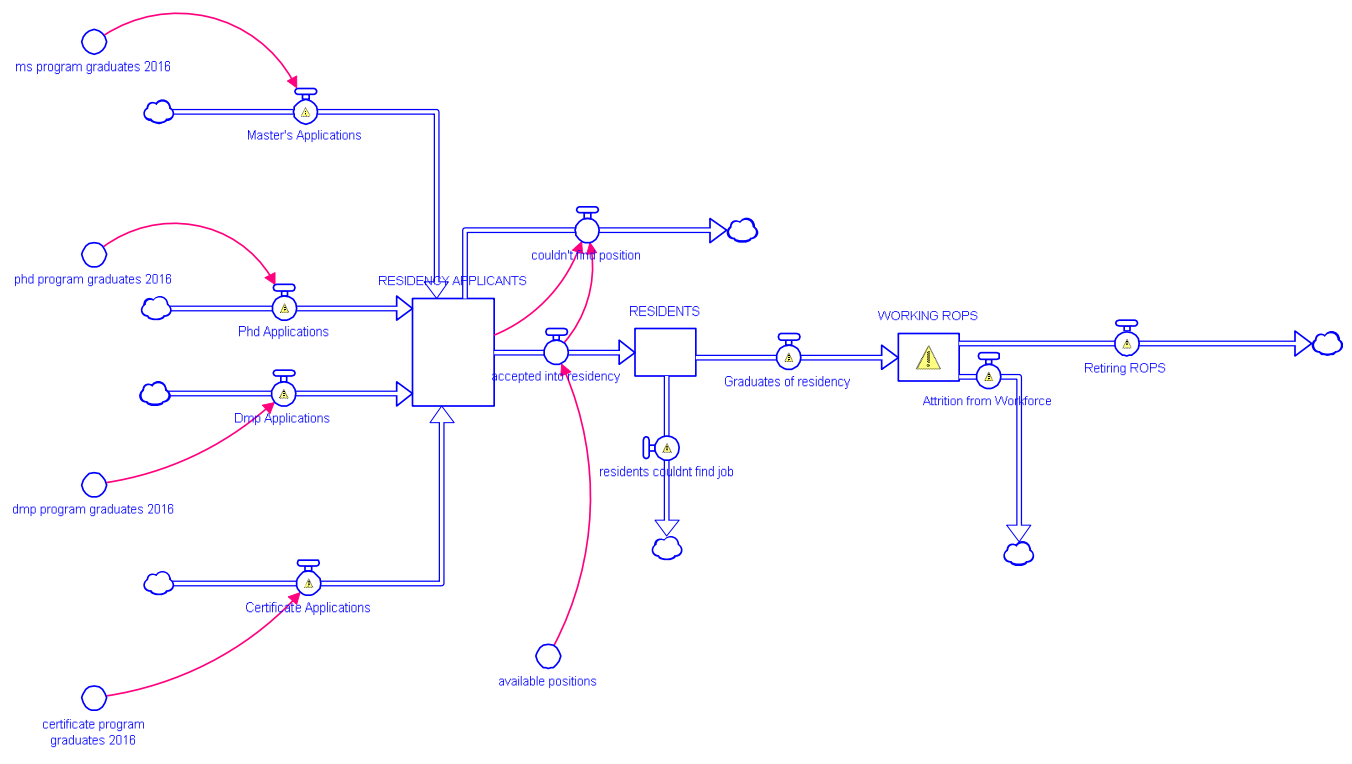

Figure 4: Supply side of model version 1

The next component was the demand side. The demand side was primarily influenced by the model developed by Dr. Michael Mills. There are three main driving 
forces on the demand side. The first is the increase in cancer patients annually due to a growing population for which the model refers to this sector as the cancer demand. The second and third driving factors are about the ROP demand. One of these is the number of patients for which each FTE (full time equivalent) ROP physicist can manage the care and the other component is the rate of attrition from the workforce by ROPs whether it be due to retirement or alternative reasons. A very early version of the demand model can be seen in Figure 5 below.

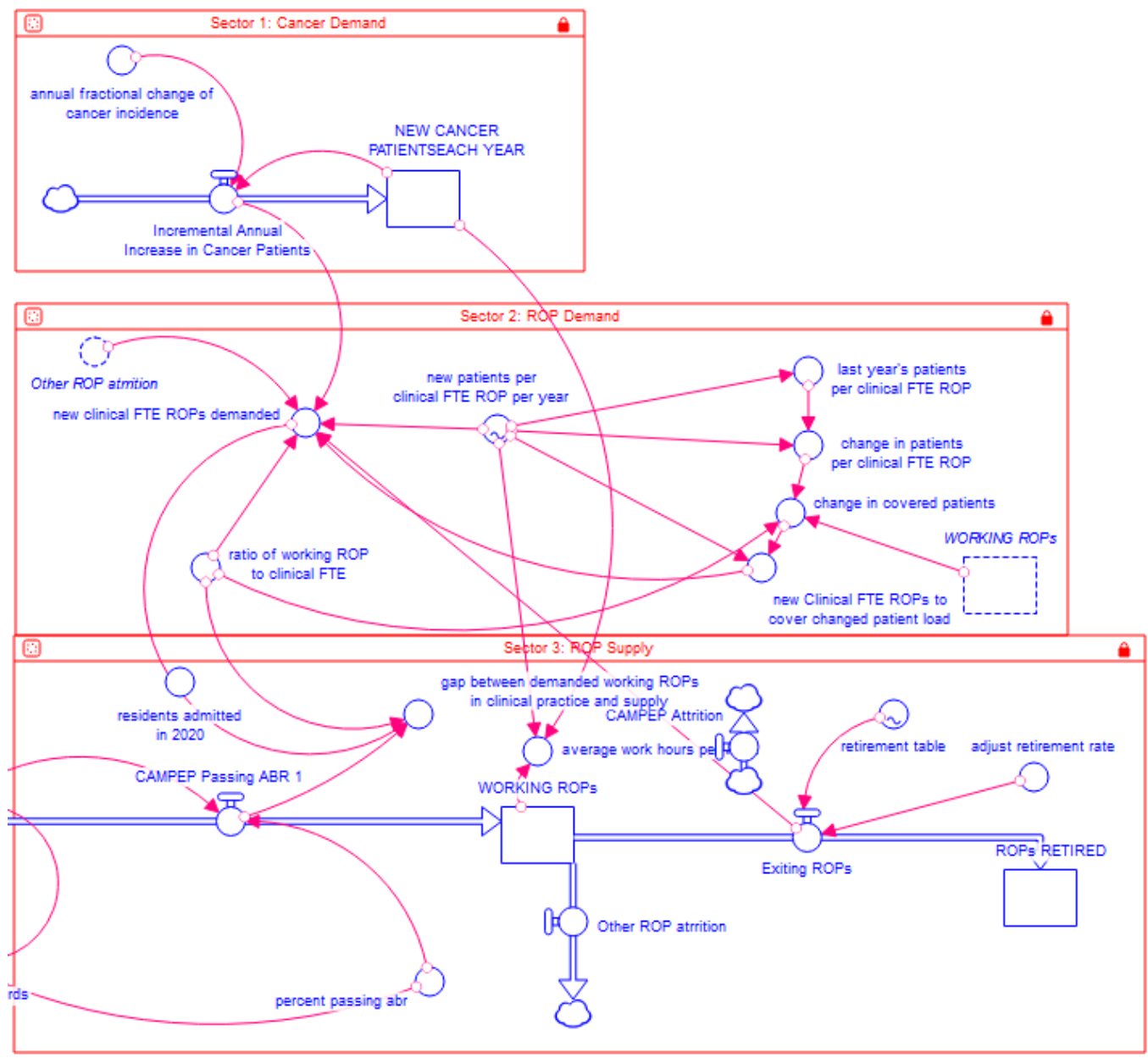

Figure 5: Demand side of model version 1 
The supply and demand side are then integrated and several more components added as the impact of various components on one another is evaluated. Through several revisions and iterations, a final structure is established, as shown in figure 6.

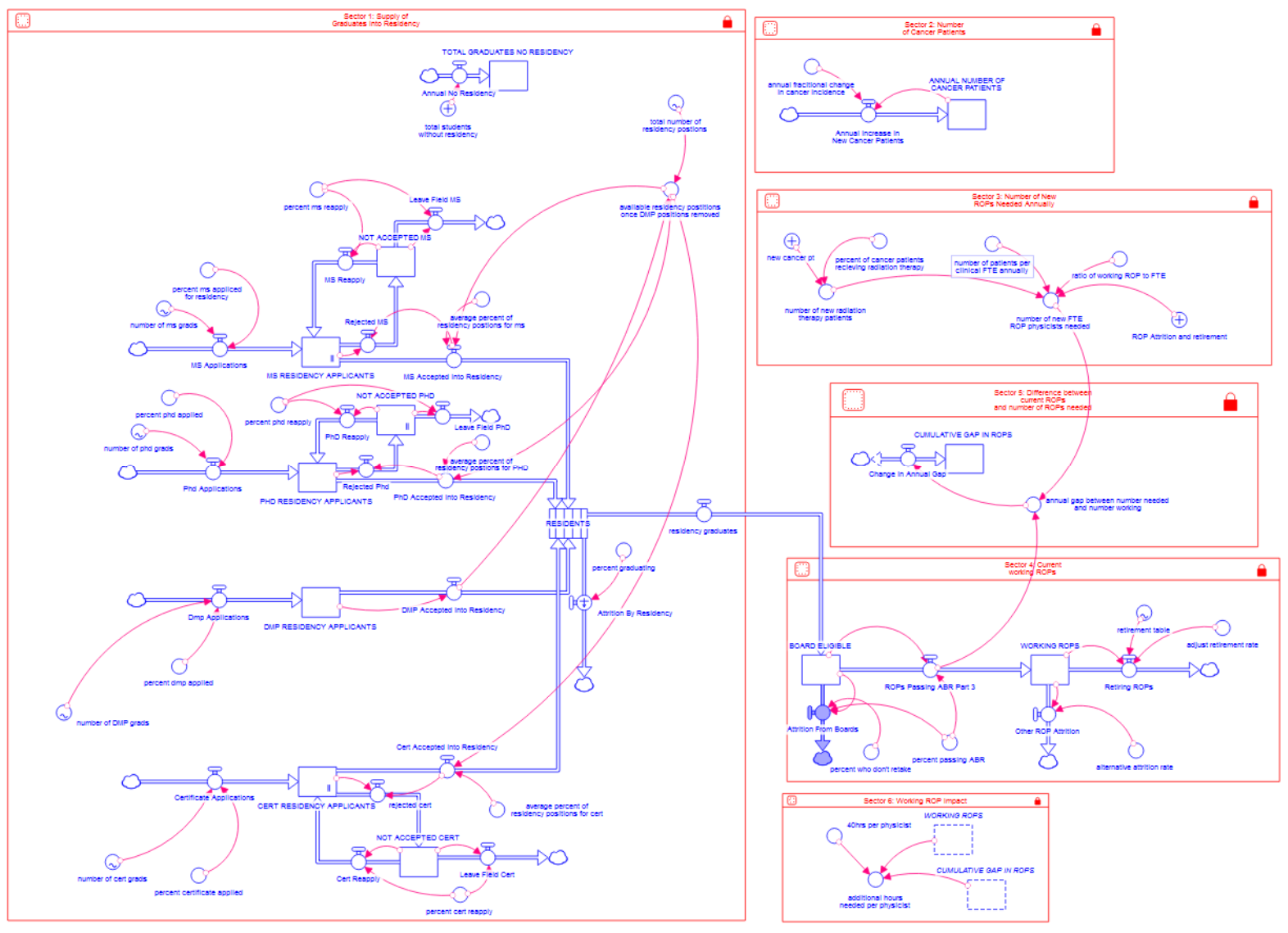

Figure 6: Final Supply and Demand Model

Once the structure is developed, the next step is to begin to populate the model with current data and get the model to run in equilibrium status. Equilibrium status means that we could get all of the supply and demand factors to balance and could also show how things balance if no changes are made to prove the model is stable. Once equilibrium is established, trend data and change data over time are added to predict what will happen.

Starting with the supply side, the number of recent graduates and residents are populated using data from the annual CAMPEP reports (CAMPEP, 2017; Clark, 2018). 
Each year CAMPEP writes a report-summarizing enrollment, graduates, and other information about the graduate programs and residency programs. For the starting points to determine equilibrium, the 2016 graduate data was used which was 139 Masters graduates, 89 PhDs, 6 DMPs, and 24 Certificate graduates (Clark, 2018). Then using the residency data, the total number of residency positions in 2016 was added. Then the positions by degree type were calculated using the average acceptance rate by each degree. Based on the years 2015-2017, all DMP students found residency positions as it was part of their program. Taking those positions out of the total number of positions the remaining positions are distributed by $40 \%$ to Masters, $50 \%$ to $\mathrm{PhDs}$ and $10 \%$ to Certificate graduates (CAMPEP, 2015, 2017; Clark, 2015, 2018). This is to say if there are 110 total residency positions and DMP students, there are 10 DMP residents admitted (100\%), 40 masters $(0.4 \times(110-10)), 50$ Ph.D. (0.5x(110-10)), and 10 certificate students admitted (.1 x (110-10)). Using this method, the model is not driven by applicants, but rather the limitations are controlled by the number of available residency positions. The remaining applicants that are not accepted are looped back in to the application pool, assuming approximately a seventy percent reapplication rate. The model does not consider how many years a given student is in the application pool due to complexity; rather the assumption is made that of all of those rejected seventy percent will continue to reapply and thirty percent will not reapply and pursue a different field. It does not consider how many years a candidate is in the application pool just that thirty percent of those who do not get accepted do not continue. The exact locations of these students are not critical to the model since they are either still residing in the applications stocks or the total number of students without a residency stock. This is important since they do not 
actually drive the residency stock with the exception that there are enough applicants to meet residency demand, which has been a nonissue thus far. Those students who do not re-apply are collected in a summation stock to see the cumulative number over time of the number of students who could not find placement and thus are ineligible to become board certified. It should also be noted that the portion of students who chose to go on to Ph.D. programs or not pursue a residency are already removed from the model through the q́percent ñxò appliedôconverter with $\mathrm{x}$ being the respective program categories.

The next input was determining the graduation rate from residencies, which has historically been relatively high with the data from 2016, and 2017 estimating graduation rates around 95\% (CAMPEP, 2017). Moving past the residency flow and into the board eligibility stock portion of the model, the average number of examinees was 230 for the Medical physics Part 3 oral exam and a pass rate of 67 percent (ABR, 2018). The next component is the transition from the supply to the demand which is the working ROPs stock which started with 3,519 FTE physicists in 2016. The number of FTE ROPs is driven by the three flows, one inflow and two outflows. The inflow is the number of board physicists who passed the boards as discussed above. The two outflows are the retirement ROPs and the ROPs who left through other means of attrition. The retirement group was determined by using the age profile of the AAPM membership and then based on the data from the US census bureau report on Working Beyond Retirement age; the average chance of retiring at any given age was applied to the membership profile (Holder \& Clark, 2008). Then by aging the membership profile that would reach retirement age within the timeline of this model and applying the odds of retirement to that distribution, the average annual retirement rate was determined and added to the 
model. The fractional rate based on the AAPM membership ranges anywhere from 0.014 to 0.019 annually. For the alternative attrition rate prior models by University of Albany suggested one percent leave in early career and three percent in mid-career (Forte, 2010). Since some of the mid-career attrition is considered in retirement tables, this model uses a conservative one percent attrition rate; but it can be dynamically adjusted to demonstrate how increased attrition will affect demand.

The demand side is primarily driven by the annual increase in cancer patients and the number of patients each physicist can serve. To determine the number of new patients annually the current number of cancer patients in the United States is multiplied by the annual fractional change in cancer incidence. Beginning in 2016 there were approximately 1.7 million new cancer patients in the United States (Society, 2016). For the annual fractional change various publications site numbers ranging from 0.0192 to 0.04548 (AAMC, 2007; Institute, 2017). For this model, the more conservative 0.0192 was used so as not to overestimate demand. To determine the number of new patients for radiation oncology physicist demand, the total number of new cancer patients is then adjusted by the percent of cancer patients who receive radiation therapy. While various studies once again site a range on the percentage of patients who receive radiation, for this model a conservative value of fifty percent is used (Jaffray \& Gospodarowicz, 2015). The number of new radiation therapy patients is then combined with the number of patients per clinical FTE ROP annually, the ratio of working ROP to FTE, and the total number of ROPs who left the field through attrition or retirement. To populate the number of patients per clinical FTE to ROP annually, the ABT studies of the Medical Physicist Work Values for Radiation Oncology Physics Services were used. The ABT 
studies are a collaboration between members of the AAPM led by Dr. Michael Mills and ABT Associates. They were originally commissioned by the ACMP (American College of Medical Physics) and AAPM in 1995, to evaluate the time and effort spent by medical physicists in performing various clinical responsibilities (Associates, 2015). The 1995 ABT study was repeated in 2003, 2007, and most recently in 2014. From the surveys, the average number of patients treated annually per clinic is divided by the number of physicists reported per clinic to develop an assumed annual caseload of patients per FTE physicist. As complexity increases and physicist involvement in treatment planning rises, the ABT study is reporting a steady decline in the caseload managed per physicist. From the 2003 survey it was approximately 400 patients per physicist, by 2007 it was around 300 , and with the 2014 results, it is down to about 225 patients per physicist (Abt Associates, 2015). The next component for the ratio of working ROP to FTE accounts for the fact that physicists do not spend the entire workday working clinically, rather there is a large portion of time spent that is not specific to any one patient, but rather is on administrative work, policy, education, etc. Based on previous models and reports from the ABR, this model assumes physicists on average spend only seventy-five percent of their time working clinically, which translates to a ratio of 1.333 working ROPs to FTE (Frey \& Ibott, 2016; M. Mills, Thornewill, J., and Esterhay, R., 2010). The final converter impacting the new FTE ROP needed is a summing converter combining the number of retiring ROPs with the number leaving early through attrition from the supply side of the model.

The model then uses the new number of ROPs passing the boards and compares it to the number of new FTE ROPs needed to determine the annual gap. The annual gap is 
then summed to over time to determine the cumulative gap. Since the current gap is unknown, the model starts with a gap of zero. Therefore, the results assume that in 2016 the supply and demand were equally balanced and that the deficit only began then. A justification for this assumption is that the 2010 Mills study indicated approximately a balance between supply and demand in 2016. In addition, in 2016, there was not a consensus that the market was undersupplied. This was most likely due to a large influx of students into the field prior to the 2014 residency requirement for board certification, which most likely compensated for the lower entry in the years following. According to ABR statistics between 2008 and 2010 the average number of board certificates given to Medical Physicists in Therapy was on average 177 per year. Once the residency requirement drew near the number jumped to an average of 228 annually between 2011 and 2015. In 2016 the number dropped below 200 to 196 and in 2017 it was down to the lowest number in ten years to a mere 155 (ABR, 2018). Additionally the AAPM annual salary survey done in 2015 showed there was still a solid demand with physicists who changed employment getting an increase in median salary by about thirteen percent (AAPM, 2015). Once the model was constructed and trends were evaluated the next phase of the project was to determine if the workforce perceptions matched those seen in the model.

\subsection{Survey}

The second phase of the study is a series of surveys involving three groups from the medical physics community. The three groups chosen are the recent graduates from Ph.D., Masters, DMP, and certificate programs, recent graduates from residency programs, and recent retirees. These three groups were selected since they are the groups 
that have the biggest impact on the model. The first step was to develop the survey using Likert scale questions. Three separate surveys were generated and sent to five current physicists who had completed residency programs themselves for beta testing. After beta testing minor revisions were made to the surveys and retested for functionality. To generate a list of recent graduates the survey went through the AAPM Workforce Committee and with their support, the Executive Committee of AAPM was contacted and agreed to supply an email list. Based on limitations of how membership is sorted within the AAPM, the lists generated included one list of emeritus members and a second list of junior and resident members. Emeritus membership is defined as members who have completed a career in medical physics and have retired from the field of medical physics. Applicants must have been a Full or Associate member of AAPM for 10+ consecutive years and be over the age of 55 (AAPM, 2019). Junior membership is for a Post-doctoral Student, a Resident in a Non-CAMPEP accredited program, or Fellow on a full- or parttime basis in a medical physics training, while Resident membership is open to Residents in CAMPEP Accredited Residency Programs(AAPM, 2019).

Since recent graduates of graduate school programs and residencies could not be filtered, the two surveys for recent graduates of graduate programs and residency programs were combined. By combining the surveys, respondents could then self-select which portion of the survey they should respond to from a few preliminary questions that would direct them to the appropriate portion of the survey. Preliminary questions were multiple choice and included questions comparable to: ñDid you attend either a CAMPEP MS Graduate Program, CAMPEP PhD Graduate Program, Professional Doctorate, or Certificate program?ò and ñHave you completed a CAMPEP residency?ò Depending 
upon a respondentôs answer it would then direct them to one of five sections. The first section was for people who had not yet completed a graduate school program or certificate program that simply thanked them for their time. The second section was for students who had graduated and not found a placement in a residency program. Next was the section for students who had graduated from graduate school and found a residency position. Then there was the section for those who had completed residency and not found a job. Finally, the section for residency graduates that found a job as a medical physicist.

The survey was distributed via email with an invitation to take the survey through Survey Monkey, a third-party website. In order to participate, respondents first had to acknowledge a preamble consenting their participation was voluntary according to IRB guidelines (see Appendix 3 for entire surveys including the Preamble). After the initial round of responses, a reminder email was sent through survey monkey to elicit additional responses. Since for a few categories, the number of respondents was still low, the list of residency program directors was generated from the CAMPEP website and an email was sent with a link to the survey to request additional responses from their current and previous students. The surveys were open for a total of seven months.

At the end of the survey, respondents were given the option to participate in a follow up survey by providing either an email or a phone number to contact as well as provide any additional open response feedback. The follow up survey consisted of openended questions that was sent via email to the respondents. The email method was selected since that is how the majority of participants chose to communicate when given the option. All participants who provided an email for follow-up were sent the additional 
survey and results were collected over an additional three-month period. The open-ended responses and follow up surveys were then manually coded. To code the response, various themes were established such as location of job, the match program, salary, etc. and then the number of times someone referenced that theme was recorded as a promoter, neutral, or detractor. 


\section{CHAPTER 3- RESULTS}

\subsection{Supply and Demand Modeling Results}

The Stella model is broken into six sectors each focusing on a different component and working together to develop the full model. In the first sector, the focus is on the supply of medical physics graduates and residents as shown in Figure 7. This

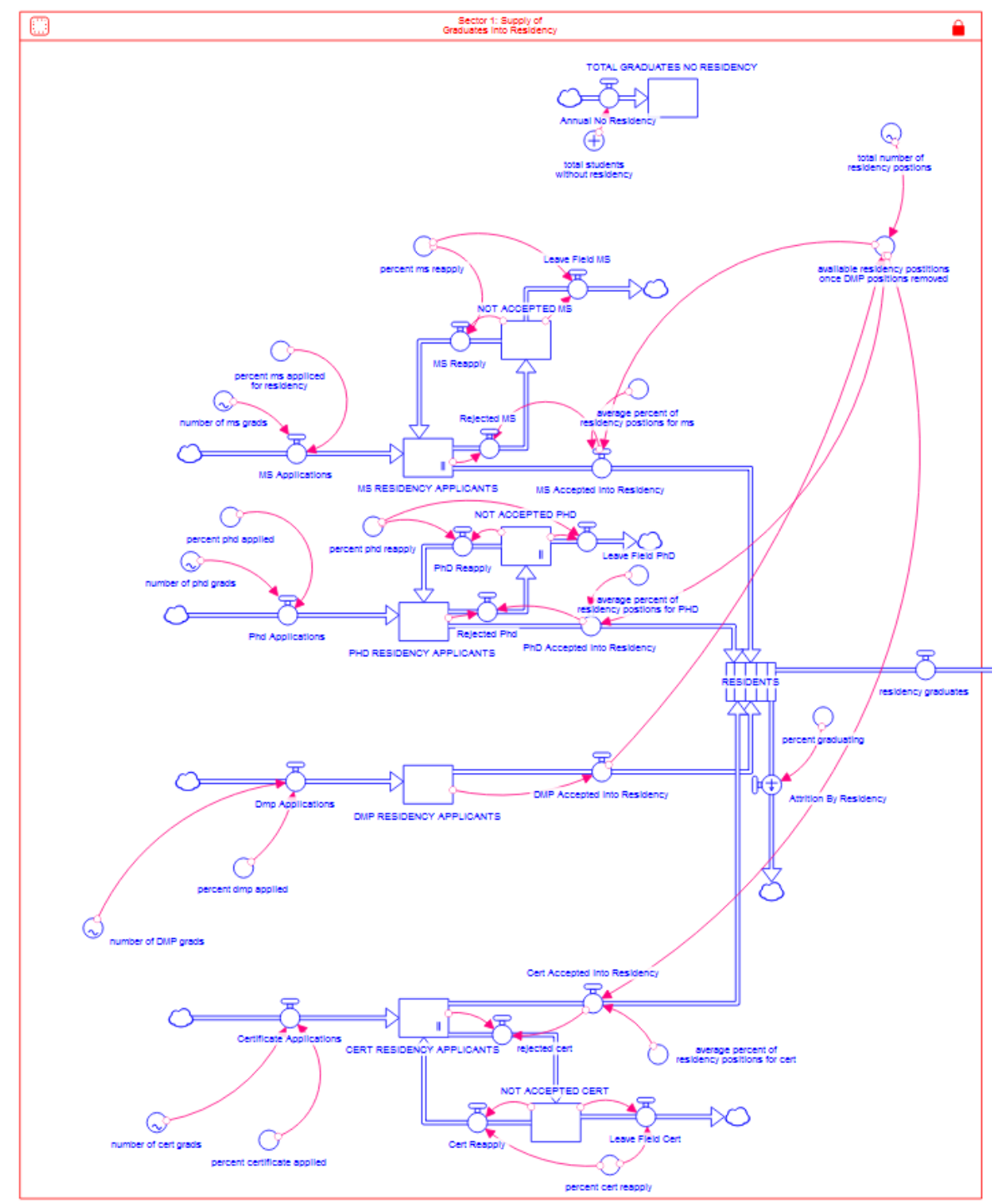

Figure 7: Sector 1- Supply of Graduates into Residency 
sector inputs all of the recent graduates from Masters, Ph.D., DMP, and certificate programs and multiplies them by their application rate for residency programs to create a stock of residency applicants from each of the respective programs. Focusing first on the masterô pathway the applicants are then diverted into two flows. The flow for those accepted into a residency is controlled by two converters. The first converter is the available residency positions once DMP positions are removed. DMP residency positions are removed from the total since those entering the DMP program enter with a residency attached to their graduate program. This will be more thoroughly discussed on that pathway. The number of available residency positions once DMP positions are removed is then multiplied by the average percent of residency positions for MS. This converter is the average percent of positions that are granted to masterô applicants. These converters allow the average annual number of masterô students that are accepted into residency positions to flow to the RESIDENTS stock. The other flow coming from the MS residency applications stock is the flow of those who are not accepted into the residency program. This flow is driven by the remaining MS applications subtracting out those accepted into residency. Those not accepted enter the NOT ACCEPTED MS stock which is then divided into those who leave the field and those who decide to reapply. Both of the flows out are controlled by the percent MS reapply converter and the NOT ACCEPTED MS stock. The reapplication flow is the percent that reapply multiplied by those who are not accepted and the leave field flow is (1-percent_ms_reapply/100) *NOT_ACCEPTED_MS.

The flow for each degree type is identical to the masterô pathway with the exception of the values for the various stocks and converters. The one exception is the 
DMP pathway in which all of the graduate students already have placement in a residency as part of their program. Due to that, one hundred percent of DMP applicants flow into the RESIDENTS stock. The flow for DMP accepted to residency is what controls the converter that is the available residency positions once DMP is removed. For this converter, which helps to drive all of the other pathways, there is an equation of: total_number_of_residency_postions-dmp_accepted_to_residency.

With these four pathways established there is now a RESIDENTS stock and three flows of graduates leaving the field. The three flows of graduates leaving the field is summed in a summing converter and put into an annual flow of graduates with no residency to feed a stock that cumulates the total number of students that graduated but could not find residency placement. This stock will be an important factor in the results discussion as it shows the number of students that graduated, wanted to find placement in a residency to achieve board certification, and were unable to do so. The RESIDENTS stock is a special type of stock called a conveyor. The conveyor allows the population to stay at that point for more than one unit of time. Since a residency is two years this conveyor has a two-year transit time. With the four programs feeding the residents conveyor the two flows out are the residency graduates and the attrition by residency. The flow out is a leaking flow controlled by a percent graduating converter and the formula: 1-(percent_graduating/100). Those that do not leak out move on from Sector 1 into the board eligible stock in Sector 4 which is the sector focusing on the current working physicists that will be discussed later.

The second sector in the mode 1 is the number of cancer patients. This sector is quite simple in that it just takes the annual fractional change in cancer incidence 
multiplied by the annual number of cancer patients and uses that to drive the flow to continually increase the number of cancer patients shown in Figure 8. Basically, the

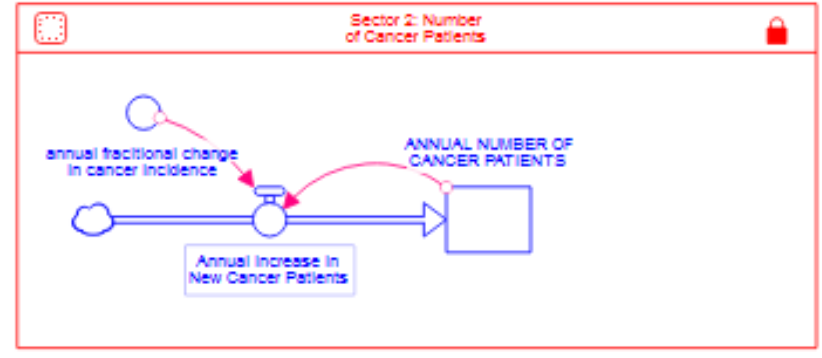

Figure 8: Sector 2- Number of Cancer Patients

annual increase in the number of patients is the annual number of cancer patients multiplied by the annual fractional change in cancer incidence. By modeling it this way, the number of patients continues to rise by the annual increase and will be able to dynamically affect the annual increase in subsequent years. The annual increase in cancer patients flow is the input into a summing converter in Sector 3 to influence the number of physicists needed.

Sector 3 is the number of new physicists needed based on the changes in demand.

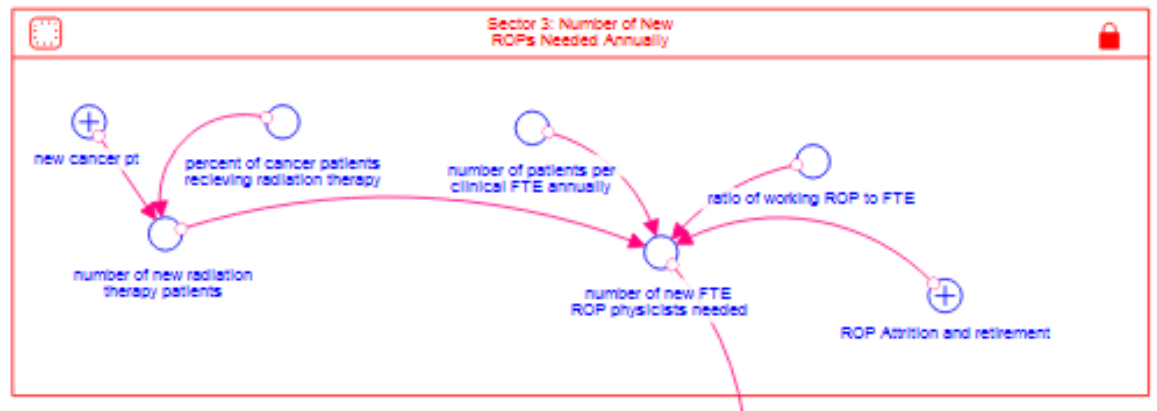

Figure 9: Sector 3- Number of New ROPs Needed Annually

The number of new ROPs is impacted by four things, which are the number of radiation patients, the number of patients each physicist can serve annually, the ratio of ROPs to FTE ROPs, and the number of ROPs leaving the field through attrition and retirement. To determine the number of new radiation patients the number of new cancer patients 
from sector 2 is multiplied by the percent of cancer patients that receive radiation therapy. That number of new patients is used in the number of new FTE ROP physicists needed converter along with the number of patients per clinical FTE annually, ratio of working ROP to FTE, and ROP attrition and retirement converters. The ratio of working ROP to FTE is the 1.333 value discussed in the methods section that is a result of physicists not spending the entire workday on clinical patients rather only around $75 \%$. The number of patients per clinical FTE annually is from the ABT study results also discussed in the methods section. Finally, the ROP attrition and retirement is a summing converter from sector 4 . These are combined using the equation: (number_of_new_ radiation_therapy_patients*ratio_of_working_ROP_to_FTE/number_of_patients_per_cli nical_FTE_annually)+(ROP_Attrition_and_retirement/ratio_of_working_ROP_to_FTE). The output results in an annual number of new ROPs needed to satisfy the increase in demand. This output will be used in Sector 5 to determine the difference in the supply of new ROPs actually entering the field annually versus the number needed annually.

Sector 4 is the final component of the supply side, which evaluates the number of Board eligible physicists to working ROPs and ROPs moving into retirement or other attrition from the field shown in Figure 10. Sector 4 begins with the flow discussed in

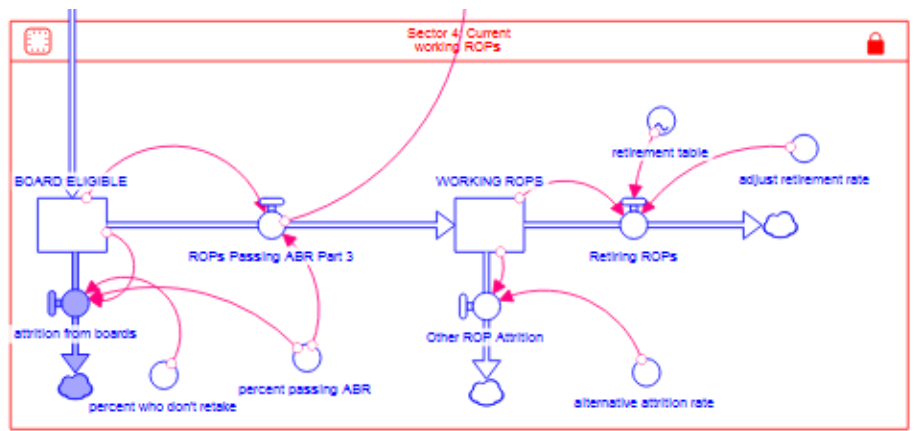

Figure 10: Sector 4- Working ROPs

Sector 1 , which is the residency graduates. From residency graduation, they enter the 
board eligible stock due to the delay between being a residency graduate and the next time the oral board exam is offered. Residencies are finished at the end of June annually and the ABR oral exam is not offered until May annually so there is almost an entire year between residency completion and the next opportunity to take the board exam. From the board eligible stock, physicists can either pass the Part 3 of the board exam and move on to become a working ROP or if they fail the board exam they can remain in the board eligible stock or decide not to retake the exam and exit the field. These flows are controlled by the converters that are the percent passing ABR and percent who do not retake. For the flow of ROPs passing ABR Part 3 the equation is percent_passing _ ABR/100*BOARD_ELIGIBLE. The attrition flow is controlled by BOARD_ ELIGIBLE*(1-(percent_passing_ABR/100))*(percent_who_don't_retake/100). The remaining board eligible stay in the stock to try again the following year. The working ROPs stock is drained from two separate flows that are then used in Sector 3 as discussed. Those two flows are the retiring ROPs and other attrition. The retiring ROP flow is based on the retirement rate calculated from the membership age profile of the AAPM and national retirement rates as discussed in the methods. This rate can be dynamically adjusted by a retirement rate converter should trends change from the expected in future years. The attrition flow is controlled by an alternative attrition rate which is set at a low one percent given there is minimal data on ROP attrition rates in the United States. From Sector 4 the ROPs passing ABR part 3 is taken and compared to the number of new FTE ROPs needed from Sector 3 in Sector 5. 
Sector 5 is the major output from the entire model. Sector 5 is simple in design but has the most valuable output data. This sector determines the difference between

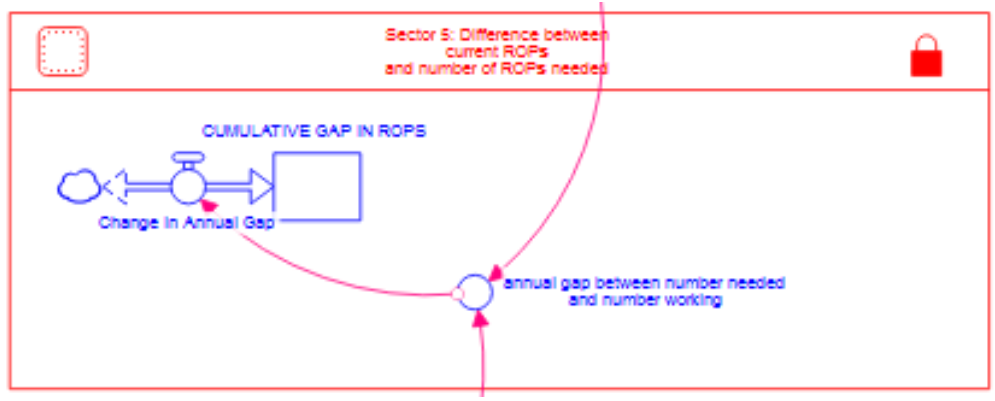

Figure 11: Sector 5- Difference between current ROPs and number of ROPs

current ROPs and the number of ROPs needed. The two inputs into the annual gap between number needed and number working is determined by the number of new FTE ROP physicists needed and the number of ROPs passing ABR part 3. This annual gap then drives a bi-flow that controls a stock with the cumulative gap in ROPs. The cumulative gap is the total number of physicists needed at any given time during the model.

The final sector evaluates the impact of a shortage of medical physicists on the rest of the workforce. Sector 6 has ghosts of the working ROP and cumulative gap in

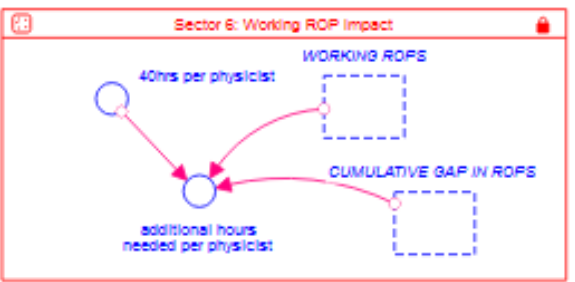

Figure 12: Sector 6- Working ROP

ROP stocks. A ghost allows stocks to be moved to other sectors as inputs while maintaining current connections. The ghosted stocks of the working ROPs and the cumulative gap in ROPs are used to determine the additional hours that would need to be worked by all ROPs to compensate for the shortage assuming a forty-hour workweek and assuming that workload could be evenly distributed amongst the workforce. The 
additional hours are determined by the cumulative gap multiplied by the forty-hour workweek each of the ROPs would work divided by the number of working ROPs.

The model is run with several variations in the number of residency positions to determine what the appropriate supply would be to meet the current projected demand by 2030. The first run is done with the number of residencies not increasing from the number of residencies at the end of 2017. If no additional residencies or graduate programs were credentialed after 2017, there would be 153 total radiation oncology residency positions annually, which would result in an annual gap ranging from 25 to 60 people a year leading to a cumulative gap of 607 physicists by 2030 that is a shortage of about fifteen percent of the workforce. Additionally, with the current number of graduate
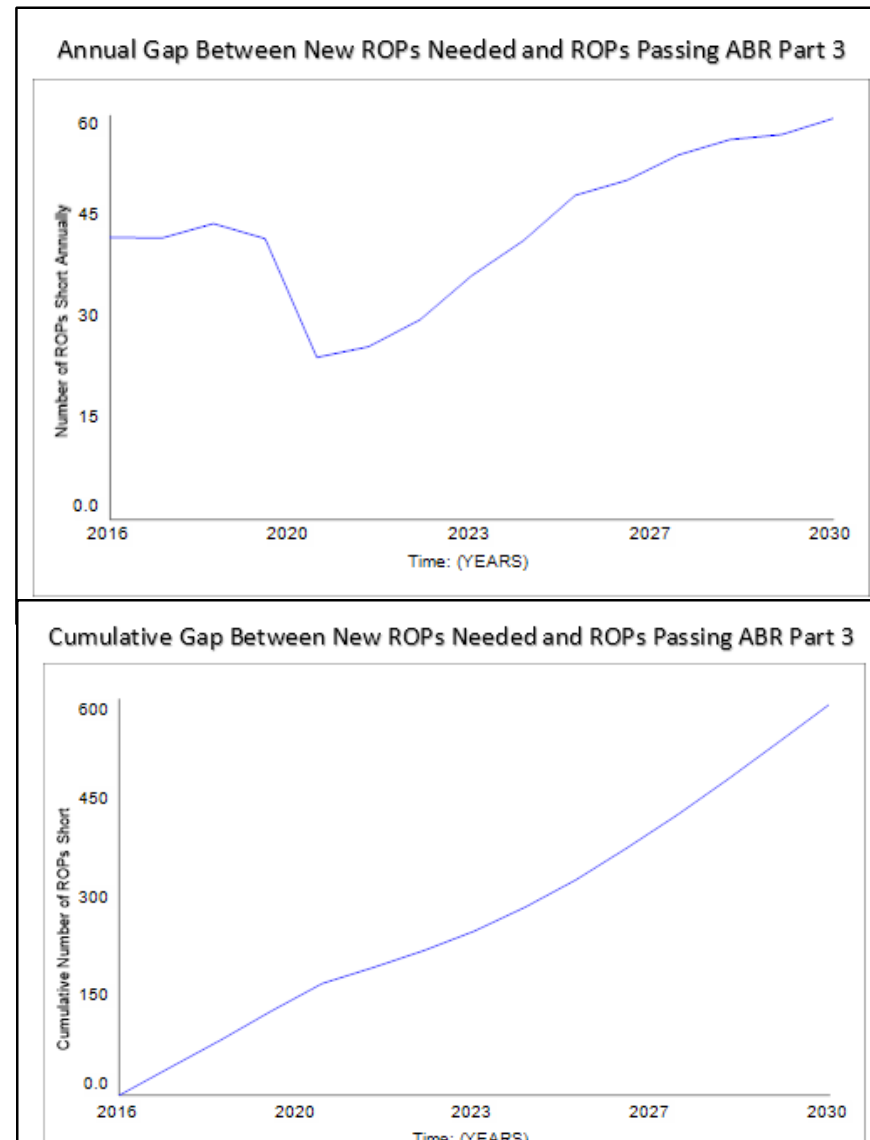

Figure 13a and $b$ : Annual and Cumulative gap in ROPs needed and ROPs passing the ABR part three exam to become board certified if there was no change to the number 
programs and residency, positions there will be approximately 700 graduate students with no pathway to certification by 2030 .

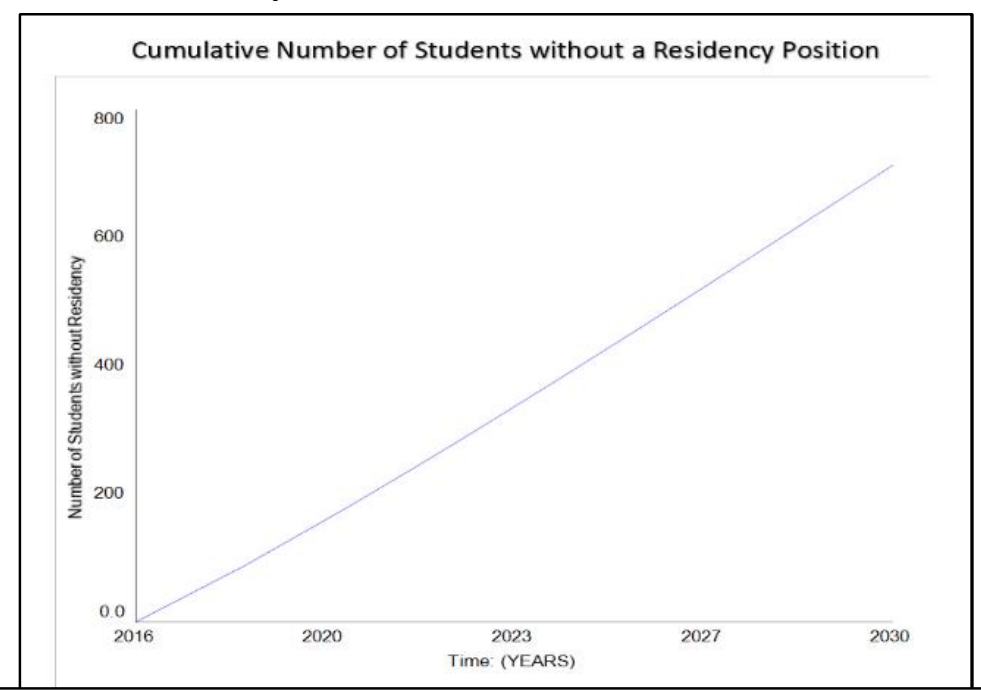

Figure 14: The projected cumulative number of Graduate students that applied and could not find placement in a residency program upon completion of a DMP, $\mathrm{PhD}$., MS, or certificate program

Next the model was manipulated to determine what immediate residency growth would be needed for the supply and demand to level out by 2030. The model shows that in order to have a cumulative gap of less than five there would need to be 250 new

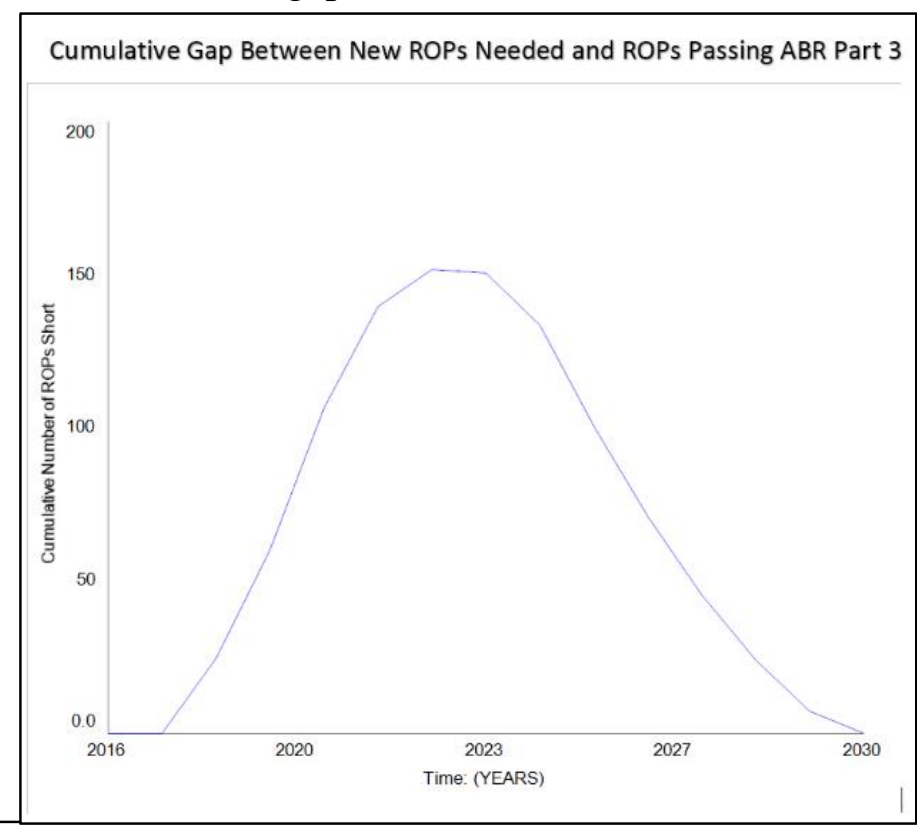

Figure 15: The projected cumulative gap between the number of ROPs needed and the number passing ABR part 3 if the number of residency positions grew to 250 by 2021 
residents admitted by the 2021 incoming class. If linear growth from 153 up to 250 residents in 2021, and then 250 residents are admitted annually from 2021 to 2030, by 2030 the cumulative gap would reduce to approximately four ROPs nationwide. There would be an oversupply for several years from 2022 to 2030 to make up for the deficit experienced until 2022. However, after 2030 the model shows the annual gap leveling out and the potential need for more residencies after 2030 to keep pace with the future demand.

While this growth is ideal to meet demand, the jump to 250 residency positions by 2021 is unrealistic due to the time and resources needed for credentialing new programs and positions. The model was adjusted with a more realistic growth rate, which adds five to ten new residency positions annually to eventually reach 250 in 2030 . With an

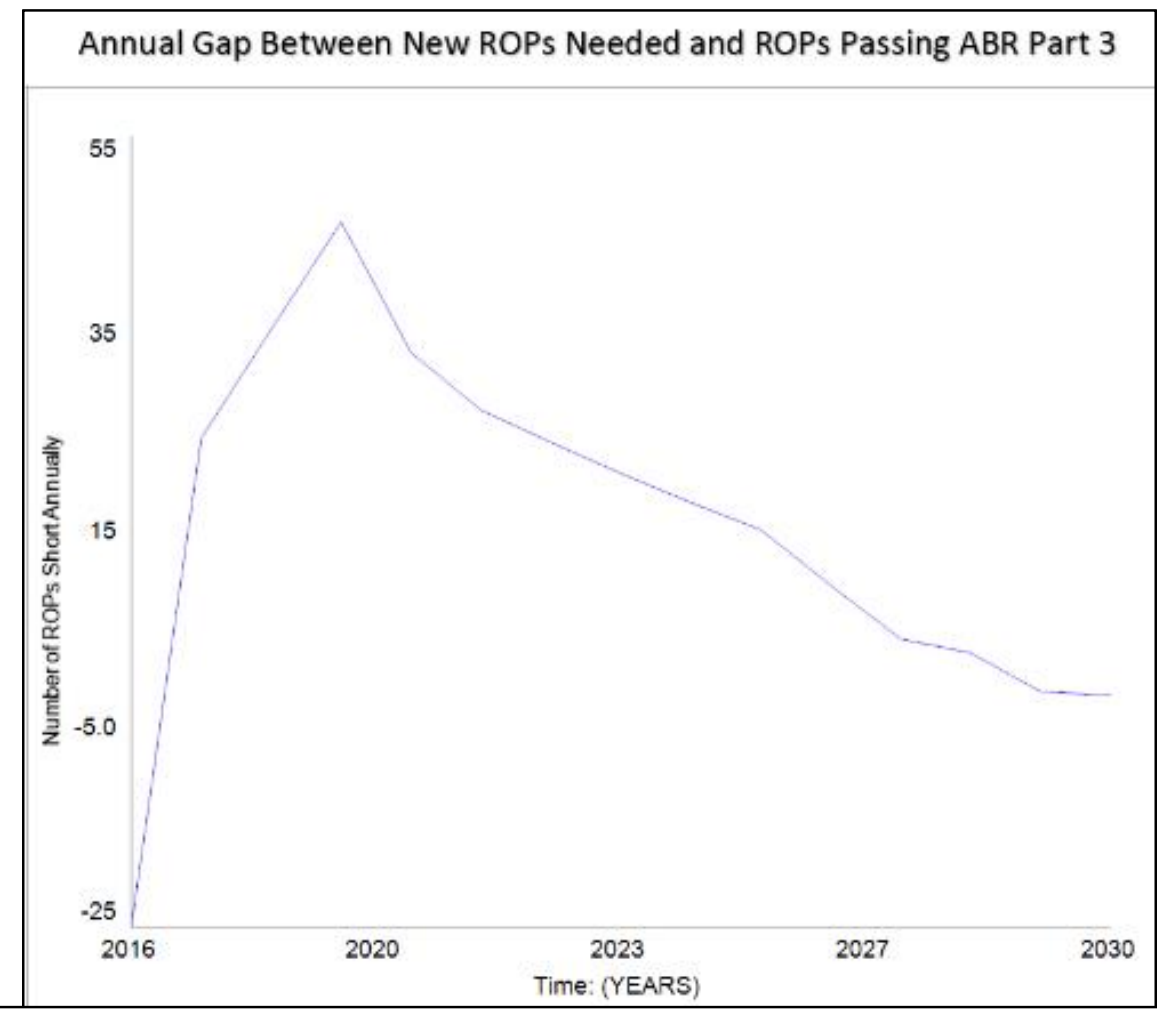

Figure 16: Annual gap in ROPs needed and ROPs passing the ABR part three exam to become board certified if there was growth in the number of residency positions to 250 by 2030 


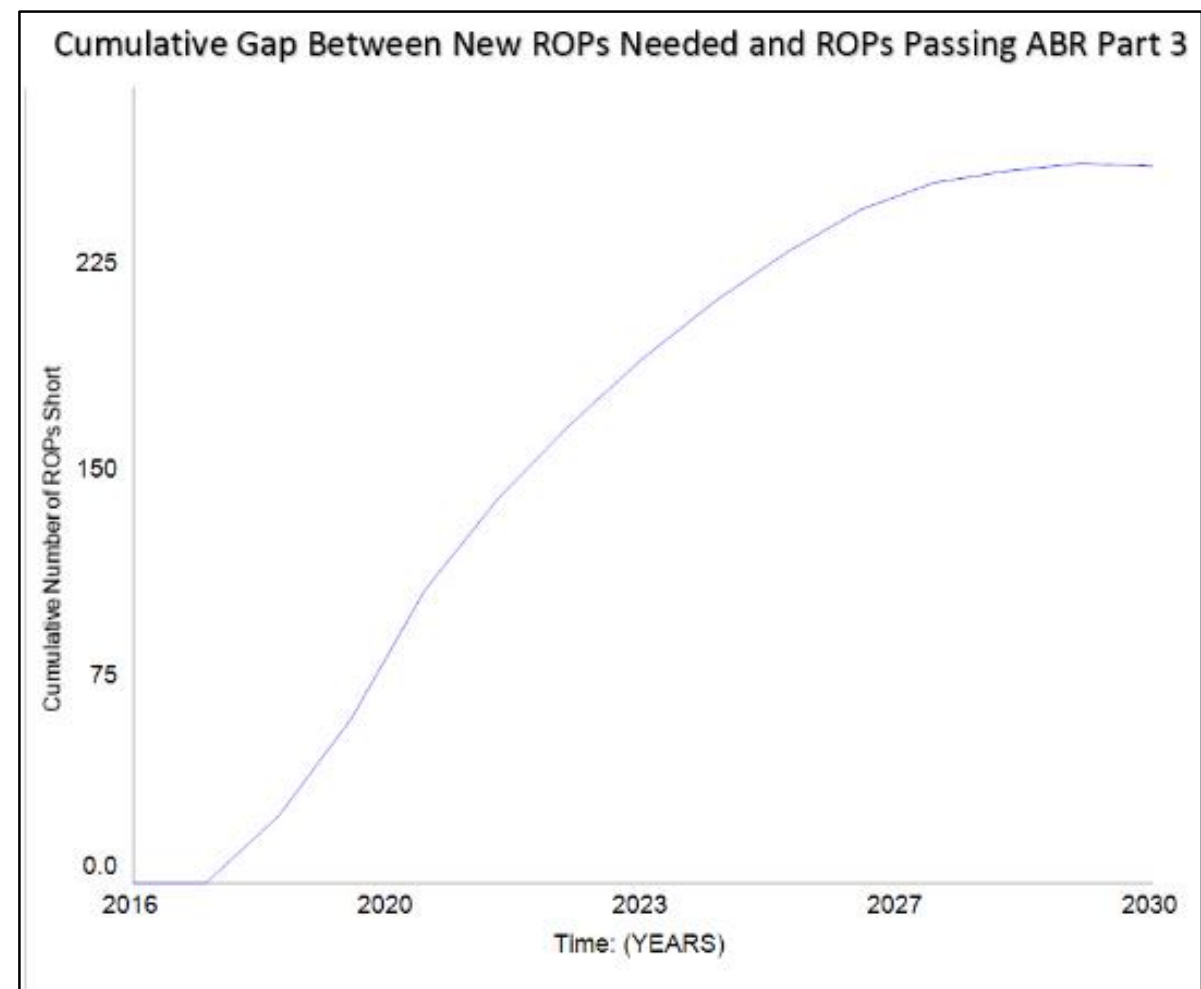

Figure 17: Cumulative gap in ROPs needed and ROPs passing the ABR part three exam to become board certified if there was growth in the number of residency positions to 250 by 2030

achievable growth in residencies of 250 by 2030 , the model still shows a deficit in the workforce but a much more manageable deficit of 261 ROPs by 2030 and an almost perfect annual balance by 2028. Since the demand most likely will continue to increase, the 250 positions would need to be re-evaluated in 2030 and in all probability continue to growth beyond 250 residency positions. For this simulated graduate school program, growth was also increased to match the current trends in program growth over the last five years. If graduate programs continue their previous growth and the number of residency programs grows to 250 by 2030 , the model predicts there will still be over 450 graduates without a pathway to board certification by 2030 . 


\subsection{Student and Junior Member Likert Survey Results}

The Likert question survey for graduate students and residents was sent out to 1,169 people and of those 182 responded. Thirty-seven of the respondents were ineligible to complete the survey since they had not attended a CAMPEP graduate or certificate program and moved to the disqualification page of the survey. The majority of the respondents eligible to take the survey were masters graduates (82 out of 145) followed by Ph.D. (30 out of 145), Certificate (18 out of 145), and DMP (4 out of 145), with 11 additional respondents that had not yet graduated from a program. The eleven respondents who had not completed a program were also sent to the disqualification page and not included in the results analysis.

\begin{tabular}{|lccc|}
\hline Respondent Type & $\begin{array}{c}\text { Number of } \\
\text { Respondents }\end{array}$ & $\begin{array}{c}\text { Percent of } \\
\text { Respondents }\end{array}$ & $\begin{array}{c}\text { Percent of AAPM } \\
\text { Junior/Resident } \\
\text { Membership }\end{array}$ \\
\hline Masters & 82 & $45 \%$ & $7 \%$ \\
Ph.D. & 30 & $16.5 \%$ & $2.6 \%$ \\
D.M.P. & 4 & $2.2 \%$ & $0.3 \%$ \\
Certificate & 18 & $9.9 \%$ & $1.5 \%$ \\
Ineligible Respondent & 48 & $26.4 \%$ & $4.1 \%$ \\
\hline Total & 182 & $100 \%$ & $15.5 \%$ \\
\hline
\end{tabular}

TABLE 1- Degree Type of Respondents

Forty-nine respondents were unable to find a residency postgraduate school while sixty respondents were recent graduates who had found residency positions. The remaining thirty-five respondents were residency graduates of which thirty-three had found jobs and only two had not. The two respondents without a job post residency are a statistically insignificant sample size and their responses will be discussed with that limitation noted. Fifty-five of the sixty students who found residency positions completed the remainder of the survey and thirty of the forty-nine who did not find residency positions completed the survey. 


\begin{tabular}{|lccc|}
\hline $\begin{array}{l}\text { Respondent Type by } \\
\text { Level of Training and } \\
\text { Education Completed }\end{array}$ & $\begin{array}{c}\text { Number of } \\
\text { Respondents }\end{array}$ & $\begin{array}{c}\text { Percent of } \\
\text { Respondents } \\
\text { (with complete } \\
\text { surveys) }\end{array}$ & $\begin{array}{c}\text { Percent of } \\
\text { AAPMior/Resident } \\
\text { Membership }\end{array}$ \\
\hline Graduate with Residency & 55 & $42.7 \%$ & $4.3 \%$ \\
Graduate without Residency & 30 & $25.6 \%$ & $2.5 \%$ \\
Residency Graduates with Job & 30 & $25.6 \%$ & $2.5 \%$ \\
Residency Graduates without Job & 2 & $1.7 \%$ & $0.2 \%$ \\
\hline Total & 117 & $100 \%$ & $10 \%$ \\
\hline
\end{tabular}

TABLE 2- Training and Education completed by respondents.

From the group that did not find a residency position it is important to note that fifteen of the thirty did not apply and pursued additional education or other careers instead of a residency. Those who did not apply for a residency are filtered out of the results related to residency availability but are included in the perceptions of the quality of the graduate programs. The majority of respondents who had success getting a residency position did so in the first year with an approximately only less than twenty percent of needing to reapply.

\begin{tabular}{|c|c|c|c|c|}
\hline $\begin{array}{l}\text { Number of Years } \\
\text { Applied for Residency }\end{array}$ & $\begin{array}{l}\text { Residency } \\
\text { Graduates } \\
\text { with a job }\end{array}$ & $\begin{array}{c}\text { Residency } \\
\text { Graduates } \\
\text { without a } \\
\text { job }\end{array}$ & $\begin{array}{l}\text { Graduates } \\
\text { with } \\
\text { Residency }\end{array}$ & $\begin{array}{c}\text { Graduates } \\
\text { without } \\
\text { Residency }\end{array}$ \\
\hline 1 Year & $\begin{array}{c}25 \\
(83.3 \%)\end{array}$ & $\begin{array}{c}1 \\
(50.0 \%)\end{array}$ & $\begin{array}{c}44 \\
(80.0 \%)\end{array}$ & $\begin{array}{c}9 \\
(30.0 \%)\end{array}$ \\
\hline 2 Years & $\begin{array}{c}4 \\
(12.5 \%)\end{array}$ & $\begin{array}{c}1 \\
(50.0 \%)\end{array}$ & $\begin{array}{c}8 \\
(14.6 \%)\end{array}$ & $\begin{array}{c}6 \\
(20.0 \%)\end{array}$ \\
\hline 3 Years or more & $\begin{array}{c}1 \\
(3.1)\end{array}$ & & $\begin{array}{c}3 \\
(5.4 \%)\end{array}$ & $\begin{array}{c}0 \\
(0.0 \%)\end{array}$ \\
\hline Did not apply & & & & $\begin{array}{c}15 \\
(50.0 \%)\end{array}$ \\
\hline Total & 30 & 2 & 55 & 30 \\
\hline
\end{tabular}

Table 3- Number of years for applicants have applied for a residency position. Note the graduates without residency are still applying, pursuing an advanced degree, or have moved on to a different profession. 
As far as studentsôbelief in their education and their preparedness for residency, there was a strong correlation between both the graduates with a residency and the graduates without a residency groups. For analysis, the Likert scale answers will merge the strongly agree and agree answers into one category of a positive response and the strongly disagree and disagree answers for the negative response. Both groups had strong positive reactions to the quality of their education and training prior to residency. Ninety three percent of those with a residency and eighty-seven percent of those without believed that overall their education was a good value and almost seventy five percent of each group felt well prepared for a residency. Both groups also felt as though their didactic curriculum was stronger than the clinical component in their graduate education as shown in Table 4.

The variation in the two groups became evident when looking at their perceptions on the availability of residency positions. While only thirty-two percent of current residents had difficulty finding a residency position, sixty-eight percent of residents agree that there are not enough positions available. As expected one hundred percent of graduates without placement in a residency not only had difficulty finding placement but believe there are not enough positions as well. Additionally as one would expect those who found success with the residency placement where twice as likely to answer favorably about the match as their counterparts did in the nonresidency group. Another point of note is that almost seventy percent of the students who responded found themselves in debt because of their medical physics education. This is relevant since a growing number of students are unable to find a pathway to board certification and thus having difficulty find a job to pay back their debt. Of the thirty respondents not in a residency, twenty are still pursuing their education, fifteen of those did not try for a residency while five continued on since they could not find placement with their current degree. Four out of the remaining ten found a non-professional (or a position not requiring board certification position in medical physics and six are unemployed waiting for the next match cycle. 


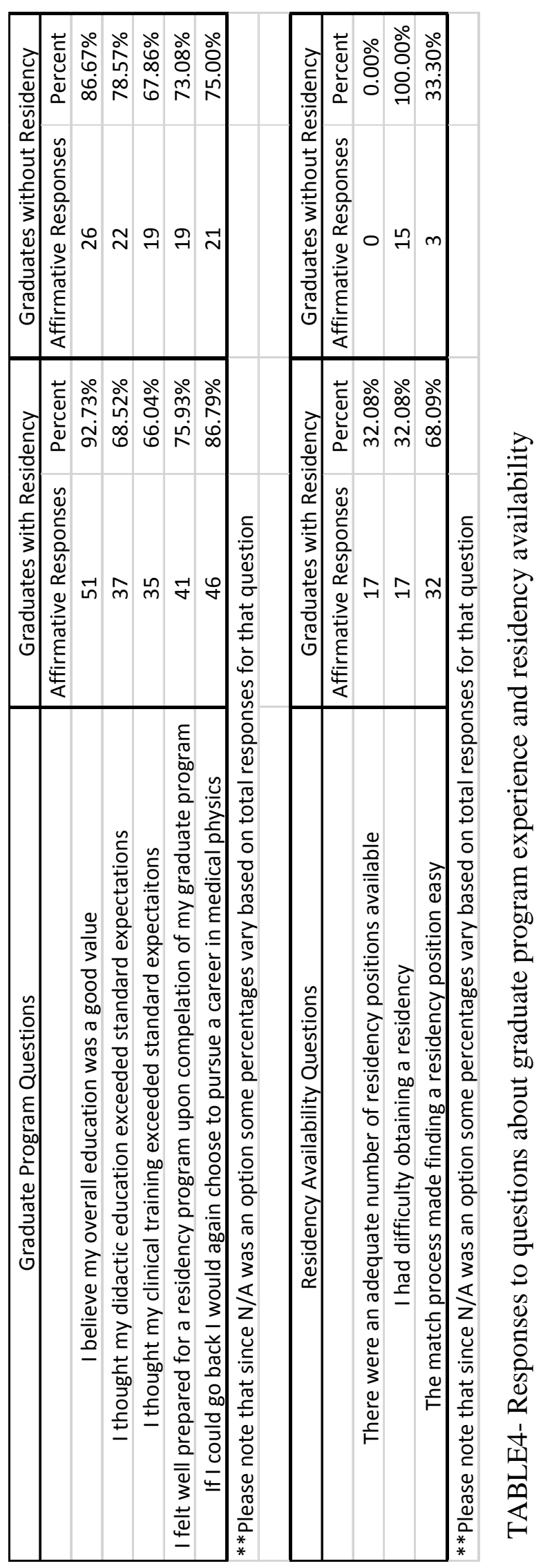


The respondents who were post residency were in two different categories the first being employed and unemployed as clinical ROPs. Over ninety percent of respondents were able to find employments post residency leaving a very small sample size of two respondents for the unemployed group. For this discussion, their answers will be included, but the greater significance of it cannot be applied to the profession as a whole due to the small sample. Employment post residency ranges from working for a vendor to a large academic institution. The two that have not found employment are both

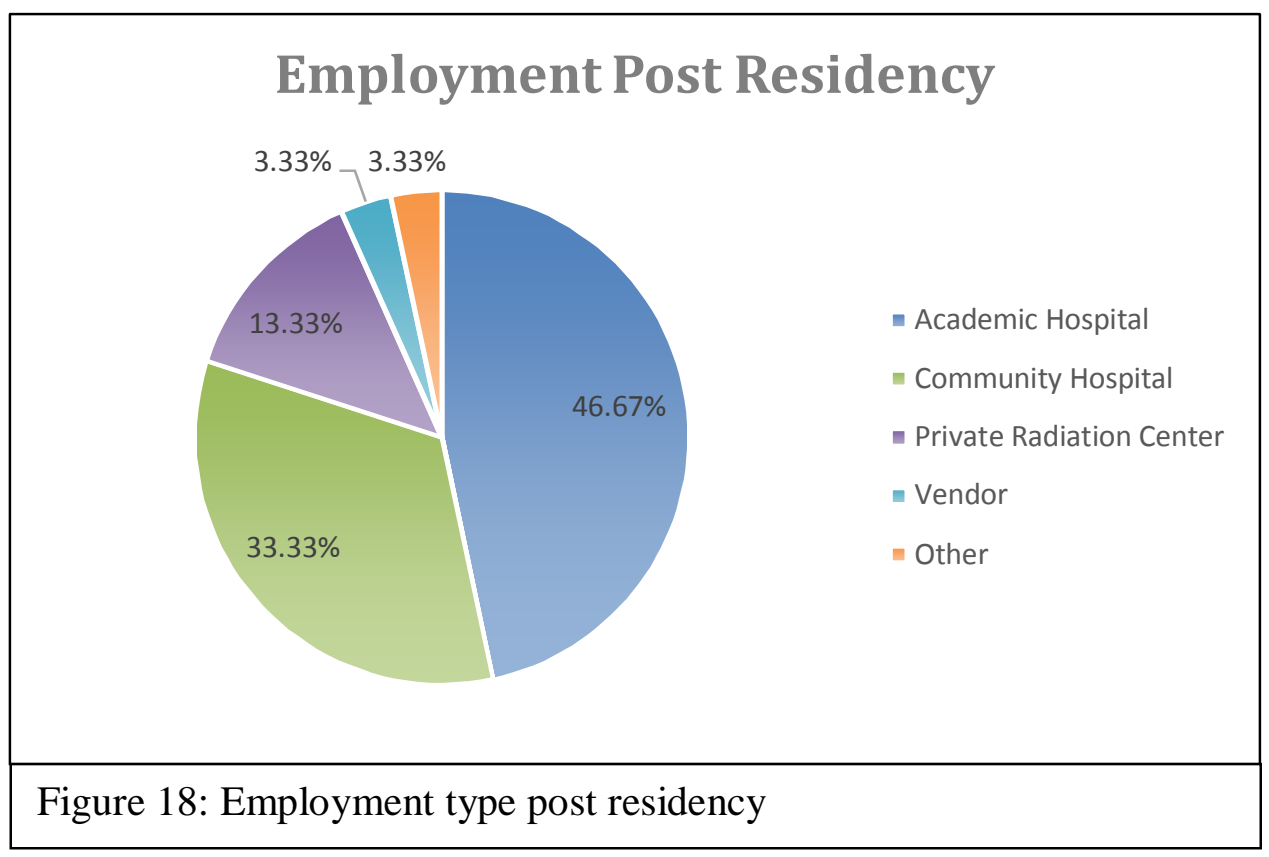

still pursuing a career in medical physics. One of the two is continuing a degree in biomedical imaging in the interim. Focusing on the group who found a job post residency there are several important results to note. The first is that only five of the thirty respondents reported having difficulty finding a job post-residency. Furthermore, the majority of responses had a favorable perception of their training, compensation, and the experiences in the profession in general. The one question that elicited negative responses was in regards to the availability of jobs in the location desired by the respondent. With the limited size of the radiation oncology medical physics field in the 
United States job availability by location is a natural issue with there being a limited

need. The responses from the two individuals without employment post residency agreed

with their counterparts that they both felt well prepared for a career in medical physics

post residency. Additionally they also though that location was a large obstacle while

only one of the two thought jobs in general were difficult to find.

\begin{tabular}{|c|c|c|}
\hline Post Residency Education Questions & \\
\hline & Affirmative Responses & Percent \\
\hline I felt well prepared for a residency program upon compelation of my graduate program & 26 & $86.66 \%$ \\
\hline I believe my residency training has prepared me well for a career in medical physics & 28 & $93.33 \%$ \\
\hline I thought my residency clinical education exceed standard expecations & 24 & $80.00 \%$ \\
\hline Job Availability Questions & \multicolumn{2}{|c|}{} \\
\hline & Affirmative Responses & Percent \\
\hline I did not have difficulty finding a job after my residency & 25 & $83.33 \%$ \\
\hline Thre were an adequate number of medical physics jobs available & 23 & $76.67 \%$ \\
\hline My starting pay was competitive with current salary surveys & 24 & $80.00 \%$ \\
\hline It was easy to find a job in the location I desired & 10 & $33.33 \%$ \\
\hline I am satisfied with my first job in the medical physics profession & 28 & $93.33 \%$ \\
\hline
\end{tabular}

Table 5- Responses from employed physicists post residency.

\begin{tabular}{|c|c|c|}
\hline Post Residency Education Questions & \\
\hline & Affirmative Responses & Percent \\
\hline I believe my residency training has prepared me well for a career in medical physics & 2 & $100.00 \%$ \\
\hline I thought my residency clinical education exceed standard expecations & 1 & $50.00 \%$ \\
\hline Job Availability Questions & \\
\hline I had difficulty finding a job after my residency & Affirmative Responses & Percent \\
\hline Thre were an adequate number of medical physics jobs available & 2 & $100.00 \%$ \\
\hline It was easy to find a job in the location I desired & 1 & $50.00 \%$ \\
\hline Given the opportunity again, I would re-pursue a career in medical physics & 0 & $0.00 \%$ \\
\hline
\end{tabular}

Table 6- Responses from unemployed physicists post residency

\subsection{Student and Junior Member Open Survey Results}

At the end of each Likert survey respondents had the option to respond to an open-ended question that asked, ñPlease provide any additional comments about the value of your residency training and your experiences with residency placement.ò Additionally there was a question probing for participants in a follow up open-ended survey. Out of the 30 respondents categorized as graduates without a residency seven left open-ended responses and seventeen agreed to provide information for follow up. Of 
those seventeen, four responded to the open-ended survey. For the group of graduates with a residency, twelve left feedback on the survey and thirty-three agreed to receive the follow up survey. Of those thirty-three, twelve sent in full responses. The responses for both groups were combined, coded, and analyzed. For those with a residency the questions sent were:

1. Are you in debt from your medical physics education?

2. How did debt add pressure to find residency position?

3. Did you encounter many obstacles in finding a residency position? If so, what were they?

4. How is your residency program experience?

5. How are your hours and salary?

6. How do you feel about your overall experience in the medical physics field?

For those without a residency the questions sent were:

1. What field have you found work in?

2. Are you satisfied in your current career?

3. What barriers did you encounter in finding a residency position?

4. Are you in debt from your medical physics education?

5. How do you intend to resolve debt?

6. How did debt add pressure to find residency position or alternate career?

7. How do you feel about your overall experience in the medical physics field?

Several themes emerged from the data. The most predominant theme was overall the majority of respondents felt positive about their overall experience. Ten of the sixteen open-ended responses had positive sentiments about their overall experiences, four were neutral with generally positive personal experiences but worries about the state of the field and work life balance in general, and two were negative. To note the two negative 
responses were from the respondents who had not been able to obtain a residency

position. One important thing to note is that one of the two negative responses was from a respondent with a very strong reaction and the response included suicidal thoughts.

The response was sent to IRB and the respondent was followed up with to provide resources for assistance. This is significant to the results to show that while the majority had a positive experience this problem is putting some students in a very difficult and serious situation.

- Examples of survey responses- Positive:

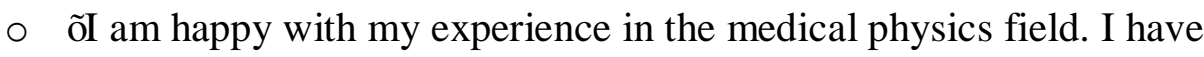
enjoyed my residency, and am excited for the next step.ò

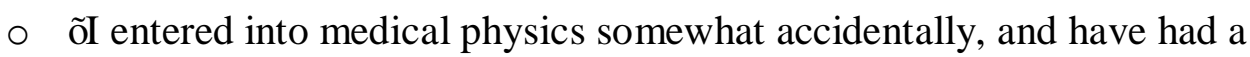
grown passion for it ever since. My opinion is that medical physics is dynamic, multidisciplinary, at the forefront of medical science and fulfilling.ò

○ ñVery excited, optimistic and fruitfulò

- Examples of survey responses- Neutral:

○ ñOverall, positive. I love what I do; the main struggle is work-life balance. I worry about finding a long-term position after residency that has a balance of professional satisfaction and reasonable hours/time off, but I imagine this is a struggle many in our field face.ò

○ ñOverall, I love this field. I enjoy doing everything I do day-to-day. The only negative I'd have to say is about the amount of hours I work per week. I wish there was more of a work/life balance. I'd even take a pay cut to have more time at home.ò

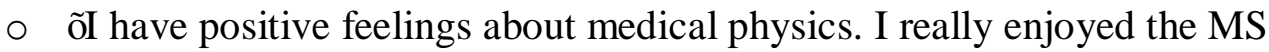
program at ---------, and have enjoyed my experience working as a resident. I did not enjoy the stress of finding a residency position knowing that there were over 300 students applying for 106 spots, and I often deter 
people from joining the field by sharing the current fact that only about $30 \%$ of graduates can achieve board certification.ò

○ ñThe field as currently designed is a mess for students trying to enter the profession in the MS + Residency track. My overall experience turned out alright but I feel for the students that paid for a degree that they ended up not being able to use in a clinic.ò

- Examples of survey responses- Negative:

○ ñMy knee-jerk response is, "Choosing to pursue medical physics has been the worst mistake of my life," but that is something of an oversimplification, because my problems were also due to immaturity, an attitude problem ("if only my health problems were resolved then I would be happy" rather than choosing to be happy despite suffering), and possibly even clinical depression (though my experiences as a student were likely a catalyst). œé ò Thinking of all these problems, I feel very negatively about my overall experience in the medical physics field. It consists largely on the wealthy preying on the poor, both program directors and university faculty misusing studentsò

○ ñMy experience has made me very bitter overall. It saddens me that the field used to be run by the physicists and now it is run by the government. We have lost all freedom in this transition and should completely drop the $\mathrm{ABR}$ as the accrediting body behind medical physicists. It should be the AAPMò

Another positive theme that emerged was that in general respondents felt as though their residency was beneficial and needed. Twelve different respondents included affirmations about their residency experience, only one response was negative and three had neutral feedback. The neutral feedback focused primarily on the quality of various programs and the need for additional standardization or enforcement of quality standards in residency programs. 
- Examples of survey responses- Positive:

○ ñMy residency has been an excellent experience. I feel that I am receiving all the training I will need to work independently after residency and to pass my boards. The workload is tough, but that is the best way to learn and I feel it is necessary in a field where improper training could lead to significant harm to patients.ò

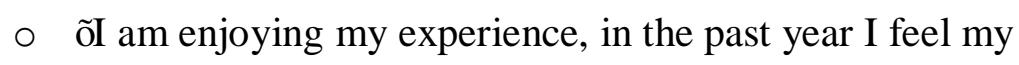
understanding and confidence have improved tremendously. And I really appreciate starting in a role that is semi-training focused, which allows me to be comfortable asking questions and having my work reviewed by my superiors.ò

○ r̃Educationally, it is excellent. I feel my residency program is preparing me very well for board certification and independent practice. I also feel the experiences I am gaining during the residency will make me more competitive in the job marketplace, even compared to residents graduating from other programs.ò

○ ñMy residency training has been invaluable to my development as a radiation oncology physicist and is helping to prepare me for ABR Parts 2 and 3. I highly doubt I would be anywhere near as prepared to take Parts 2 and 3 and generally be a safe and effective physicist without the structured residency training.ò

- Examples of survey responses- Neutral:

- ñMy residency training thus far has been valuable but I am surprised by the lack of enforcement by CAMPEP (eg that the residency program actually provides the training that it says it does). It seems quite variable and up to the whims of the residency supervisors. I think my time would likely be better and more efficiently spent with a $\sim 6$ month training period at the institution and in the role where I accept a permanent position rather than in a more general residency that touches on many subjects (many of which I won't work with in the future) and reflects the practices 
only of the physicists running the residency (not necessarily the field more generally). However, I completely understand the need to have a standardized clinical training program for physicists to get board certifiedò

○ ñResidency programs would greatly benefit from a curriculum standard, such as minimum necessary time spent with ""x"" topic. Having a structured system of educational attainment necessary for appropriate learning to occur will produce better residents with minimal knowledge gaps in key areas.ò

○ ñAcceptable, not great. It is a new program so it is generally poorly organized and not particularly rigorous (which, to me as a trainee, has its pros and cons). However, I have still had plenty of opportunities to get a lot of hands-on clinical experience and some clinical research experienceò

- Examples of survey responses- Negative:

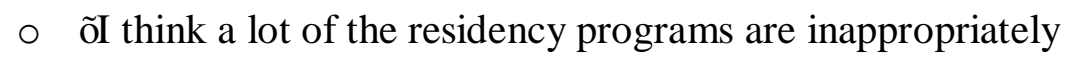
emphasizing PhD's and research over clinical training and this is leading to unmotivated an incompetent physicists in the clinical workforceò

The match was another area that most respondents felt positively about. While several respondents entered the field prior to the match, of those who utilized the matching program five had positive experiences while only two had negative feedback.

- Examples of survey responses- Positive:

○ ก̃The MATCH helped with ensuring that applicants weren't holding onto offers while they waited for a better one to come along giving plenty of opportunity for everyone part of the MATCH.ò

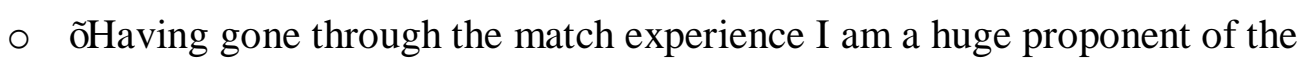
current system. The match streamlined the process and eliminated having to make my decision before I had all of my options in front of meò 
- Examples of survey responses- Negative:

- ñSince I was applying to jobs and a single residency position, I was furious that I suddenly had to participate in the Match, because it was not simple, straightforward to get an answer about whether or not I had a positionò ñ did not appreciate this process, especially because this was the first year the match started. Luckily, it all worked out, but was the most stressful experience of my life.ò

○ ñThe match system was a horrible idea to pursue. It has caused a lot of people in the beginning of their careers a great deal of problems. For instance, I refused to participate in the match after my masters because I was interested in pursuing a $\mathrm{PhD}$ but had I not been so fortunate to get accepted somewhere then I would have been out of luck. You have taken a lot of freedom away from people just entering the field by demanding first a residency, which I do not have as much of an issue with, but then you forced us to use this horrible system that takes away all of our freedom to choose the program that best suits us and reduces the competitiveness of each candidate. It would be in the best interest of both the institution and the workforce to drop the match as the way for workers to get picked for their residency.ò

Although respondents feel generally positive about their residency placement and experiences there were several concerns that were repeated throughout the responses. The first and most predominant was the lack of residencies for the number of graduate programs. Throughout both response groups, there was a repetition of too many graduates for the number of residency positions available. The sentiment of many respondents who had been able to secure a residency themselves was that even though they were fortunate to find a position many of their classmates were not as fortunate. The only responses related to the number of graduate and residency positions were fourteen people stating that there were not enough residencies for the number of graduates and that 
people who did not secure a position have no pathway to clinical employment. No respondents gave a contradictory opinion to this.

- Examples of survey responses:

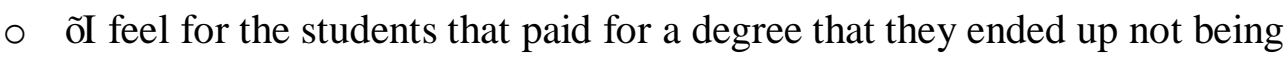
able to use in a clinic.ò

○ ñMany applicants came through our program for interviews and candidates that I thought would match without a problem surprisingly were not matched with a program.ò

○ $\tilde{n}$ don't know anything, but it sounds like the problem is not insufficient residency positions, but rather too many CAMPEP accredited graduate program graduates.ò

- Residency placement is close to impossible.

○ ñThere was a significant lack of positions compared to applicants. I applied to one place where there were 120 applicants and 3 positions.ò

$\checkmark \quad \tilde{n}$ hope the number of student from CAMPEP accredited program should be limited. Finding a residency position is real huddle.ò

The final theme that emerged was the issue of money. Several respondents mentioned debt from education or the excessive costs of interviewing. Debt from education was a split issue with several respondents getting funding through grants, scholarships, teaching assistant positions, etc. For most of those who were not able to secure funding debt was not only present but also a major stressor. For all of the responses the presence of debt was split half with debt and half without, but three of those without debt mentioned financial hardships from applications or from friends who were less fortunate to find funding.

- Examples of survey responses with financial hardships: 
○ ñTravel and accommodation costs made the residency interview process prohibitively expensive.ò

○ ñThe cost of flying out for interviews was difficult. I'm paying off my student loans slowly on a pay-scaled plan, and I'm doing a small amount of tutoring on the side to help pay things off a little faster, particularly since I have some minor personal debt related in part to the cost of flying out for residency interviews.ò

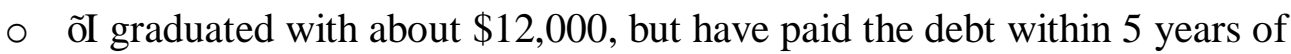
graduation. Debt added significant pressure to find any sort of employment after my education. I worked in industry directly after graduation, instead of going to residency. Acceptance into residency did not occur until 4 years after graduationò

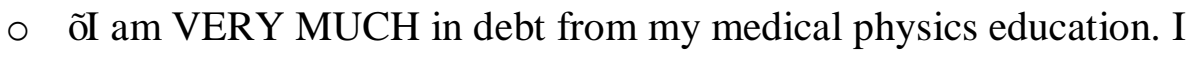
justified entering debt by convincing myself that I could probably pay the whole thing off over my residency. I did not find a residency right away, which added immense pressure to qualify for one. I am now almost finished residency and have moved my debt relief prospects away to a distant hope of paying the whole thing off over my first 5 years of work at normal medphys pay. Itôs been horrible and stressful, but manageable.ò

○ ñYes, I now owe $\$ 140,000$ at 7.7\% interest and consider my life financially ruined by pursuing medical physics as a career. Moreover, I have sacrificed marital life pursuing this career, unable to start a family or date since still in school and without substantial incomeòé ñ chose to pursue the first PhD I was offered $і ̈$ in ---- -- to try to become a competitive applicant again for residencies to pursue this clinical career to repay this debt. Essentially, the debt has enslaved me, and I have regarded it as my life's master, and it is a horribly depressing feeling together with choices I have felt compelled to make, to the point of creating thoughts of suicide as an escape, as if trapped in an inescapable pit or carrying a mountain. ̀̀ 
The second group of survey respondents had some similar themes. The second group of respondents are the people who have recently completed a residency and are now in the workforce. Out of the thirty respondents to the Likert survey, twenty were willing to receive a follow up survey, seven completed it and thirteen supplied a response to the open-ended question at the end of the survey that asked, ñPlease provide any additional comments about the value of your residency training and your experiences with job placement post residency.ò

The follow up survey sent asked the following questions:

1. What is your current job title?

2. Is this your first job post-residency?

3. How many years have you been in your current position?

4. What was your experience for finding your first position post-residency? (Location, salary, hours, etc.)

5. Did you have issues finding a job prior to passing the board exam? If so explain.

6. Are you satisfied with your current position?

7. What do you think about the current job market in medical physics based on your experiences?

Just as the group of graduate students responded, the working physicist respondents also thought there was an issue with too many graduate students and not enough residencies. This response is interesting since none of the probing questions asked about the state of graduate programs or residency programs. Five of the respondents mentioned the surplus of graduate schools and limitation of residencies in their responses 
Overall, the survey responses match what is shown in the STELLA model. Availability of residency positions is the restriction on the pathway into board certification and thus a working ROP. There are an excess of graduates wanting to enter the field with not enough residency positions to allow board certification. Once graduates find placement in a residency position typically they are able to move on to employment with the main restriction being location of job availability.

- Examples of survey responses about residencies and graduate programs:

○ ก̃The job market for medical physicists is very poor due to the fact that there are more physicists being churned out than positions available. The heart of this issue is that there is no regulation/limit on the number of students that graduate programs accept. The CAMPEP graduate programs do not get "punished" for accepting too many students for the job market. There are some programs that have more than 20 students per class which is absurd for the demand for physicists. And of course there is now the issue that there aren't enough residency spots either, which is all the more reason that these graduate programs shouldn't be allowed to accept so many studentsò

○ ñé the root of the issue which is that graduate programs are accepting too many students for the needs of the workforce. They continue to do so because there is no restrictions or repercussions for these programs and they make money off of students who have no idea how difficult it is to get a job or residency. œ̀ ñAAPM or CAMPEP should be doing something to force graduate programs to very clearly publish their job/residency placement rates and CAMPEP should only accredit schools with a reasonable number of students.ò

○ ñThere are not enough residencies to force people to go through residency in order to take part 2 of the ABR. Everyone knows that without Board Certification a career in medical physics will be impossible. Nationally, 
the schools that are CAMPEP accredited admit more students than residency positions. A few schools in particular are the biggest offenders, with class sizes as high as 20 . This is irresponsible and can ruin people's careers and leave them mired in debt. Either relax the residency requirement for Board Certification or CAMPEP needs to reduce the class size of universities.ò

Two other emerging themes were the issues of jobs preferring Ph.D. or ABR certification. The issue with ABR certification is that most people cannot take Part 3 of the ABR exam until they complete their residency, which is typically in June. Part 3 is offered in late April or May annually which means there is about a year gap between residency completion and board certification. Ten respondents mention either the need for board certification or the preference of Ph.D. as issues in finding job placement. Five respondents said $\mathrm{ABR}$ certification was not an issue in finding a job, but the guarantee of certification was a part of their employment contract.

- Examples of survey responses about certification or degree:

○ I have a DMP degree. In my job search I have found the DMP to be useless because HR screening tools don't recognize anything except Ph.D. My applications are being excluded from employment consideration. Also many hiring managers don't have a clue what a DMP is, or what benefits it provides

○ ñAdditionally, I think that such an emphasis has been placed on our rigorous certification process that many employers are not willing to hire non-certified physicists even if they are board-eligible. Similarly, others will always prefer $\mathrm{PhD}$ physicists over MS ones.ò

○ ñAdditionally there is another problem for those with MS degrees - there are several job posting that "require" PhDs despite the position being a solely clinical position which in reality does not *need*a $\mathrm{PhD} .0 ̀$ 


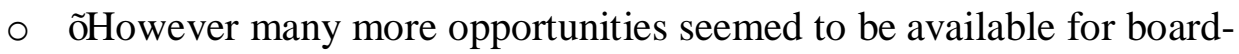
certified physicists. My job offer required that I be certified within 2 years of hire, which I was able to do.ò

The last obstacle that many respondents reported was the issue of finding a job in a desirable location. Specifically finding a job in a major city (i.e. New York, Chicago, Boston, etc.) was a barrier. While respondents mostly agreed that there are jobs available, it was a common response that first positions were typically in undesirable locations and that physicists could relocate once they had certification and more experience. Most of the respondents who were satisfied with location had found employment where they had completed their residency or doctoral work. As with any small field, positions in cities are limited and typically, those positions in the major cities only open up through retirement or attrition, which is not common in the medical physics field due to the longevity of most physicistsôcareers.

- Examples of survey responses about job location:

○ ก̃There are enough jobs that it is not difficult to be employed if you donâ care where you go, but if you want to limit yourself to certain categories/geography, the process becomes more difficultò

○ ñThe other issue relates to specific geographical job markets. Though there are physicist jobs available across the country at any given time, it is not realistic for people, especially those who are married/with families/etc. to be able to just move where a job is. Despite there being several hospitals in all these major metropolitan locations, the physicist job market is terrible in that typically only 1-2 positions are posted per *year*, with some cities having 0 postings per year: Chicago, Atlanta, DC, Boston, Seattle, Portland, San Francisco \& the Bay Area, San Diego, 
Denver, Austin, and the list goes on. There have even been years recently where no jobs were posted in the NYC or Boston area at all! ò

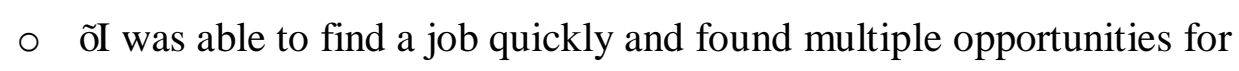
interviews although not in preferred locations.ò

Despite these concerns, the respondents in the working physicist group were ultimately satisfied with their career choice. No respondents reported dissatisfaction with their career choice while twelve stated that they were satisfied. Ultimately, one respondents captured all of these themes in their response:

○ ñYes I am satisfied in my career. I believe there are a reasonable number of openings for board-certified medical physicists, although many require $\mathrm{PhD} /$ management experience or are not in a desirable location. I think the hard part was getting the residency... more or less smooth sailing from there.ò

\subsection{Emeritus Likert Survey Results}

The Likert question survey for emeritus members was sent out to 540 people and 40 responded. Seventy percent of the respondents had spent 30 years or more in the

\section{Years in Medical Physics Profession}

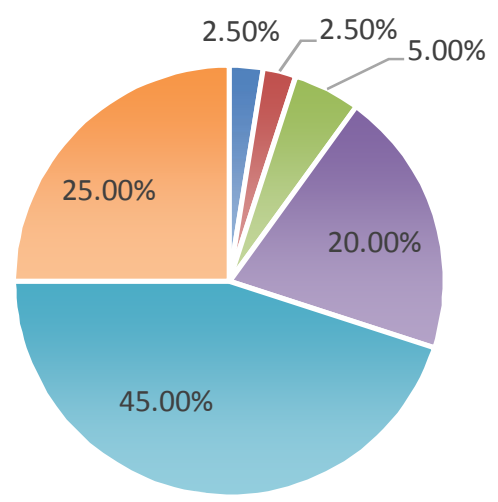

$$
\begin{aligned}
& =5-10 \text { years } \\
& =11-15 \text { years } \\
& =16-20 \text { years } \\
& =21-30 \text { years } \\
& =31-40 \text { years } \\
& - \text { more than } 40 \text { years }
\end{aligned}
$$

Figure 19: Number of years in medical physics profession prior to retirement 
medical physics field. Less than ten percent of the emeritus members had left the field with less than 20 yearsôexperience. Half of the respondents ended their career as chief of physics with an additional two respondents who became vice presidents of medical device companies. Reasons for leaving the profession varied from workplace conflicts to health issues, but the primary reason was retirement. It should be noted that respondents

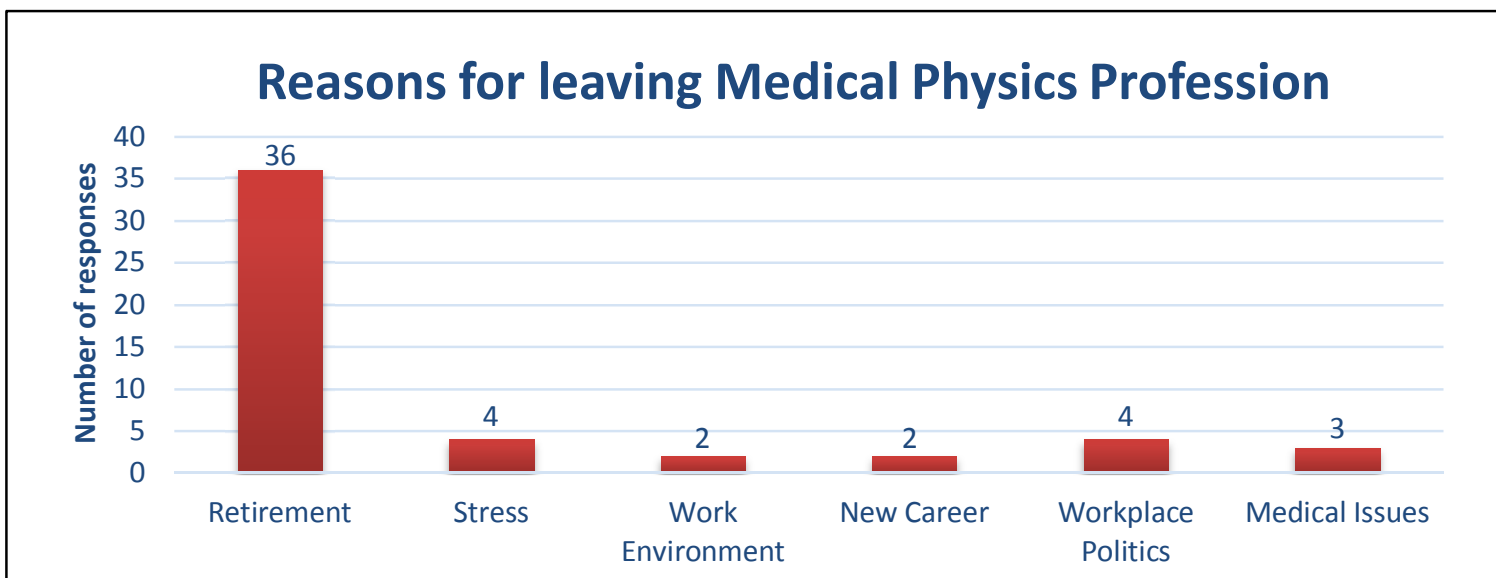

Figure 20: Reasons for leaving medical physics profession

could select multiple answers. Interestingly most respondents reported that even in retirement from the field they are still participating in the medical physics profession in some capacity whether it be through service or consulting. The biggest take away from

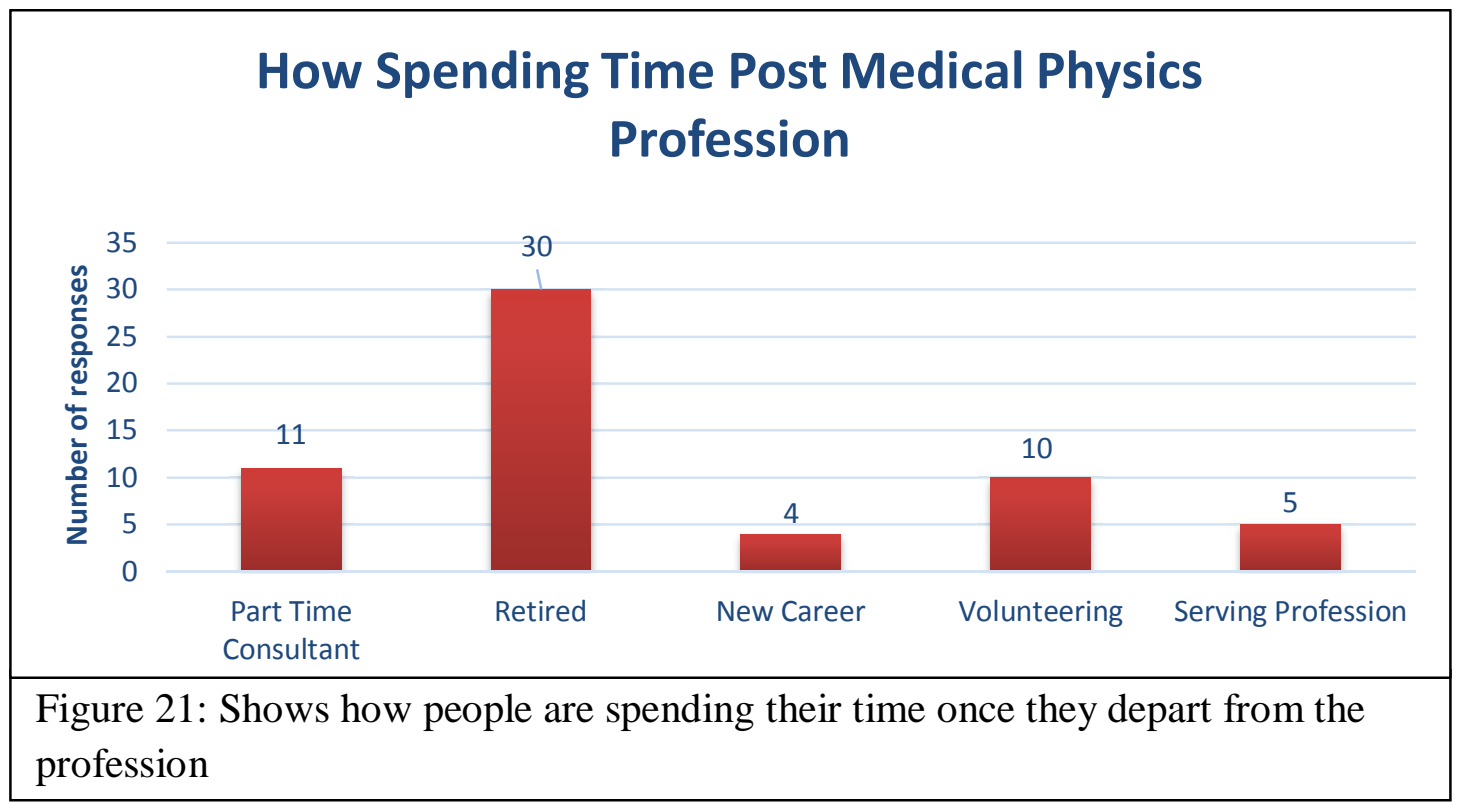

the emeritus group is the overwhelming positive response they had in regards to their 
time in the medical physics profession. Despite the fact fifty percent reported that they worked an unreasonable amount of hours, over eighty-five percent of respondents felt they were compensated well, enjoyed their career, and would repeat the decision to enter the profession. More importantly, $92.5 \%$ feel as though the field has evolved in a positive way and that they would recommend the profession to a student or friend.

\subsection{Emeritus Open Survey Results}

At the end of the emeritus Likert survey respondents had the option to respond to an open-ended question that asked, ñPlease provide any additional comments about your experience in the medical physics profession and any insight into why you chose to leave the profession. ̀̀ Additionally there was a question probing for participants in a follow up open-ended survey. Out of the forty respondents, twenty-seven left open-ended responses and thirty-one agreed to provide information for follow up. Of those thirtyone, eight responded to the open-ended survey. The questions sent for follow up were:

1. Explain why you retired from the medical physics field and what are you doing now.

2. What changes would you want to see take place in the medical physics profession?

3. If considering a career today, would you repeat your decision to pursue career in medical physics? Why or why not?

4. Do you feel like you have left a legacy? If so how?

5. Did you have an "AHA" moment in your career as a medical physicist? If so what?

6. What do you think about the current state of the medical physics profession? (Salary, job market, technology, residency programs, certification, etc.)

7. What changes, if any, would you like the AAPM to make to better serve the retirement community? 
The biggest takeaway from the emeritus survey responses was that eighteen of the respondents reported some sort of satisfaction with their career as a medical physicist.

The three respondents with reservations about repeating their career was primarily related to concerns about the future of the field and training pathways. Two additional themes that emerged were cause for concern for the future of the field. Those two themes were issues with the new pathways to become a ROP and the elitism that is beginning to infiltrate the medical physics community.

- Examples of survey responses about job satisfaction -Positive:

○ ñ̃My biggest "AHA" was discovering medical physics itself. It married my love of biology and my early health physics training and I knew I'd found a home! ’̀

○ ñYes, I would make the same decision. Medical Physics has been a very rewarding career and it continues to be rewarding even as a volunteer.ò

○ ñBeing a Medical Physicist the last 40+ years, and watching the profession develop and mature has been a wonderful and fulfilling experience.ò

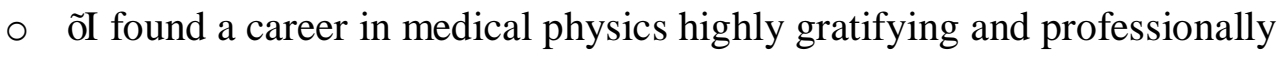
rewarding. ò

- Example of survey response about job satisfaction -Negative:

○ ñob satisfaction and security were small or inconsistent. I felt that my career was in the hands of a few people whose behavior was petty and unprofessional. I and my family made many sacrifices in moving many times to different cities to continue my career under better conditions. Over forty years, I never stayed more than eight years with the same employer.ò

- Example of survey response about certification:

○ $\tilde{n}$ think that the changes to the path to a career in medical physics that have taken place this past decade are not necessarily for the good of the 
profession. I believe more serious discussions need to be pursued. It is very confusing to the aspiring physicist, and very much unorganized on a general level. Given the new requirements and restrictions, I would not do it today. I feel that the state of AAPM residency programs, certifications, education, etc. are in tremendous flux and makes it very difficult and unfair to prospective physicists.ò

○ ñWhen I started out students didn't incur a lifetime school debt to get a job in a desired career. I fear for the profession because of the cost of education before on the job training opportunities.ò

○ ก̃The opportunities in medical physics are fewer compared to when I entered. I would have preferred keeping the option that "pure" physicists could be trained as med physicists rather than the regs currently in place.ò

- Example of survey response about elitism:

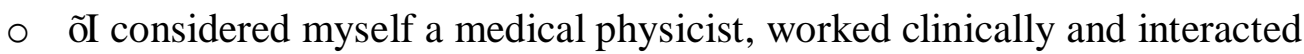
with numerous clinical scenarios. My only concerns is the "march" to elitism, ignoring the fundamental changes medicine is undergoing today. This march may isolate, and potentially endanger the very profession due to technologies that are replacing some of the very tasks medical physicists prided themselves in doing. Beware.ò

○ $\tilde{n}$ 've seen a continual creep toward the $\mathrm{PhD}$ requirement. There is a hang up of being on "par" with physicians. Radiation Oncology will always be a team effort, and the problem is not that the physicist is a MS or $\mathrm{PhD}$. The problem is that physician training, for all doctors, emphasizes that they are in control and responsible (and rightly so), but it does not train them to respect and use the talents of their physicist colleagues. Less than half of the physicians I've worked with knew what I could do for them, and refused to listen, or entertain any ideas other than their own, (or those of their trainers). The axiom is still true, that the $\mathrm{PhD}$ is just the Union Card to teach at the University level. It is not necessary to deliver quality medical physics care.ò

○ ñThe Association trends to be very exclusiveò 
Overall, emeritus respondents had long, impressive careers. Despite their individual success and experience, many caution about the future of the medical physics profession if changes are not made. Whether they be concerns about too much standardization, not enough creativity, restrictive pathways, or cost of education their responses make it clear that they fear something must change for the profession to continue to thrive. 


\section{CHAPTER 4 DISCUSSION}

While the growth of cancer incidence is well established, there are continuing questions about evolving technology and changes in health care policies. The Stella model took a conservative approach in demand erring on underestimating need when conflicting data existed. As with all models, it is based on many assumptions, but where models are most beneficial is showing potential problems and guiding researchers to new and theoretically better questions. The model currently projects that there needs to be 250 new residents annually by 2030 , preferably sooner, if growth is to continue to come close to meeting the rising demand. To meet this demand there needs to be major initiatives to find the resources for additional training programs and to get those programs credentialed in a timely manner. Further investigation with the model could be done to show additional endogenous feedback dynamics. For example, connections could be added to show how the system responds to the likely growing ROP workloads as the shortage of ROPs increases. Additional feedback loops and mechanisms could be added to show the potential breaking point when the shortage drives up salaries, increases attrition rates, and so on.

By modeling the supply leading into the residency, the model also shows another issue, which concerns graduates and applicants not finding placement in a residency program. There is a potential ethical demand on the field to provide a pathway to employment for more of the students being admitted into medical physics graduate 


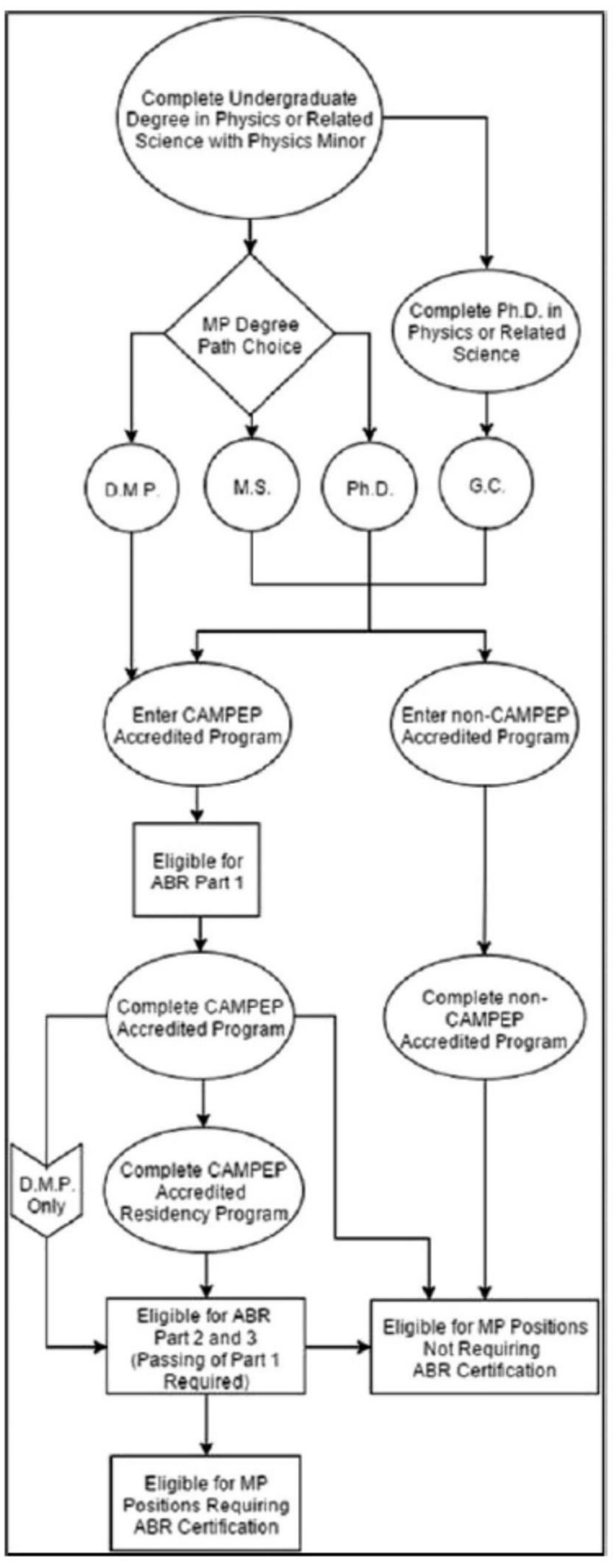

Figure 22: Education Pathways in medical physics. (Silverstein, Burmeister, \& Fullerton, 2016) programs. Unfortunately, limiting graduate programs would be a risk to the field because those physicists are needed to meet increase in demand, but without an adequate number of residency positions, there is no pathway to certification. This is not only an ethical problem but also one that threatens the survival of the profession. If there becomes a shortage of board certified physicists, more radiation oncology departments may turn to non-certified physicists or physics assistants to fill the deficit. If this becomes a trend and administrators prefer the costs savings of a non-certified physicist it could potentially displace certified physicists and lower the value of certification as a whole.

The system as a whole needs improvement. As shown by the Stella model and survey results, there is a need. It is a professional and ethical obligation to fix the certification pathway. While most ROPs have agreed that residencies and certification are a good pathway to a safer and

more consistent workforce, several issues remain. Based on survey results there is a need to increase program standards and enforcement of those standards for both graduate 
programs and residencies. Additionally, graduate programs should have some accountability for low placement into residency programs. If a program is admitting over 20 students annually, but only finding residency placement for five to ten of those students that program should re-evaluate their program. Whether it be that those programs work to increase their own residency programs, or better prepare prospective students for low match rates, there is some responsibility on the programs to help their students find a pathway to employment in the profession. Moreover, the profession should publish data more clearly about programs and match rates. CAMPEP requires in the standards for accreditation of graduate education programs in medical physics that:

ñAn accredited program must publicly describe the program and the achievements of its graduates and students, preferably through a publicly accessible web site. This information must be updated no less often than annually and must include, for each program (MS, PhD or Certificate), the numbers of applicants to the program, of students offered admission, of students matriculated, and of graduates. Where possible, information on the subsequent positions of graduates must also be provided, i.e., residencies, industrial positions, etc. This information should not identify individuals.ò (CAMPEP, 2018).

On the CAMPEP website, there are tables with each graduate program and the data listed above, but the tables are not ranked and are difficult to locate unless someone knows what data they are searching for. Instead of being in a quick link on the same page with the list of certified programs, the tables with the aggregate program data are in a separate area of the website under two drop downs of public disclosures and then an additional link within that webpage. The data is also only for the most recently reported year and does not show historical data. Additionally, the https://natmatch.com/ website posts nationwide match rates, but it does not show program specific match rates in one 
consolidated location (NMSI, 2019). Individual graduate schools are required to post match rates on their websites, but they do not tell how that compares to other programs and can sometimes be difficult to navigate and interpret for students. While it is possible to find these details, these resources are not easy to find or interpret. More importantly, most prospective students are not even aware of these issues when choosing to enter the profession. In 2018, 204 students entered the match and only 116 of them were matched and only 13 positions left unfilled by the match (NMSI, 2019). That left 88 students who pursued a residency, with the end goal of becoming a board certified medical physicist, without a pathway to that goal. That is over forty percent. For one of the most successful years of the match program, there were still forty-three percent of students who participated in the match that did not find placement. It is unethical and irresponsible for there not to be a change. That is not to say that there is an issue with the match. The match can only find positions for students that are available. If there are more graduates then residencies there is nothing the match itself can do to correct for that except to connect as many people with positions as exist. It does however highlight the results from the model and survey, which is that there is a large population that is stuck with a financial burden from their education and no clear career pathway due to a shortage of residency positions.

Another issue restricting entrance into the profession is the board exam itself. Over the past three years, the average board-passing rate for first time takers in medical physics has been 62.3 percent, with an average conditional rate of 16 percent and a fail rate of 21.7 percent (ABR, 2019). To condition the board exam means the physicist failed one of the five subject areas and can retake that one section in the fall. 
Comparatively, physician pass rates for the board exam average right around ninety percent for first time test takers. The low passing rates for medical physics is a concern as the looming shortage in the field approaches. The original goal in medical physics was with standardized residencies and training, the pass rates would increase accordingly, but that has not been seen in recent years. Perhaps low pass rates are reflective of enforcement of program training standards. Additionally, the gap between the completion of a residency program in June, and the time for Part three of the board ABR board exam to be administered in May causes issues in employment opportunities post residency. This may be another compounding factor for board passing rates with stress and time being spent on finding employment, relocation, and onboarding instead of preparing for the exam. The issues associated with employment and relocation for nonboard certified physicists is seen throughout the survey respondents with job availability and location being restricted for non-board certified physicists even if they are boardeligible. Further investigation into the timing and administration of the board exam could be another way to reduce the potential shortage of qualified ROPs in the upcoming years.

The medical field is constantly changing and evolving, none more so than the technology based subfields like radiation oncology. Radiation oncology has evolved dramatically in the past five to ten years with a push towards hypo fractionation and adaptive planning; the role of the radiation oncology medical physicist has never been so critical to safe patient care. With the continual rise in cancer incidence and the evolving technology, the demand for medical physicists will most likely continue to grow. Despite this projected growth, there are still many uncertainties in the medical physics field specifically in the ability to supply an adequate number of qualified radiation oncology 
physicists to keep up with demand. This potential shortage leads to a number of serious concerns in the future quality and safety of cancer care. There are still many unseen impacts in the medical physics field particularly related to hypo fractionation and adaptive planning. As more changes occur with new technology, there will be fewer treatments and therefore less machines, which would potentially decrease physics demand. However, with those specialized treatments comes increased complexity and increased physics involvement per patient. While the future of the field is very much in flux, it seems the role of the physicist in radiation oncology will continue to be of growing importance. It is a critical time for administrators of CAMPEP, SDAMPP, and the AAPM to come together and evaluate the educational and credentialing pathways into the medical physics profession.

If no changes are made to the current system, it is almost certain that a deficit in the workforce will result in a significant impact on the system. Whether it be in salary increases due to high demand with low supply, a move to an increase in employed noncertified physicists, or small centers in rural areas being unable to staff their clinics, there are major economical and safety risks at stake. There is an urgent need for administrators and leaders in the medical physics community to continue assessing and developing mechanisms for dealing with the looming shortage. If there is not an urgent response to this issue, there could be a risk to patient safety and the medical physics profession. 


\section{REFERENCES}

AAMC. (2007). Forecasting the Supply of and Demand for Oncologists: A report for the American Society of Clinical Oncology (ASCO) from the AAMC Center for Workforce Studies. Retrieved from

AAPM. (2015). Professional Survey Report Calendar Year 2014. Retrieved from https://www.aapm.org/pubs/protected_files/surveys/AAPM-Salary14.pdf

AAPM. (2019). Membership. Membership Categories \& Requirements-2019. Retrieved from https://www.aapm.org/memb/default.asp\#cos

ABR. (2018). 2017 Annual Report. Retrieved from Tucson, AZ: https://www.theabr.org/wp-content/uploads/2018/02/AR-2017.pdf

ABR. (2019). Exam Results. Retrieved from https://www.theabr.org/medicalphysics/initial-certification/part-3-exam/exam-results

Abt Associates. (2015). The Abt Study of Medical Physicist Work Values for Radiation Oncology Physics Services Round IV. Retrieved from Bethesda, MD:

ASTRO. (2015, 6/13/2013). Statistics About Radiation Therapy. Retrieved from http://www.rtanswers.org/statistics/aboutradiationtherapy/

CAMPEP. (2015). 2014 Annual Residency Report. Retrieved from College Park, MD: http://www.campep.org/campeplstres.asp

CAMPEP. (2017). 2017 Annual Residency Report. Retrieved from College Park, MD: https://www.campep.org/2017AnnualResidencyReport.pdf 
CAMPEP. (2018). CAMPEP Standards for Graduate Programs. In I. Commission on Accreditation of Medical Physics Educational Programs (Ed.). Alexandria, VA. Clark, B. (2015). CAMPEP Graduate Program Report. Retrieved from

Education Pathways in medical physics Clark, B. (2018). CAMPEP Graduate Program Report - 2017. Retrieved from https://www.campep.org/2017AnnualGraduateReport.pdf

Forte, G. (2010). Modeling Medical Physicists Supply and Demand Retrieved from http://www.aapm.org/meetings/amos2/pdf/49-14390-28043-305.pdf

Frey, G. D., \& Ibott, G. S. (2016). Medical Physics Report. Retrieved from Tucson, AZ:

Gelband, H., Jha, P., Sankaranarayanan, R., Horton, S., \& Banque internationale pour la reconstruction et le, d. v. (2015). Cancer Disease control priorities, third edition ; volume 3, Retrieved from Accès via World Bank e-Library http://elibrary.worldbank.org/doi/book/10.1596/978-1-4648-0349-9

Accès au document via EBSCO http://proxy.uqtr.ca/login.cgi?action=login\&u=uqtr\&db=ebsco\&ezurl=http://searc h.ebscohost.com $/ \operatorname{login}$. asp $x$ ?direct=true \&scope $=$ site $\& d b=n l e b k \& d b=$ nlabk $\& A N=$ $\underline{843000}$

Holder, K. A., \& Clark, S. L. (2008). Working Beyond Retirement Age. Paper presented at the American Sociological Association Annual Conference, Boston, MA.

Institute, N. C. (2017, 3/22/2017). What is cancer? Retrieved from https://www.cancer.gov/about-cancer/understanding/statistics

Jaffray, D. A., \& Gospodarowicz, M. K. (2015). Radiation Therapy for Cancer. In H. Gelband, P. Jha, R. Sankaranarayana, \& e. al. (Eds.), Cancer: Disease Control 
Priorities (Third ed., Vol. 3). Washingon (DC) The International Bank for Reconstruction and Development/The World Bank.

Jemal, A., Ward, E. M., Johnson, C. J., Cronin, K. A., Ma, J., Ryerson, A. B., . . Weir, H. K. (2017). Annual Report to the Nation on the Status of Cancer, 1975ï 2014, Featuring Survival. JNCI: Journal of the National Cancer Institute, 109(9), djx030-djx030. doi:10.1093/jnci/djx030

Langelier, M. (2010). Medical Physics Workforce Study Components. Retrieved from http://www.aapm.org/meetings/amos2/pdf/49-14390-13903-290.pdf

LaPointe, J. (2011). Medical physicists and health physicists: Radiation occupations. Occupational Outlook Quarterly, 55(2), 16-21.

Lee, T.-F., Yang, J., Wuu, C.-S., Liu, A., Fang, F.-M., \& Yeh, S.-A. (2015). Radiation Oncology and Medical Physics. BioMed Research International, 2015, 1-3. doi: $10.1155 / 2015 / 297158$

Mills, M. (2014). Acquiring initial American Board of Radiology certification in the United States. Quantitative Imaging in Medicine and Surgery, 4(6), 2.

Mills, M., Thornewill, J., and Esterhay, R. (2010). Future trends in the supply and demand for radiation oncology physicists. Journal of Applied Clinical Medical Physics, 11(2), 11.

NMSI. (2019, May 8, 2018). MedPhys Match Statistics. Retrieved from https://natmatch.com/medphys/statistics.html

Paliwal, B., \& Tewatia, D. (2009). Advances in radiation therapy dosimetry. Journal of Medical Physics, 34(3), 108-116. doi:10.4103/0971-6203.54842 
Silverstein, E., Burmeister, J., \& Fullerton, G. (2016). SDAMPP student guide to a medical physics career. Alexandria, VA: Society of Directors of Academic Medical Physics.

Society, A. C. (2016). Cancer Facts and Figures 2016. In A. C. S. Inc. (Ed.). Atlanta, GA. Systems, I. (2015). STELLA Systems Thinkng for Education and Research. Retrieved from http://www.iseesystems.com/softwares/Education/StellaSoftware.aspx Systems, I. (2016). Stella online Help, Tutorials, and Printed Documentation. 
APPENDIX 1- TABLE OF ACRONYMS

American Association of Physicists in Medicine

AAPM

American College of Medical Physics

ACMP

American Board of Radiology

ABR

American Society for Radiation Oncology

ASTRO

Certified Medical Dosimetrist

CMD

Full Time Equivalent

FTE

Image-Guided Radiotherapy

IGRT

Institutional Review Board

IRB

Intensity Modulated Radiation Therapy

IMRT

National Cancer Institute

NCI

Qualified Medical Physicist

QMP

Radiation Oncology Physicist

ROP 


\section{APPENDIX 2- TERMINOLOGY}

Algorithm: a procedure or formula the computer uses to solve problems. In radiation therapy algorithms are used to calculate dose distributions on ct scans for treatment planning purposes.

American Association of Physicists in Medicine (AAPM): a scientific and professional organization, composed of more than 8000 scientists whose clinical practice is dedicated to ensuring accuracy, safety and quality in the use of radiation in medical procedures such as medical imaging and radiation therapy

American Board of Radiology (ABR): a not-for-profit organization and is one of 24 independent national boards that are members of the American Board of Medical Specialties. Main mission is to certify that diplomats demonstrate the requisite knowledge, skill, and understanding of their disciplines to the benefit of patients

Brachytherapy: the treatment of cancer by the insertion of radioactive implants directly into the tissue.

Collimators: a device that narrows a beam of particles or waves. To narrow can mean either to cause the directions of motion to become more aligned in a specific direction (i.e., make collimated light or parallel rays), or to cause the spatial cross section of the beam to become smaller (beam limiting device)

Commission on Accreditation of Medical Physics Education Programs (CAMPEP): is a nonprofit organization, independent of its Sponsoring Organizations, whose objectives are the review and accreditation of educational programs in medical physics

Contour: outline of an organ or tumor on some sort of imaging (i.e. MRI, CT, etc.) 
Dosimetry: the calculation and assessment of the radiation dose received by the human body

Electron: a charged particle accelerated and used to irradiate superficial tumors

Fiducials: an object placed in the field of view of an imaging system, which appears in the image, produced, for use as a point of reference or a measure

Fractions: the number of treatments given, or a way to refer to a given treatment.

Gray: the measurement for radiation given

Hypofractionation: Radiation treatment in which the total dose of radiation is divided into large doses and treatments are given once a day or less often. Hypofractionated radiation therapy is given over a shorter period of time (fewer days or weeks) than standard radiation therapy

Intensity Modulated Radiation Therapy (IMRT): external beam radiation where the beam is attenuated by the moving mlcs with a variable dose rate to spare healthy tissue and preferentially irradiating tumor

Linear Accelerator (linac): customizes high energy x-rays to conform to a tumorô shape and destroy cancer cells while sparing surrounding normal tissue

Keloids: an area of irregular fibrous tissue formed at the sites of a scar or injury

Medical Dosimetrist: a member of the radiation oncology team who has knowledge of the overall characteristics and clinical relevance of radiation oncology treatment machines and equipment is cognizant of procedures commonly used in brachytherapy and has the education and expertise necessary to generate radiation dose distributions and dose calculations in collaboration with the medical physicist and radiation oncologist

Megavoltage X-rays: are produced by linear accelerators ("linacs") operating at voltages in excess of $1000 \mathrm{kV}(1 \mathrm{MV})$ range, and therefore have an energy in the $\mathrm{MeV}$ range. They are used in external beam radiotherapy to treat tumors. 
Multileaf Collimator (MLC): a device made up of individual "leaves" of a high atomic numbered material, usually tungsten that can move independently in and out of the path of a particle beam in order to block it

Quality Assurance (QA): all those planned and systematic actions necessary to provide adequate confidence that a product or service will satisfy the given requirements for quality. As such, it is wide ranging, covering all relevant procedures, activities and actions. In radiotherapy, it is all procedures that ensure consistency of the medical prescription and safe fulfilment of that prescription, as regards the dose to the target volume, together with minimal dose to normal tissue, minimal exposure of personnel and adequate patient monitoring aimed at determining the result of the treatment.

Patient Specific QA: measurements and calculations done for each patientôs treatment plan to ensure safe delivery

Machine $\mathbf{Q A}$ : daily, weekly, quarterly, and annual tests run on the treatment and imaging machines to verify functionality of all delivery mechanisms and safety interlocks

Chart QA: weekly reviews of patient charts to check for completeness and correctness to verify that treatments are proceeding as planned

Plan QA: physicist reviews each plan for safety and feasibility before approval to check doses to critical structures, adequate tumor coverage, contour correctness, algorithm parameters, and ability for machine to properly deliver within given tolerance

Photons: a form high energy x rays used for radiation therapy

Radiation Therapy: the treatment of disease, especially cancer, using X-rays or similar forms of radiation

Stereotactic radiation therapy: submillimeter precision radiation therapy typically given over less than five fractions with high doses per fraction

Treatment fields: individual beams that make up a treatment plan 
Vault Shielding: radiation vaults are shielded to protect people outside of the vault from radiation exposure. Special calculations are done to ensure there is adequate shielding based on occupancy, distance, types of radiation used, and other variables 
APPENDIX 3- STELLA MODEL

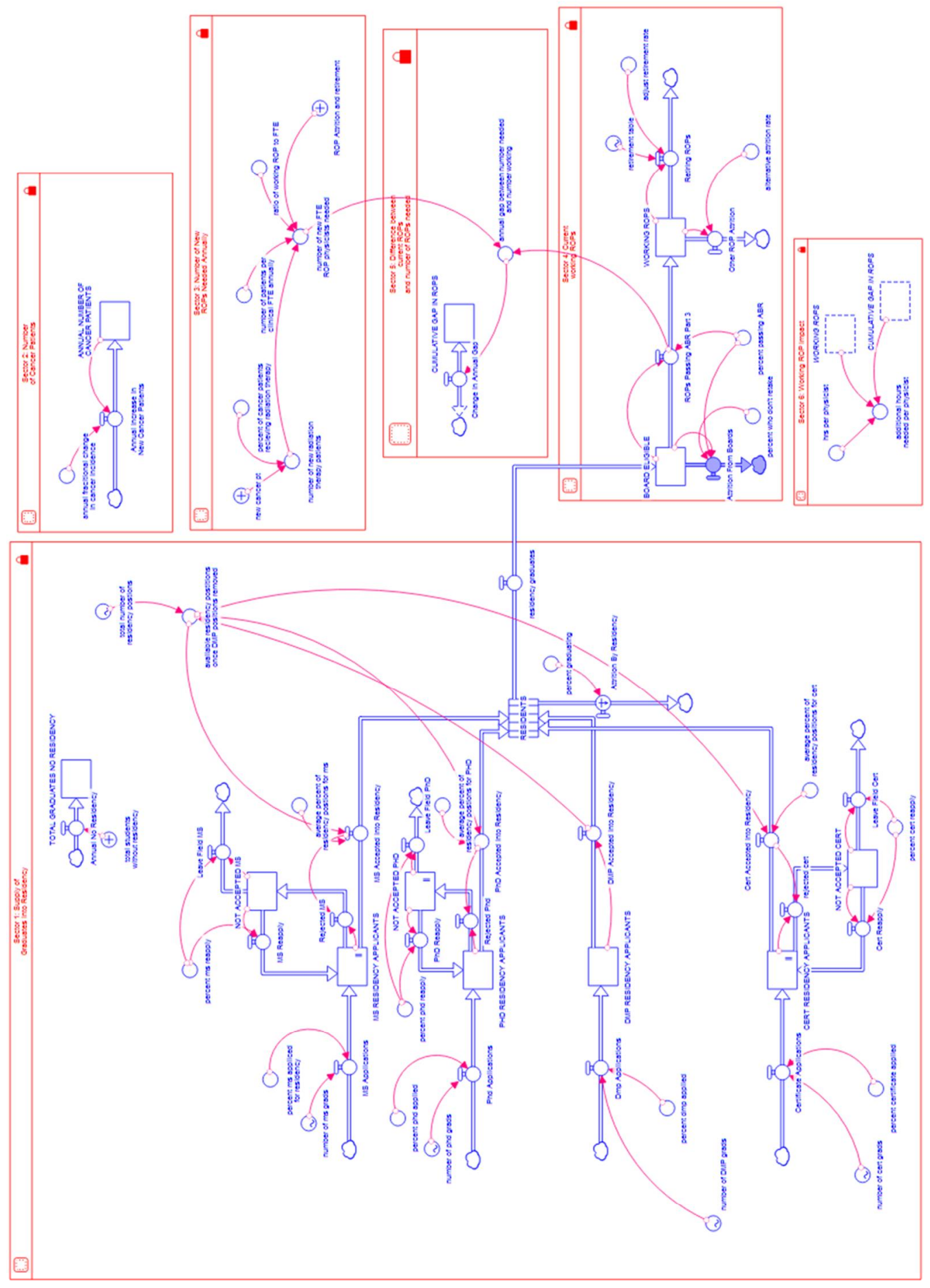




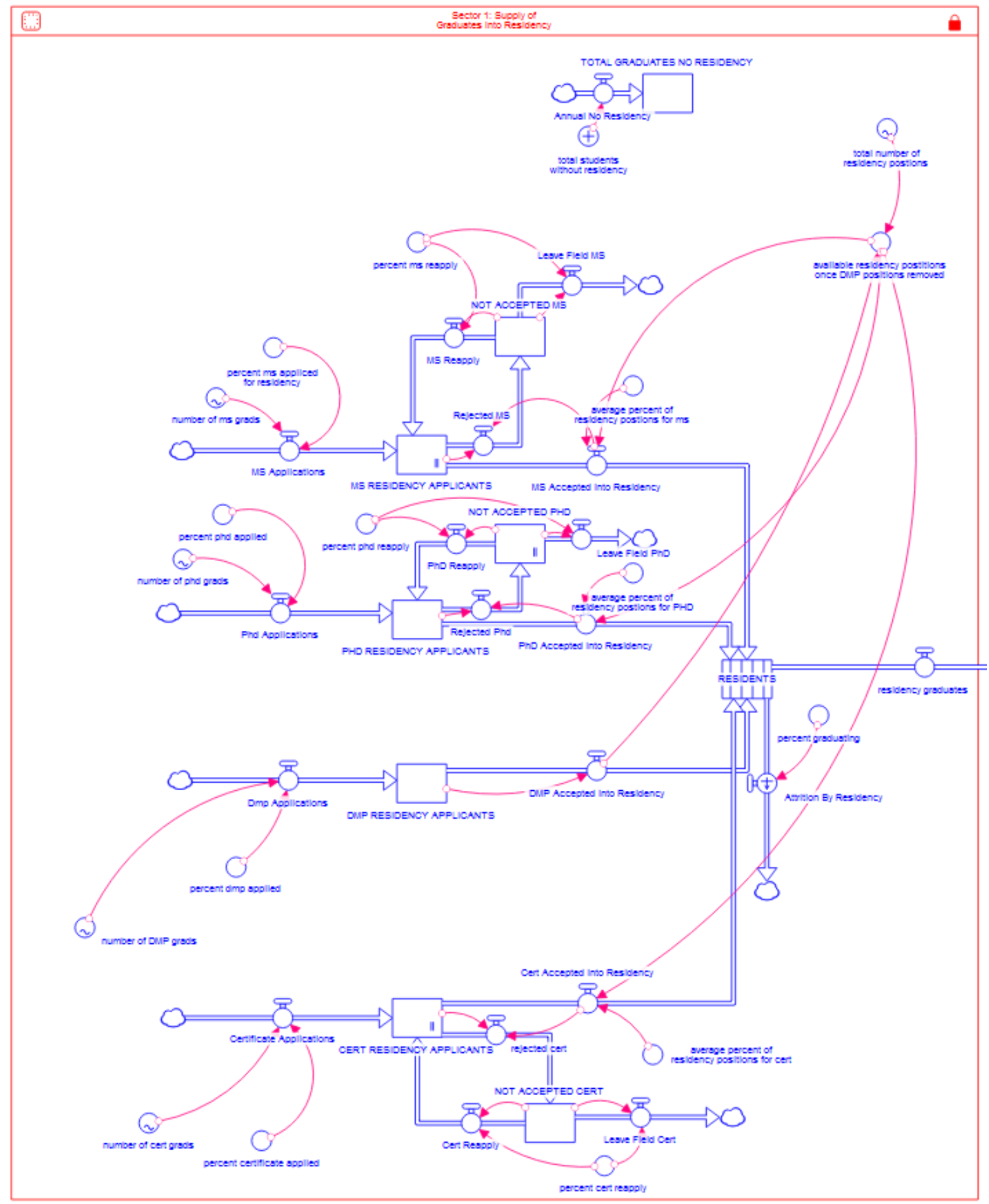



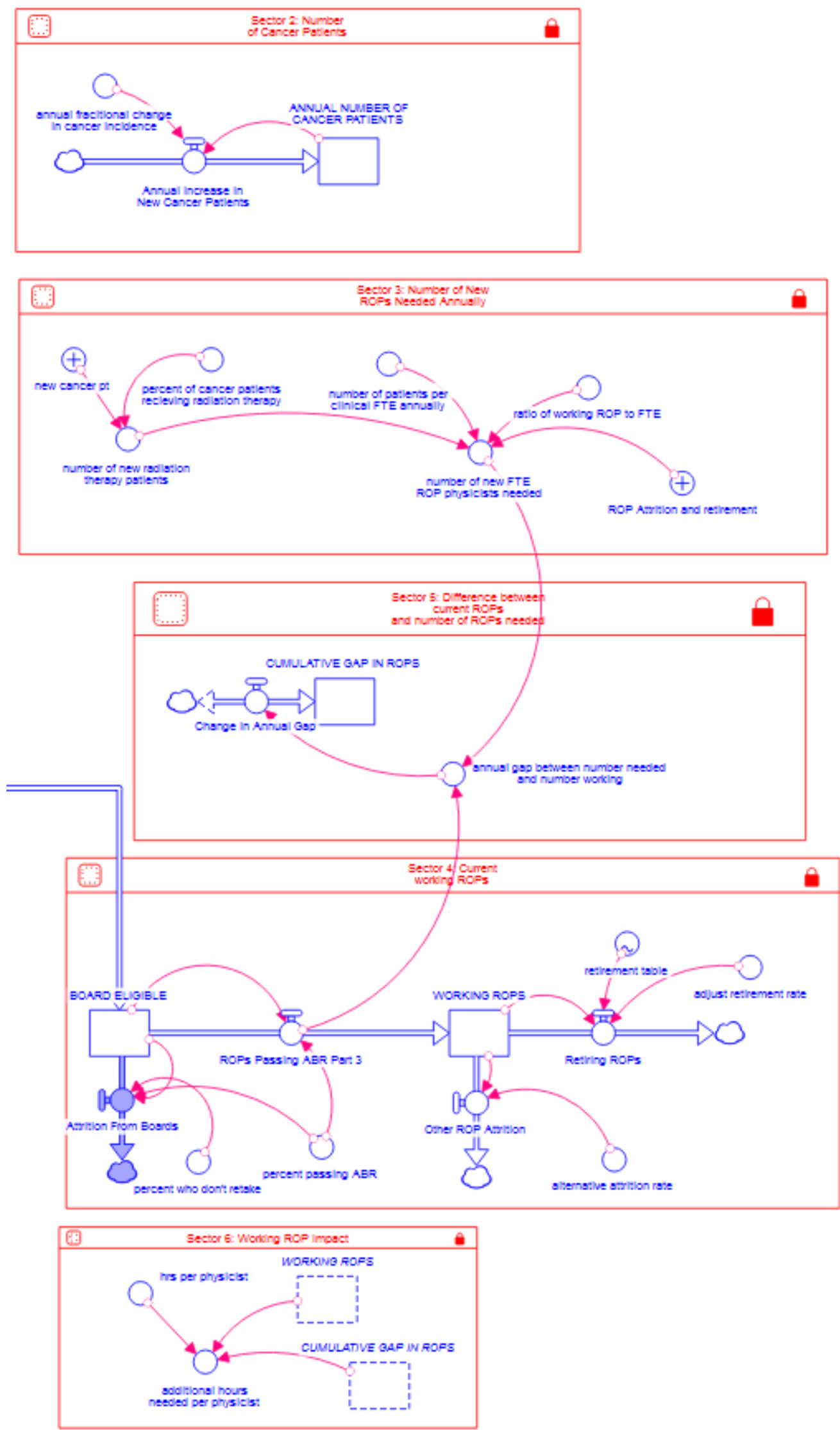


\section{APPENDIX 4- JUNIOR RESIDENT MEMBER SURVEY QUESTIONS}

Welcome to My Survey

A Mixed Methods Evaluation of the Supply and Demand of Radiation Oncology Medical Physicists in the United States

IRB Number: 16.0780

Dear Sir or Madame:

You are being invited to participate in a research study by answering the attached survey about understanding perceptions of the current medical physics workforce in the United States. There are no known risks for your participation in this research study. The information collected may not benefit you directly. The information learned in this study may be helpful to others. The information you provide will provide insight to better understand networks and the factors may or may not influence participation. Your completed survey will be stored at Survey Monkey. The survey will take approximately 5-10 minutes of your time to complete.

Individuals from the Department of Health Management and System Sciences at the University of Louisville School of Public Health and Information Sciences, the Institutional Review Board (IRB), the Human Subjects Protection Program Office (HSPPO), and other regulatory agencies may inspect these records. In all other respects, however, the data will be held in confidence to the extent permitted by law. Should the data be published, your identity will not be disclosed.

Taking part in this study is voluntary. By completing this survey you agree to take part in this research study. You do not have to answer any questions that make you uncomfortable. You may choose not to take part at all. If you decide to be in this study 
you may stop taking part at any time. If you decide not to be in this study or if you stop taking part at any time, you will not lose any benefits for which you may qualify.

If you have any questions, concerns, or complaints about the research study, please contact: Christine Swanson (502)-299-1353

If you have any questions about your rights as a research subject, you may call the Human Subjects Protection Program Office at (502) 852-5188. You can discuss any questions about your rights as a research subject, in private, with a member of the Institutional Review Board (IRB). You may also call this number if you have other questions about the research, and you cannot reach the research staff, or want to talk to someone else. The IRB is an independent committee made up of people from the University community, staff of the institutions, as well as people from the community not connected with these institutions. The IRB has reviewed this research study.

If you have concerns or complaints about the research or research staff and you do not wish to give your name, you may call 1-877-852-1167. This is a 24 hour hot line answered by people who do not work at the University of Louisville.

Sincerely,

Christine Swanson, MS, DABR, Phd(c).

1. Did you attend any of the following programs: a CAMPEP MS Graduate Program, CAMPEP PhD Graduate Program, Professional Doctorate, or Certificate program? Yes or No

**If NO- Go to Disqualification Page

2. What is the highest degree you completed through a CAMPEP program? Masters Degree, Ph.D., Professional Doctorate, Certificate, Did Not Complete **If Did Not Complete- Go to Disqualification Page

3. Did you pass part one the the ABR board certification exam for Medical Physics prior to 2012? Yes or No 
4. Did you find placement in a CAMPEP residency program? Yes or No

**If No Skip to Question 46

5. Have you completed a CAMPEP residency program?

**If No Skip to Question 34

6. How many application cycles did it take to get a residency position? FirstYear, 2 years, 3 years, more than 3 years

7. What year did you complete your residency program? Prior to 2014, 2015, 2016

8. Upon completion of residency program, were you able to find job placement in the medical physics field? Yes or No

**If No Skip to Question 21

9. In what sector did you find your first medical physics job post residency? Academic Hospital, Research Facility, Community Hospital, Private Radiation Center, Vendor, Other

Questions 10 ï 18 are Likert with the options: Strongly Disagree, Disagree, Agree, Strongly Agree, N/A

10. I felt well prepared for a residency program upon completion of my graduate or certificate program.

11. I believe $\mathrm{m}$ residency training has prepared me well for a career in medical physics.

12. There were an adequate number of medical physics jobs available.

13. It was easy to find a job in the location I desired.

14. I thought my residency training was subpar.

15. I thought my residency clinical education exceeded standard expectations.

16. I had difficulty obtaining a job after my residency.

17. My starting pay was competitive with current salary surveys.

18. I was/am satisfied with my first job in the medical physics profession. 
19. Please provide any additional comments about the value of your residency training and your experiences with job placement post residency. Open Response 20. May we contact you with further questions? Yes or No

***If Yes go to Question 63

**If No go to End of Survey Page

21. Are you still pursuing a career in medical physics? Yes or No

22. Have you found a new career outside of medical physics? If yes, in what field have you found employment? No or Yes with open response

Questions 23 ï 31 are Likert with the options: Strongly Disagree, Disagree, Agree, Strongly Agree, N/A

23. I felt well prepared for a residency program upon completion of my graduate or certificate program

24. I believe my residency training has prepared me for a career in medical physics. 25. There were an adequate number of jobs available.

26. It was easy to find a job in the location I desired.

27. I thought my residency clinical training was subpar.

28. I thought my residency clinical education exceeded standard expectations.

29. I had difficulty obtaining a job after my residency.

30. I am satisfied in my current career.

31. Given the opportunity again, I would re-pursue a career in medical physics.

32. Please provide any additional comments about the value of your residency training and your experiences with job placement post residency. Open Response 33. May we contact you with further questions? Yes or No

If Yes go to Q63

If No go to End of Survey Page

34. How many application cycles did it take to get a residency positon? First year, 2 years, 3 years, more than 3 years 
Questions 35 ï 43 are Likert with the options: Strongly Disagree, Disagree, Agree, Strongly Agree, N/A

35. I believe my overall education was a good value.

36. I thought my training was subpar.

37. I thought my didactic education exceeded standard expectations.

38. I thought my clinical training exceeded standard expectations.

39. I felt well prepared for a residency program upon completion of my graduate program.

40. There were an adequate number of residency positions available.

41. I had difficulty obtaining a residency position.

42. The match process made finding a residency position easy.

43. If I could go back, I would again choose to pursue a career in medical physics.

44. Please provide any additional comments about the value of your residency training and your experiences with residency placement. Open Response

45. May we contact you with further questions? Yes or No

**If Yes go to Question 63

**If No go to End of Survey Page

46. Did you participate in the match program? Yes or No

47. How many years did you apply for a residency position? 1 year, 2years, more than 2 years, did not apply

48. Did you find a non-professional position in medical physics? (i.e. a position not requiring a residency or board certification) Yes or No

49. Did you continue on to pursue further education in medical physics other than a residency position? (i.e. Ph.D. Program, post doctorate, etc) Yes or No

50. Did you pursue a non-medical physics career? If yes, what field? No or Yes with open response

Questions 51 ï 60 are Likert with the options: Strongly Disagree, Disagree, Agree, Strongly Agree, N/A 
51. I believe my overall education was a good value.

52. I thought my training was subpar.

53. I thought my didactic education exceeded standard expectations.

54. I thought my clinical training exceeded standard expectations.

55. I felt well prepared for a residency program upon completion of my graduate program.

56. I am in debt as a result of my medical physics education/

57. There were an adequate number of residency positions available.

58. I had difficulty obtaining a residency position.

59. The match process made finding a residency position easy.

60. If I could go back, I would again choose to pursue a career in medical physics.

61. Please provide any additional comments about the value of your residency training and your experiences with residency placement. Open Response

62. May we contact you with further questions? Yes or No

**If Yes, Question 63

** If No, End of Survey

63. Please provide the best email, telephone number, and time to reach you. Open response

Disqualification Page: Thank you for completing our Survey.

End of Survey Page: Thank you for taking this survey. 


\section{APPENDIX 5- JUNIOR RESIDENT MEMBER SURVEY RESPONSES}

Note- Open response answers with identifiable information have been redacted to protect the privacy of respondents. Some questions are skipped due to respondentô ineligibility to answer that question.

Q1. Did you attend any of the following programs: a CAMPEP MS Graduate Program, CAMPEP PhD Graduate Program, Professional Doctorate, or Certificate program?

\section{Answer Choices Responses}

Yes $\quad 86.81 \% \quad 158$

No

$13.19 \% \quad 24$

Answered 182

Skipped $\quad 0$

Q2. What is the highest degree you completed through a CAMPEP program?

Answer Choices Responses

Masterôs Degree $\quad 56.55 \% \quad 82$

$\mathrm{PhD} \quad 20.69 \% \quad 30$

Prof Doctorate $\quad 2.76 \% \quad 4$

$\begin{array}{lll}\text { Certificate } & 12.41 \% & 18\end{array}$

Did Not Complete $\quad 7.59 \% \quad 11$

Answered 145

Skipped $\quad 37$

Q3. Did you pass part one the the ABR board certification exam for Medical Physics prior to 2012 ?

Answer Choices Responses

Yes $\quad 28.97 \% \quad 42$


No

$71.03 \%$

103

Answered 145

Skipped $\quad 37$

Q4. Did you find placement in a CAMPEP residency program?

Answer Choices Responses

Yes $\quad 66.21 \% \quad 96$

No $\quad 33.79 \% \quad 49$

Answered 145

Skipped $\quad 37$

Q5. Have you completed a CAMPEP residency program?

Answer Choices Responses

Yes $\quad 36.84 \% \quad 35$

No $\quad 63.16 \% \quad 60$

Answered 95

Skipped $\quad 87$

Q6. How many application cycles did it take to get a residency position?

Answer Choices Responses

First year $\quad 82.35 \% \quad 28$

$\begin{array}{lll}2 \text { years } & 14.71 \% & 5 \\ 3 \text { years } & 2.94 \% & 1 \\ >\text { 3 years } & 0.00 \% & 0\end{array}$

Answered 34

Skipped $\quad 148$

Q7. What year did you complete your residency program?

Answer Choices Responses

prior to $2014 \quad 17.65 \% \quad 6$

$2015 \quad 23.53 \% \quad 8$ 
Answered $\quad 34$

Skipped $\quad 148$

Q8. Upon completion of residency program, were you able to find job placement in the medical physics field?

\begin{tabular}{llll}
\multicolumn{2}{l}{ Answer Choices } & Responses & \\
Yes & & $94.12 \%$ & 32 \\
No & & $5.88 \%$ & 2 \\
& & Answered & 34 \\
& Skipped & 148
\end{tabular}

Q9. In what sector did you find your first medical physics job post residency?

\begin{tabular}{lll} 
Answer Choices & Responses \\
Academic Hospital & $46.67 \%$ & 14 \\
Research facility & $0.00 \%$ & 0 \\
Community Hospital & $33.33 \%$ & 10 \\
Private Radiation Center & $13.33 \%$ & 4 \\
Vendor & $3.33 \%$ & 1 \\
Other (please specify) & $3.33 \%$ & 1 \\
\multicolumn{3}{c}{ Answered 30 } \\
\multicolumn{3}{c}{ Skipped 152 } \\
$1 \quad$ consulting physics company
\end{tabular}

Q10. I felt well prepared for a residency program upon completion of my graduate or certificate program.

$\begin{array}{lll}\text { Answer Choices } & \text { Responses } & \\ \text { Strongly Disagree } & 6.67 \% & 2 \\ \text { Disagree } & 6.67 \% & 2\end{array}$

Agree $\quad 43.33 \% \quad 13$




$\begin{array}{llll}\text { Strongly Agree } & 43.33 \% & 13 \\ \text { N/A } & & 0.00 \% & 0 \\ & & \text { Answered } & 30 \\ & \text { Skipped } & 152 & \end{array}$

Q11. I believe my residency training has prepared me well for a career in medical physics.

$\begin{array}{lll}\text { Answer Choices } & \text { Responses } & \\ \text { Strongly Disagree } & 3.33 \% & 1 \\ \text { Disagree } & 3.33 \% & 1 \\ \text { Agree } & 16.67 \% & 5 \\ \text { Strongly Agree } & 76.67 \% & 23 \\ \text { N/A } & 0.00 \% & 0 \\ \quad \text { Answered } & 30 & \\ \quad \text { Skipped } & 152 & \end{array}$

Q12. There were an adequate number of medical physics jobs available.

$\begin{array}{lll}\text { Answer Choices } & \text { Responses } & \\ \text { Strongly Disagree } & 6.67 \% & 2 \\ \text { Disagree } & 16.67 \% & 5 \\ \text { Agree } & 70.00 \% & 21 \\ \text { Strongly Agree } & 6.67 \% & 2 \\ \text { N/A } & 0.00 \% & 0 \\ \quad \text { Answered } & 30 & \\ \quad \text { Skipped } & 152 & \end{array}$

Q13. It was easy to find a job in the location I desired.

$\begin{array}{lll}\text { Answer Choices } & \text { Responses } & \\ \text { Strongly Disagree } & 10.00 \% & 3 \\ \text { Disagree } & 56.67 \% & 17 \\ \text { Agree } & 26.67 \% & 8\end{array}$




$\begin{array}{llll}\text { Strongly Agree } & 6.67 \% & 2 \\ \text { N/A } & & 0.00 \% & 0 \\ & & \text { Answered } & 30 \\ & \text { Skipped } & 152 & \end{array}$

Q14. I thought my residency clinical training was subpar.

$\begin{array}{lll}\text { Answer Choices } & \text { Responses } & \\ \text { Strongly Disagree } & 60.00 \% & 18 \\ \text { Disagree } & 26.67 \% & 8 \\ \text { Agree } & 3.33 \% & 1 \\ \text { Strongly Agree } & 6.67 \% & 2 \\ \text { N/A } & 3.33 \% & 1 \\ \quad \text { Answered } & 30 & \\ \quad \text { Skipped } & 152 & \end{array}$

Q15. I thought my residency clinical education exceeded standard expectations.

$\begin{array}{lll}\text { Answer Choices } & \text { Responses } & \\ \text { Strongly Disagree } & 6.67 \% & 2 \\ \text { Disagree } & 13.33 \% & 4 \\ \text { Agree 46.67\% } & 14 & \\ \text { Strongly Agree } & 33.33 \% & 10 \\ \text { N/A 0.00\% 0 } & \\ \quad \text { Answered } & 30 & \\ \text { Skipped } & 152\end{array}$

Q16. I had difficulty obtaining a job after my residency.

$\begin{array}{lll}\text { Answer Choices } & \text { Responses } & \\ \text { Strongly Disagree } & 26.67 \% & 8 \\ \text { Disagree } & 56.67 \% & 17 \\ \text { Agree } & 10.00 \% & 3\end{array}$




$\begin{array}{llll}\text { Strongly Agree } & 6.67 \% & 2 \\ \text { N/A } & & 0.00 \% & 0 \\ & & \text { Answered } & 30 \\ & \text { Skipped } & 152 & \end{array}$

Q17. My starting pay was competitive with current salary surveys.

$\begin{array}{lll}\text { Answer Choices } & \text { Responses } & \\ \text { Strongly Disagree } & 10.00 \% & 3 \\ \text { Disagree } & 10.00 \% & 3 \\ \text { Agree } & 56.67 \% & 17 \\ \text { Strongly Agree } & 23.33 \% & 7 \\ \text { N/A } & 0.00 \% & 0 \\ \quad \text { Answered } & 30 & \\ \quad \text { Skipped } & 152 & \end{array}$

Q18. I was/am satisfied with my first job in the medical physics profession.

$\begin{array}{lll}\text { Answer Choices } & \text { Responses } & \\ \text { Strongly Disagree } & 3.33 \% & 1 \\ \text { Disagree } & 3.33 \% & 1 \\ \text { Agree } & 56.67 \% & 17 \\ \text { Strongly Agree } & 36.67 \% & 11 \\ \text { N/A } & 0.00 \% & 0 \\ \quad \text { Answered } & 30 & \\ \quad \text { Skipped } & 152 & \end{array}$

Q19. Please provide any additional comments about the value of your residency training and your experiences with job placement post residency.

$\begin{array}{ll}\text { Answered } & 13 \\ \text { Skipped } & 169\end{array}$


1 The approximately one year gap between residency graduation and first opportunity for ABR certification seems to limit the potential employment opportunities for residency graduates immediately following graduation.

2 My residency training is very comprehensive. I had experiences in many aspects, including some special techniques not available in other residency programs. I was looking at job opportunities nationwide, so it was easy for me to get several job offers. I accepted one that I like very much. However, it will be more difficult if someone prefers one certain city or area.

3 "Much of the residency was spent performing machine commissioning. more clinical time would have been useful. I had connections within the residency program that greatly helped my placement. The opportunities were scarce otherwise."

4 Residency seemed to be valued in the job market. I was able to find a job quickly and found multiple opportunities for interviews although not in preferred locations.

$5 \quad$ "This survey should have asked questions about how long it took for people to find a position to give a better idea of how bad this problem is. This survey also does not address the root of the issue which is that graduate programs are accepting too many students for the needs of the workforce. They continue to do so because there is no restrictions or repercussions for these programs and they make money off of students who have no idea how difficult it is to get a job or residency. Possible ways to address the unemployed medical physicist problem is that AAPM or CAMPEP should be doing something to force graduate programs to very clearly publish their job/residency placement rates and CAMPEP should only accredit schools with a reasonable number of students. I was lucky to have gotten a residency at an academic center because I have an MS and was their first resident; after their 2nd resident they began only hiring PhDs. Additionally - the only reason I did the residency was because it was the only job I could get after graduation (residency was not yet required). I started looking for a post residency job over a year before finishing residency. I didn't get a full time position until 4 months after I finished residency and I got the position $100 \%$ on my own paying to go to AAPM and walking up to physicist after physicist asking about jobs. Other students in my graduate program were not so lucky - some were unemployed for 6 months, others 
never found a medical physicist position and had to abandon the field after paying for 2 years of graduate school!

6 I was fortunate enough that the hospital where I did my residency was opening a new satellite facility right at the end of my time there, so I actually didn't even apply to any other positions

7 It took me about a month to have a permanent position post-residency. I believe my residency did a wonderful job with clinical experience and balancing responsibilities. 8 Good for both.

9 Was hired as staff physicist at the same academic hospital where I completed my residency

10 The certificate program I attended in no way prepared me for ABR exams or the residency experience. I regret spending the $\$ 30 \mathrm{k}$ tuition for a MP certificate. Residency was likewise disappointing. Apparently no one in the clinic bought into the concept of MP residents participating in or learning through clinical practice. It was expected that learning take place through observation only -- no hands-on. Finally, since staff MPs were generally overworked, they were not amenable to teaching. For example, monthly linac QA was typically an exercise in robotically finishing a series of tasks as quickly as possible. My previous experience in industry -- ___ environment -- took quality more seriously, taking time to ensure all employees felt comfortable all processes and equipment.

11 My job search may have been uniquely affected by sudden changes (or reductions) in medical reimbursements, which had a chilling effect on the job market. Additionally, I think that such an emphasis has been placed on our rigorous certification process that many employers are not willing to hire non-certified physicists even if they are board-eligible. Similarly, others will always prefer $\mathrm{PhD}$ physicists over MS ones. I did not perceive a comparable value being placed on the completion of a CAMPEP residency.

12 There are not enough residencies to force people to go trough residency in order to take part 2 of the ABR. Everyone knows that without Board Certification a career in medical physics will be impossible. Nationally, the schools that are CAMPEP accredited admit more students than residency positions. A few schools in particular are the biggest 
offenders, with class sizes as high as 20 . This is irresponsible and can ruin people's careers and leave them mired in debt. Either relax the residency requirement for Board Certification or CAMPEP needs to reduce the class size of universities. That's how medical schools handle it. They're only accredited for a certain class size per year.

13 In my residency, I was basically working as a junior physicist for the 2nd year. As a result, transitioning to a working medical physicist was relatively pain-free. The advice I was given during my job search was that once I'm board certified, I can find a job in whatever location I desire, but until then, I may have to settle somewhere. I found that to be true.

Q20. May we contact you with further questions?

Answer Choices Responses

Yes $\quad 66.67 \% \quad 20$

No $\quad 33.33 \% \quad 10$

Answered 30

Skipped $\quad 152$

Q21. Are you still pursuing a career in medical physics?

Answer Choices Responses

Yes $\quad 100.00 \% \quad 2$

No $\quad 0.00 \% \quad 0$

Answered 2

Skipped $\quad 180$

Q22. Have you found a new career outside of medical physics? If yes, in what field have you found employment?

Answer Choices Responses

No $\quad 50.00 \% \quad 1$

Yes $\quad 50.00 \% \quad 1$

Answered 2

Skipped $\quad 180$

1 Continuing with graduate studies in biomedical imaging 
Q23. I felt well prepared for a residency program upon completion of my Graduate or Certificate program.

$\begin{array}{lll}\text { Answer Choices } & \text { Responses } & \\ \text { Strongly Disagree } & 0.00 \% & 0 \\ \text { Disagree } & 0.00 \% & 0 \\ \text { Agree } & 0.00 \% & 0 \\ \text { Strongly Agree } & 50.00 \% & 1 \\ \text { N/A } & 50.00 \% & 1 \\ \quad \text { Answered } & 2 & \\ \quad \text { Skipped } & 180 & \end{array}$

Q24. I believe my residency training has prepared me for a career in medical physics.

$\begin{array}{lll}\text { Answer Choices } & \text { Responses } & \\ \text { Strongly Disagree } & 0.00 \% & 0 \\ \text { Disagree } & 0.00 \% & 0 \\ \text { Agree } & 0.00 \% & 0 \\ \text { Strongly Agree } & 100.00 \% & 2 \\ \text { N/A } & 0.00 \% & 0 \\ \quad \text { Answered } & 2 & \\ \quad \text { Skipped } & 180 & \end{array}$

Q25. There were an adequate number of jobs available.

$\begin{array}{lll}\text { Answer Choices } & \text { Responses } & \\ \text { Strongly Disagree } & 0.00 \% & 0 \\ \text { Disagree } & 50.00 \% & 1 \\ \text { Agree } & 0.00 \% & 0 \\ \text { Strongly Agree } & 50.00 \% & 1 \\ \text { N/A } & 0.00 \% & 0 \\ \quad \text { Answered } & 2 & \\ \quad \text { Skipped } & 180 & \end{array}$


Q26. It was easy to find a job in the location I desired.

$\begin{array}{lll}\text { Answer Choices } & \text { Responses } & \\ \text { Strongly Disagree } & 50.00 \% & 1 \\ \text { Disagree } & 50.00 \% & 1 \\ \text { Agree } & 0.00 \% & 0 \\ \text { Strongly Agree } & 0.00 \% & 0 \\ \text { N/A } & 0.00 \% & 0 \\ \quad \text { Answered } & 2 & \\ \quad \text { Skipped } & 180 & \end{array}$

Q27. I thought my residency clinical training was subpar.

$\begin{array}{llr}\text { Answer Choices } & \text { Responses } & \\ \text { Strongly Disagree } & 50.00 \% & 1 \\ \text { Disagree } & 0.00 \% & 0 \\ \text { Agree } & 50.00 \% & 1 \\ \text { Strongly Agree } & 0.00 \% & 0 \\ \text { N/A } & 0.00 \% & 0 \\ \quad \text { Answered } & 2 & \\ \quad \text { Skipped } & 180 & \end{array}$

Q28. I thought my residency clinical education exceeded standard

\begin{tabular}{llr} 
Answer Choices & Responses & \\
expectations. & $0.00 \%$ & 0 \\
Strongly Disagree & $0.00 \%$ & 0 \\
Disagree & $50.00 \%$ & 1 \\
Agree & $0.00 \%$ & 0 \\
Strongly Agree & $50.00 \%$ & 1 \\
N/A & $0.00 \%$ & 0 \\
$\quad$ Answered & 2 & \\
\multicolumn{1}{c}{ Skipped } & 180 &
\end{tabular}


Q29. I had difficulty obtaining a job after my residency.

$\begin{array}{lll}\text { Answer Choices } & \text { Responses } & \\ \text { Strongly Disagree } & 0.00 \% & 0 \\ \text { Disagree } & 0.00 \% & 0 \\ \text { Agree } & 50.00 \% & 1 \\ \text { Strongly Agree } & 50.00 \% & 1 \\ \text { N/A } \quad 0.00 \% & 0 \\ \quad \text { Answered } & 2 & \\ \quad \text { Skipped } & 180\end{array}$

Q30. I am satisfied in my current career.

\begin{tabular}{lll} 
Answer Choices & Responses & \\
Strongly Disagree & $0.00 \%$ & 0 \\
Disagree & $50.00 \%$ & 1 \\
Agree & $50.00 \%$ & 1 \\
Strongly Agree & $0.00 \%$ & 0 \\
N/A $\quad 0.00 \%$ & 0 \\
\multicolumn{1}{c}{$\quad$ Answered } & 2 & \\
$\quad$ Skipped & 180
\end{tabular}

Q31. Given the opportunity again, I would re-pursue a career in medical physics.

$\begin{array}{lll}\text { Answer Choices } & \text { Responses } & \\ \text { Strongly Disagree } & 0.00 \% & 0 \\ \text { Disagree } & 50.00 \% & 1 \\ \text { Agree } & 50.00 \% & 1 \\ \text { Strongly Agree } & 0.00 \% & 0 \\ \text { N/A } \quad 0.00 \% & 0 \\ \quad \text { Answered } & 2 & \\ \quad \text { Skipped } & 180\end{array}$


Q32. Please provide any additional comments about the value of your residency training and your experiences with job placement post residency.

Answered 2

Skipped $\quad 180$

1 Too much supply, not enough demand.

2 I have a DMP degree. In my job search I have found the DMP to be useless because HR screening tools don't recognize anything except Ph.D. My applications are being excluded from employment consideration. Also many hiring managers don't have a clue what a DMP is, or what benefits it provides.

Q33. May we contact you with further questions?

Answer Choices Responses

Yes

$100.00 \% \quad 2$

No

$0.00 \% \quad 0$

Answered 2

Skipped $\quad 180$

Q34. How many application cycles did it take to get a residency position?

Answer Choices Responses

\begin{tabular}{lll} 
First year & $80.00 \%$ & 44 \\
2 years & $14.55 \%$ & 8 \\
3 years & $1.82 \%$ & 1 \\
More than 3 years & $3.64 \%$ & 2 \\
\multicolumn{1}{c}{ Answered } & 55 & \\
$\quad$ Skipped & 127 &
\end{tabular}

Q35. I believe my overall education was a good value.

$\begin{array}{lll}\text { Answer Choices } & \text { Responses } & \\ \text { Strongly Disagree } & 1.82 \% & 1 \\ \text { Disagree } & 5.45 \% & 3 \\ \text { Agree } & 40.00 \% & 22\end{array}$




\begin{tabular}{llll}
\multicolumn{2}{l}{ Strongly Agree } & $52.73 \%$ & 29 \\
N/A & & $0.00 \%$ & 0 \\
& & Answered & 55 \\
& Skipped & 127 &
\end{tabular}

Q36. I thought my training was subpar.

$\begin{array}{lll}\text { Answer Choices } & \text { Responses } & \\ \text { Strongly Disagree } & 29.09 \% & 16 \\ \text { Disagree } & 49.09 \% & 27 \\ \text { Agree } & 14.55 \% & 8 \\ \text { Strongly Agree } & 7.27 \% & 4 \\ \text { N/A } & 0.00 \% & 0 \\ \quad \text { Answered } & 55 & \\ \quad \text { Skipped } & 127 & \end{array}$

Q37. I thought my didactic education exceeded standard expectations.

$\begin{array}{lll}\text { Answer Choices } & \text { Responses } & \\ \text { Strongly Disagree } & 3.64 \% & 2 \\ \text { Disagree } & 27.27 \% & 15 \\ \text { Agree } & 38.18 \% & 21 \\ \text { Strongly Agree } & 29.09 \% & 16 \\ \text { N/A } & 1.82 \% & 1 \\ \quad \text { Answered } & 55 & \\ \quad \text { Skipped } & 127 & \end{array}$

Q38. I thought my clinical training exceeded standard expectations.

$\begin{array}{lll}\text { Answer Choices } & \text { Responses } & \\ \text { Strongly Disagree } & 5.45 \% & 3 \\ \text { Disagree } & 27.27 \% & 15 \\ \text { Agree } & 38.18 \% & 21 \\ \text { Strongly Agree } & 25.45 \% & 14\end{array}$


N/A

Answered 55

Skipped

127

Q39. I felt well prepared for a residency program upon completion of my graduate program.

$\begin{array}{lll}\text { Answer Choices } & \text { Responses } & \\ \text { Strongly Disagree } & 1.82 \% & 1 \\ \text { Disagree } & 21.82 \% & 12 \\ \text { Agree } & 41.82 \% & 23 \\ \text { Strongly Agree } & 32.73 \% & 18 \\ \text { N/A } \quad 1.82 \% & 1 \\ \quad \text { Answered } & 55 & \\ \quad \text { Skipped } & 127 & \end{array}$

Q40. There were an adequate number of residency positions available.

$\begin{array}{lll}\text { Answer Choices } & \text { Responses } & \\ \text { Strongly Disagree } & 32.73 \% & 18 \\ \text { Disagree } & 32.73 \% & 18 \\ \text { Agree } & 23.64 \% & 13 \\ \text { Strongly Agree } & 7.27 \% & 4 \\ \text { N/A } & 3.64 \% & 2 \\ \quad \text { Answered } & 55 & \\ \quad \text { Skipped } & 127 & \end{array}$

Q41. I had difficulty obtaining a residency position.

Answer Choices Responses

Strongly Disagree $\quad 20.00 \% \quad 11$

Disagree $\quad 45.45 \% \quad 25$

Agree $\quad 14.55 \% \quad 8$

Strongly Agree $\quad 16.36 \% \quad 9$ 
N/A

Answered 55

Skipped

127

Q42. The match process made finding a residency position easy.

$\begin{array}{lll}\text { Answer Choices } & \text { Responses } & \\ \text { Strongly Disagree } & 9.09 \% & 5 \\ \text { Disagree } & 18.18 \% & 10 \\ \text { Agree } & 38.18 \% & 21 \\ \text { Strongly Agree } & 20.00 \% & 11 \\ \text { N/A } & 14.55 \% & 8 \\ \quad \text { Answered } & 55 & \\ \quad \text { Skipped } & 127 & \end{array}$

Q43. If I could go back, I would again choose to pursue a career in medical physics.

$\begin{array}{lll}\text { Answer Choices } & \text { Responses } & \\ \text { Strongly Disagree } & 3.64 \% & 2 \\ \text { Disagree } & 9.09 \% & 5 \\ \text { Agree } & 34.55 \% & 19 \\ \text { Strongly Agree } & 49.09 \% & 27 \\ \text { N/A Answered } & \text { 55 } & \\ \quad \text { Skipped } & 127 & \end{array}$

Q44. Please provide any additional comments about the value of your residency training and your experiences with residency placement.

Answered 12

Skipped $\quad 170$ 
1 My first year of applying to residencies was prior to the MATCH. I had two interviews and it was difficult to gauge where the programs were in their process. The second year I was part of the MATCH program and had 3 interviews. The MATCH helped with ensuring that applicants weren't holding onto offers while they waited for a better one to come along giving plenty of opportunity for everyone part of the MATCH. With that being said, there is still a flaw in our system, whether it be how many residencies are available or how the programs are choosing their applicants. Many applicants came through our program for interviews and candidates that I thought would match without a problem surprisingly were not matched with a program.

2 I don't know anything, but it sounds like the problem is not insufficient residency positions, but rather too many CAMPEP accredited graduate program graduates. 3 Residency placement was relatively painless, and despite having a clinical rotation in my MS training I have realized I was not ready to work solo in the clinic. My residency experience is helping to ameliorate that.

$4 \quad$ My residency training has been invaluable to my development as a radiation oncology physicist and is helping to prepare me for ABR Parts 2 and 3. I highly doubt I would be anywhere near as prepared to take Parts 2 and 3 and generally be a safe and effective physicist without the structured residency training.

5 Travel and accommodation costs made the residency interview process prohibitively expensive.

6 There are too many qualified applicants who do not find a residency position. CAMPEP graduate programs should limit admissions to alleviate the problem.

7 Overall, I feel that my graduate school education was subpart in terms of clinical experience and training. The residency program that I am in however is excellent. With adequate didactic learning and lots of hands on clinical experience under the guidance of experienced physicists.

8 "After 4 cycles of residency applications, I finally was accepted into a residency. However, I had to switch from therapy to diagnostic physics, the residency application process was not through the new match program, and I had spent 4 years working in industry, which significantly grew my wealth of knowledge/experience, and on which the faculty's decision was largely based. Though I often exceeded the amount of knowledge 
and experience needed for a residency, I was not accepted or unable to apply because most residencies place an emphasis or requirement on Ph.D, even if it is not in medical physics. "

9 Residency placement is close to impossible.

10 "Residency programs would greatly benefit from a curriculum standard, such as minimum necessary time spent with ""x"" topic. Having a structured system of educational attainment necessary for appropriate learning to occur will produce better residents with minimal knowledge gaps in key areas. Physicians have metrics to meet such as number of cases per disease site, number of SRS, number of pediatric patients, etc. Physicists could employ a similar system, where a specific number of gating sims, a number of hand calcs, a number of SRS plans, a number of chart checks per disease site, etc could be expected. It also appears that the education related to how to approach a chart check has no standard. Time spent doing chart checks in a license state is restricted to end-of-treatment checks. To participate in another type of chart check, it is thereby necessary to observe a licensed physicist perform an initial or weekly check. This is to the detriment of comprehensive learning. Programs should be forced to ensure that, even in license states, residents are required to perform ""x"" number of initial and weekly check. This could be accomplished with licenses faculty physicists then doing the initial or weekly check themselves after, with a comparison of what was noticed during the check. Learning and building confidence in performing chart checks would then be attained by the respective resident."

11 My residency training thus far has been valuable but I am surprised by the lack of enforcement by CAMPEP (eg that the residency program actually provides the training that it says it does). It seems quite variable and up to the whims of the residency supervisors. I think my time would likely be better and more efficiently spent with a $~ 6$ month training period at the institution and in the role where I accept a permanent position rather than in a more general residency that touches on many subjects (many of which I won't work with in the future) and reflects the practices only of the physicists running the residency (not necessarily the field more generally). However, I completely understand the need to have a standardized clinical training program for physicists to get board certified. 
12 I got a residency the final year before the match was implemented. I believe the match system is much better and should be continued.

Q45. May we contact you with further questions?

$\begin{array}{llll}\text { Answer Choices } & \text { Responses } & \\ \text { Yes } & & 60.00 \% & 33 \\ \text { No } & & 40.00 \% & 22 \\ & \text { Answered } & 55 & \\ & \text { Skipped } & 127 & \end{array}$

Q46. Did you participate in the match program?

\begin{tabular}{|c|c|}
\hline Answer Choices & Responses \\
\hline Yes & $36.67 \%$ \\
\hline No & $63.33 \%$ \\
\hline Answered & 30 \\
\hline Skipped & 152 \\
\hline
\end{tabular}

Q47. How many years did you apply for a residency position?

$\begin{array}{lll}\text { Answer Choices } & \text { Responses } & \\ \text { 1 year } & 33.33 \% & 10 \\ \text { 2 years } & 20.00 \% & 6 \\ \text { more than 2 years } & 0.00 \% 0 & \\ \text { did not apply } & 46.67 \% & 14 \\ \quad \text { Answered } & 30 & \\ \quad \text { Skipped } & 152 & \end{array}$

Q48. Did you find a non-professional position in medical physics? (i.e. a position not requiring a residency or board certification)

$\begin{array}{lll}\text { Answer Choices } & \text { Responses } & \\ \text { Yes } & 33.33 \% & 10 \\ \text { No } & 66.67 \% & 20\end{array}$


$\begin{array}{ll}\text { Answered } & 30 \\ \text { Skipped } & 152\end{array}$

Q49. Did you continue on to pursue further education in medical physics other than a residency position? (i.e. Phd. Program, post doctorate, etc.)

$\begin{array}{llll}\text { Answer Choices } & \text { Responses } & \\ \text { Yes } & & 50.00 \% & 15 \\ \text { No } & & 50.00 \% & 15 \\ & \text { Answered } & 30 & \\ & \text { Skipped } & 152 & \end{array}$

Q50. Did you pursue a non-medical physics career? if yes, what field?

$\begin{array}{llll}\text { Answer Choices } & \text { Responses } & \\ \text { No } & & 90.00 \% & 27 \\ \text { Yes } & & 10.00 \% & 3 \\ & \text { Answered } & 30 & \\ & \text { Skipped } & 152\end{array}$

Respondents Response DateYes Tags

1 postdoctoral, medical physics

2 Patent Law

3 Nuclear Engineering $\mathrm{PhD}$

Q51. I believe my overall education was a good value.

$\begin{array}{lll}\text { Answer Choices } & \text { Responses } & \\ \text { Strongly Disagree } & 6.67 \% & 2 \\ \text { Disagree } & 6.67 \% & 2 \\ \text { Agree } & 33.33 \% & 10 \\ \text { Strongly Agree } & 53.33 \% & 16 \\ \text { N/A } & 0.00 \% & 0\end{array}$

Answered $\quad 30$ 
Skipped $\quad 152$

Q52. I thought my training was subpar.

$\begin{array}{lll}\text { Answer Choices } & \text { Responses } & \\ \text { Strongly Disagree } & 23.33 \% & 7 \\ \text { Disagree } & 50.00 \% & 15 \\ \text { Agree } & 10.00 \% & 3 \\ \text { Strongly Agree } & 13.33 \% & 4 \\ \text { N/A } & 3.33 \% & 1 \\ \quad \text { Answered } & 30 & \\ \quad \text { Skipped } & 152 & \end{array}$

Q53. I thought my didactic education exceeded standard expectations.

$\begin{array}{lll}\text { Answer Choices } & \text { Responses } & \\ \text { Strongly Disagree } & 0.00 \% & 0 \\ \text { Disagree } & 20.00 \% & 6 \\ \text { Agree } & 40.00 \% & 12 \\ \text { Strongly Agree } & 33.33 \% & 10 \\ \text { N/A } & 6.67 \% & 2 \\ \quad \text { Answered } & 30 & \\ \quad \text { Skipped } & 152 & \end{array}$

Q54. I thought my clinical training exceeded standard expectations.

$\begin{array}{lll}\text { Answer Choices } & \text { Responses } & \\ \text { Strongly Disagree } & 10.00 \% & 3 \\ \text { Disagree } & 20.00 \% & 6 \\ \text { Agree } & 30.00 \% & 9 \\ \text { Strongly Agree } & 33.33 \% & 10 \\ \text { N/A } & 6.67 \% & 2 \\ \quad \text { Answered } & 30 & \\ \quad \text { Skipped } & 152 & \end{array}$


Q55. I felt well prepared for a residency program upon completion of my graduate program.

$\begin{array}{lll}\text { Answer Choices } & \text { Responses } & \\ \text { Strongly Disagree } & 3.33 \% & 1 \\ \text { Disagree } & 20.00 \% & 6 \\ \text { Agree } & 40.00 \% & 12 \\ \text { Strongly Agree } & 23.33 \% & 7 \\ \text { N/A } & 13.33 \% & 4 \\ \quad \text { Answered } & 30 & \\ \quad \text { Skipped } & 152 & \end{array}$

Q56. I am in debt as a result of my medical physics education.

$\begin{array}{lll}\text { Answer Choices } & \text { Responses } & \\ \text { Strongly Disagree } & 16.67 \% & 5 \\ \text { Disagree } & 13.33 \% & 4 \\ \text { Agree } & 23.33 \% & 7 \\ \text { Strongly Agree } & 36.67 \% & 11 \\ \text { N/A } & 10.00 \% & 3 \\ \quad \text { Answered } & 30 & \\ \quad \text { Skipped } & 152 & \end{array}$

Q57. There were an adequate number of residency positions available.

$\begin{array}{lll}\text { Answer Choices } & \text { Responses } & \\ \text { Strongly Disagree } & 40.00 \% & 12 \\ \text { Disagree } & 26.67 \% & 8 \\ \text { Agree } & 3.33 \% & 1 \\ \text { Strongly Agree } & 3.33 \% & 1 \\ \text { N/A } & 26.67 \% & 8 \\ \quad \text { Answered } & 30 & \\ \quad \text { Skipped } & 152 & \end{array}$


Q58. I had difficulty obtaining a residency position.

$\begin{array}{lll}\text { Answer Choices } & \text { Responses } & \\ \text { Strongly Disagree } & 0.00 \% & 0 \\ \text { Disagree } & 3.33 \% & 1 \\ \text { Agree } & 26.67 \% & 8 \\ \text { Strongly Agree } & 26.67 \% & 8 \\ \text { N/A } & 43.33 \% & 13 \\ \quad \text { Answered } & 30 & \\ \quad \text { Skipped } & 152 & \end{array}$

Q59. The match process made finding a residency position easy.

$\begin{array}{lll}\text { Answer Choices } & \text { Responses } & \\ \text { Strongly Disagree } & 13.33 \% & 4 \\ \text { Disagree } & 10.00 \% & 3 \\ \text { Agree } & 20.00 \% & 6 \\ \text { Strongly Agree } & 3.33 \% & 1 \\ \text { N/A } & 53.33 \% & 16 \\ \quad \text { Answered } & 30 & \\ \quad \text { Skipped } & 152 & \end{array}$

Q60. If I could go back, I would again choose to pursue a career in medical physics.

$\begin{array}{lll}\text { Answer Choices } & \text { Responses } & \\ \text { Strongly Disagree } & 10.00 \% & 3 \\ \text { Disagree } & 13.33 \% & 4 \\ \text { Agree } & 33.33 \% & 10 \\ \text { Strongly Agree } & 36.67 \% & 11 \\ \text { N/A } & 6.67 \% & 2 \\ \quad \text { Answered } & 30 & \\ \quad \text { Skipped } & 152 & \end{array}$


Q61. Please provide any additional comments about the value of your residency training and your experiences with residency placement.

Answered 8

Skipped $\quad 174$

1 CAMPEP MS '11, NON-CAMPEP Residency '13. Match was unavailable at the time I applied for residency.

2 When I looked for a residency position from 2012 to 2013, there was a significant lack of positions compared to applicants. I applied to one place where there were 120 applicants and 3 positions.

3 I am in a residency that is pursuing CAMPEP accreditation.

4 I hope the number of student from CAMPEP accredited program should be limited. Finding a residency position is real huddle.

5 I'm currently in the Match program and will hear back at the end of March, as will all other students in the match, so I'm in the position of not being matched yet and therefore unable to answer most of these questions in a useful way. Since the match is a clearly scheduled and major part of our field I would highly recommend you send out this survey in April instead or rewrite it to allow for "currently in the match" responses.

6 I was in a DMP program, when I applied to residencies, I only got 2 phone interviews. I felt that most centers were competing over the same pool of students and leaving a large body of students without any interviews or options for a residency. I think a lot of the residency programs are inappropriately emphasizing $\mathrm{PhD}$ 's and research over clinical training and this is leading to unmotivated an incompetent physicists in the clinical workforce

$7 \quad$ MMP program declined clinical training, saying junior physics / residency program would provide it, whereas junior physics / residency program wanted applicants to have clinical training. program failed to make clear that the sole purpose of the $\$ 80000$ program was to apply to residencies and that applicants would only have one chance to competitively do so. 
8 I am pursuing a non CAMPEP $\mathrm{PhD}$ in with my research having a medical physics emphasis after having finished my CAMPEP master's degree.

Q62. May we contact you with further questions?

$\begin{array}{llll}\text { Answer Choices } & \text { Responses } & \\ \text { Yes } & & 60.00 \% & 18 \\ \text { No } & & 40.00 \% & 12 \\ & \text { Answered } & 30 & \\ & \text { Skipped } & 152 & \end{array}$

Q63. Please provide the best email, telephone number, and time to reach you.

$\begin{array}{ll}\text { Answered } & 74 \\ \text { Skipped } & 108\end{array}$




\section{APPENDIX 6- FOLLOW UP SURVEY STUDENT JUNIOR MEMBERS}

Note- Open response answers with identifiable information have been redacted to protect the privacy of respondents. Some questions are skipped due to respondentô ineligibility to answer that question.

\section{Group 1- GRADUATES WITHOUT A RESIDENCY}

Questions:

8. What field have you found work in?

9. Are you satisfied in your current career?

10. What barriers did you encounter in finding a residency position?

11. Are you in debt from your medical physics education?

12. How do you intend to resolve debt?

13. How did debt add pressure to find residency position or alternate career?

14. How do you feel about your overall experience in the medical physics field?

\section{Respondent 1}

1. I am currently a $\mathrm{PhD}$ student in

2. Yes, though I only anticipate being a student 2-3 more years

3. N/A - did not need a residency

4. No, I had an scholarship which covered everything

5. N/A

6. N/A

7. I have enjoyed medical physics as a profession very much during my $4+$ years in the field as a professional physicist.

Respondent 2 
1. Education PhD Student

2. Sure, but I am still planning on re-entering medical physics once my $\mathrm{PhD}$ is finished

3. The match system was a horrible idea to pursue. It has caused a lot of people in the beginning of their careers a great deal of problems. For instance, I refused to participate in the match after my masters because I was interested in pursuing a $\mathrm{PhD}$ but had I not been so fortunate to get accepted somewhere then I would have been out of luck. You have taken a lot of freedom away from people just entering the field by demanding first a residency, which I do not have as much of an issue with, but then you forced us to use this horrible system that takes away all of our freedom to choose the program that best suits us and reduces the competitiveness of each candidate. It would be in the best interest of both the institution and the workforce to drop the match as the way for workers to get picked for their residency.

4. Yes. Significantly.

5. By paying it off when I'm done with my education and residency. Most private firms allow deferment of loan repayment during both further education and residency.

6. For me the debt did not come into play at all. It was simply the match system that was considered. As mentioned above, the match system was a horrible idea and should be completely abandoned.

7. My experience has made me very bitter overall. It saddens me that the field used to be run by the physicists and now it is run by the government. We have lost all freedom in this transition and should completely drop the ABR as the accrediting body behind medical physicists. It should be the AAPM. Government involvement has never led to a good outcome in any field, and it will ruin the field of medical physics even more-so than it already has.

\section{Respondent 3}

1. Still in graduate school (PhD program), so I haven't entered the workforce yet.

2. Very satisfied and looking forward to becoming a clinical physicist. 
3. Haven't entered the residency process yet, so I can't comment.

4. I am not in debt from my medical physics education.

5. N/A

6. Thankfully because I'm not in debt, I don't feel any extra pressure.

7. Overall I've had a great experience (4 years of grad school now) and haven't been dissuaded at all from joining the field.

\section{Respndent 4}

1. I have not found "work" per se, legally speaking: I am instead legally a student. i.e. physics, is the field I am "studying", while being paid per month. I am legally "continuing my education" doing research at in , which I understand was previously state-run,

now privatized, but still categorized as being affiliated with the government.

2. No. I consider climate change, energy engineering (e.g. improving batteries for solar power, reprocessing of nuclear waste), blockchain technology (e.g. Ethereum to eliminate fraudulent economics of the US government increase monetary efficiency) to be more important problems than reducing side-effects of cancer therapy for first-world countries, and I feel as if I have wasted my life from ages 23-30 pursuing a fruitless medical physics career.

3.

a. More graduates than residency positions: e.g. University graduating 14 Masters with only 4 residencies, accepting only 1 graduate of those 14 for those 4 positions; graduating more than 20 students while likewise having less than ten residency positions.

b. refusal of the AAPM and CAMPEP to require matching number of residency positions and accepted degree students as a criteria for program certification

c. lack of industry involvement recruiting graduates

d. exorbitant, usurious student loans (__ Master of Medical Physics $\sim \$ 90,000$ at $7.8 \%$ interest) pressuring me psychologically to regard a 
clinical job as the only viable career path hired by in directly after my MMP as a junior physicist, only for them to decide in April, less than 90 days after I started, that they instead wanted a postresidency physicist: This timing made it impossible to apply to the residencies for the calendar year.

e. emphasizing mathematics and theory instead of clinical practice, even to the point of only allowing 1-2 students in the clinic per day despite accepting 14 into the program

f. emotional or psychological immaturity: I was not prepared to approach applications and interviews as an adult, lacking 'real world' experience and suffering to mature my self-reliance and world perspective.

g. psychological anxiety at seeing in job postings the text, "women and minorities (encouraged / especially encouraged) to apply", making me feel that I would be less valued as an applicant at those businesses, i.e. that they particularly wanted to hire a woman or non-European ethnicity

h. lack of career services coaching in how to write a letter of intention that stood-out from 80 other applicants

i. lack of direction from to apply early to residencies: It was not clear to me that the sole purpose of the degree was to apply for residencies, and by the time I discovered I needed to be applying to residencies in 2011, many of the deadlines had already passed.

j. Without assistance finding housing for (I am from ), the first year I accidentally signed up for an apartment an hour away, and had 2 hours commute by bus every day. This hindered my involvement and instruction in the program.

k. reluctance and even legal prohibition of non-CAMPEP residencies, i.e. elimination of junior physics positions. Some residency job postings saying "recent graduates preferred", I am strongly persuaded that only same-year graduates are seriously considered for residencies unless older applicants have some outstanding accomplishments or characteristics: If you fail to get a residency on your first try, it seems effectively impossible 
to do so

thereafter.

4. Yes, I now owe $\$ \_, 000$ at $7.7 \%$ interest and consider my life financially ruined by pursuing medical physics as a career. Moreover, I have sacrificed marital life pursuing this career, unable to start a family or date since still in school and without substantial income

5 .

a. By not paying it

b. By paying the absolute minimum in income-driven repayment plan, currently $\$ 0 /$ month (my income is $<\$ 1300 /$ month), the interest is continuing to accumulate around $\$ 800 /$ month, and utilizing the "taxable income" debt forgiveness after 23 years.

c. investing in cryptocurrency (Ethereum, Bitcoin) and seeing the US Dollar collapse, so it becomes trivial to repay the debt

d. dying in the near future, either by traffic accident or suicide (both unlikely)

e. winning the lottery

6. The ___ Master of Medical Physics student loan debt made me think that a clinical career was the only viable option, and consequently I chose to pursue the first $\mathrm{PhD}$ I was offered _ in to try to become a competitive applicant again for residencies to pursue this clinical career to repay this debt. Essentially, the debt has enslaved me, and I have regarded it as my life's master, and it is a horribly depressing feeling together with choices I have felt compelled to make, to the point of creating thoughts of suicide as an escape, as if trapped in an inescapable pit or carrying a mountain. I also missed out on numerous social opportunities, thinking I needed to repay 56-70\% of my monthly income (to be debt-free at age 79 ) rather than spend $\$ 20+$ at a dinner party or $\$ 300$ sightseeing __. I've spent many hours agonizing over the debt, calculating 1070 year repayment plans at my current or estimated future salaries. 
Since then, I have begun studying cryptocurrency, money, and the US economy, and have realized that my student loan debt is actually nothing more than a number on a spreadsheet: The US Dollar is not backed by anything physical; I do not owe anything real *per se*: The US Dollar's only value is derived from the military, foreign reputation, and the Federal Reserve's interest rates. It is created literally through loan promissory notes, i.e. debt creates US Dollars. Their primary purpose is to persuade people to work and cooperate, and the system itself unjustly favors bankers and the elite wealthy (e.g. fractional reserve banking, investment portfolios). Consequently I am far better off ignoring the debt entirely, as its only reality exists in the minds of the general public.

However, despite these epiphanies, real problems remain insofar as my debt likely prohibits me from changing careers to engineering: Who would pay for this "job retraining", for me to return to school full-time? How would I start a family? This debt also likely prohibits me from being eligible for better housing or a better car.

7. My knee-jerk response is, "Choosing to pursue medical physics has been the worst mistake of my life," but that is something of an over-simplification, because my problems were also due to immaturity, an attitude problem ("if only my health problems were resolved then I would be happy" rather than choosing to be happy despite suffering), and possibly even clinical depression (though my experiences as a student were likely a catalyst).

I think the AAPM is mostly for a conceited elite class who feel entitled to their high incomes and extravagant annual meetings, that its primary purpose is for a union to protect their salaries and their status. Those approaching the field are grossly cheated through student loans and misinformation, as more students are accepted than entry-level jobs exist, to fund universities and their faculty, and the AAPM does not care about them to take action. I even spoke with the current AAPM president at the 2015 clinical meeting in Salt Lake City, Utah about this problem, asking what she intended to do twice, and she gave me no answer except, "It is a problem": She intends to do nothing. 
Moreover, my father, a doctor of internal medicine, has a colleague whose son suffered the same problem and left the field, some years ahead of me: This problem has been apparently been ongoing for a decade, and no action has been taken.

Another problem is immigration and an unexplained fixation with diversity, as Americans are being out-competed for jobs in their own country by Chinese, Indians, etc. The field of medical physics consequently splits families apart, driving prospective applicants from their homes. There is also the feeling of being an outcast or undesired, as most job postings especially encourage "women and minorities" to apply rather than welcoming all applicants equally.

Even given this forced internationalization, the field still favors the wealthy, as likelihood of dying from cancer or developing complications is a function of where in the world you live in most cases (e.g. prostate cancer in the US vs prostate cancer in Africa).

It is also remarkable that the salaries of American radiation oncology personnel is about twice that of their Japanese counterparts, with treatment costs likewise: Do the higher salaries come from charging patients more?

Much medical physics published research now appears to be documentation rather than innovation or progress, and peer-review appears lacking as multiple papers are published in which methodology is summarized but not reproducible, with English errors and improper citations to increase $\mathrm{h}$ index. Most research is also behind Elsevier et al. "pay walls", rather than open-access to benefit everyone.

Thinking of all these problems, I feel very negatively about my overall experience in the medical physics field. It consists largely on the wealthy preying on the poor, both program directors and university faculty misusing students, and possibly even hospital personnel and insurance companies overcharging patients. 
Much time is spent protecting image and reputation, i.e. salary of those established in the system. I wish I could tell myself via time machine to pursue engineering or computer programming instead, to avoid the politics, greed, and abandonment I have suffered from the field of medical physics.

I would tell prospective students to refrain from entering the field, to pursue other majors, until five years after CAMPEP has mandated that the number of incoming students match the number of residency positions. I would also encourage the AAPM to add as a mission statement to help all countries better their own medical physics fields, rather than encourage the best Chinese to migrate to the US, displacing Americans, while neglecting their own countries as well as 'third parties' like African nations.

Thank you for your time, and my condolences if anything I wrote was distressing. I appreciate your time and your work to improve the field of medical physics and the lives of those afflicted by cancer and other health problems. Although I mentioned mitigating the risks of climate change and other social problems as seemingly more important than reducing cancer side-effects, cancer is nonetheless a devastating illness, and work done to help patients is immeasurably valuable.

One additional barrier to residency (real or perceived) that I wouldlike to add: In addition to the psychological stress of feeling less valued due to not being female or a non-European ethnicity (given the statement "women and minorities especially encouraged to apply" common on job postings), I recall reading that for both the 2016 and 2015 national residency matches, more women than men were matched: There may be a sexist mechanism present whereby, given only 1-4 positions, women are more likely to get the position, given their fewer number combined with the notion that diversity necessarily causes better outcomes.

The journal "physics today" published a study corroborating this idea concerning physics faculty a few years ago, finding that the number of female faculty at small 
physics colleges were "over-represented" relative to a random sampling of the total population: I.e. given the total distribution of physicists' sex, one should expect some colleges to be all-male if hiring were random, whereas in fact small colleges usually had at least one female faculty member. Please pardon me for not having the citation on hand (I likely saved a copy somewhere and could dig it up if I could spare the time), but it was published after 2013.

\section{Group 2- GRADUATES WITH A RESIDENCY}

Questions:

1. Are you in debt from your medical physics education?

2. How did debt add pressure to find residency position?

3. Did you encounter many obstacles in finding a residency position? If so, what were they?

4. How is your residency program experience?

5. How are your hours and salary?

6. How do you feel about your overall experience in the medical physics field?

\section{Respondent 1}

1. No.

2. N/A.

3. No.

4. Fantastic.

5. $50 \mathrm{hrs} / \mathrm{wk} ; \$ 59 \mathrm{k} / \mathrm{yr}$.

6. Great!

\section{Respondent 2}

1. No

2. I have no debt 
3. I feel that visa status affected number programs calling me for interview. Also, in the middle of the Match I received my permanent residency which allowed me to get into my residency (they are not accepting those who needs visa support). Also, weakness of my graduate program was a factor.

4. Very positive.

5. Doing about 50hrs/week, salary in the middle range of the corresponding range of AAPM salary survey report.

6. Very excited, optimistic and fruitful

\section{Respondent 3}

1. No, I was fortunate to get a funded graduate research assistant position for my Masterố degree.

2. Very little; the only debt I had was a federally-subsidized loan from undergraduate, and if I did not get a residency position, I likely would have stayed in school to pursue a Ph.D.

3. In general, no. Throughout grad school, I went out of my way to make my residency application as competitive as possible, which I believe was essential in setting myself apart. As expected, the Match process was competitive, but I matched to one of my top choices. I would say my main obstacles were having a competitive application in a large group of applicants with very similar credentials, and paying for the application/interview process (I budgeted $\$ 3000$ for the whole process, which was difficult as a graduate student).

4. Educationally, it is excellent. I feel my residency program is preparing me very well for board certification and independent practice. I also feel the experiences I am gaining during the residency will make me more competitive in the job marketplace, even compared to residents graduating from other programs.

5. My hours are not fantastic but they could be much worse. On average, I work around 55 hours a week (though it can be highly variable ï Iôre worked 70-80 hours per week multiple times, as well as 17 hour days). The most difficult aspect of my hours is they are not consistent day to day $\ddot{I}$ I often do not know I need to stay late or come in earlier than usual until shortly before itôs needed. This makes 
it difficult to coordinate with life outside of work. My salary is very good for my level in training and the cost of living where I am (my annual salary is approximately $\$ 57,000$ as a PGY-2).

6. Overall, positive. I love what I do; the main struggle is work-life balance. I worry about finding a long-term position after residency that has a balance of professional satisfaction and reasonable hours/time off, but I imagine this is a struggle many in our field face.

\section{Respondent 4}

1. Fortunately, I am not in debt from my education. However, I am only so lucky because I remained at the same university for undergraduate and graduate school and was able to obtain a GA teaching position in the department of physics. None of my other classmates were able to secure funding or assistance unless they were going for Ph.D - which was only one.

2. Debt didn't add to the pressure of finding a position. A lack of additional opportunities or avenues apart from residency added immense pressure to find a position. Debt or no debt, without residency and the ABR requirement for certification, I would've wasted a year making minimum wage until I could apply again.

3. I did not encounter any obstacles in finding a position except being taken advantage by one program given the high supply of applicants. My year was the first year of the match and one program didn't give me notice until two weeks before the onsite interview. I was very excited for the opportunity, however, the lack of notice made flights/travel extremely expensive. Once I was onsite, I learned that the program had only narrowed the pool of candidates to 30 for the one position they were offering and was by far the worst odds. The late notice coupled with lack of narrowing the onsite candidate pool made me feel like the program took advantage of the situation.

4. My residency program experience was fantastic. I had a great program director and learned a lot of material and hands-on training experience. 
5. My current hours are $\sim 48 \mathrm{hrs} /$ week with a first year, post-residency salary of $\$ 130,000$.

6. Overall, I love this field. I enjoy doing everything I do day-to-day. The only negative I'd have to say is about the amount of hours I work per week. I wish there was more of a work/life balance. I'd even take a pay cut to have more time at home.

\section{Respondent 5}

1. No

2. It did not play a role in my career decisions or job/residency search

3. No. I was lucky to be invited to a variety of interviews, and I am in a financial place where I could afford to travel to enough of them. The main challenge was the time required to travel and interview, but I tried to be smart about being selective with which programs I visited.

4. Acceptable, not great. It is a new program so it is generally poorly organized and not particularly rigorous (which, to me as a trainee, has its pros and cons). However, I have still had plenty of opportunities to get a lot of hands-on clinical experience and some clinical research experience, and I feel capable and qualified to perform the tasks of a clinical imaging physicist when I am done.

5. Very reasonable. I am paid the same as a medical resident at our institution, 55$60 \mathrm{~K} /$ year. Hours are fine, we sometimes have to work evenings but I would estimate that I typically work $40 \mathrm{hrs} /$ week.

6. It has been a good field for me. I've had great mentors and great experiences. I think that the biggest challenge as a trainee was finding dependable information on the process for career development, preparing for board certification, etc., especially because I was in a more basic-sciencey lab where my advisors were not active in AAPM (so I couldn't go to the meeting, where gathering professional development-related informational materials is much easier).

Respondent 6 
1. I am VERY MUCH in debt from my medical physics education.

2. I justified entering debt by convincing myself that I could probably pay the whole thing off over my residency. I did not find a residency right away, which added immense pressure to qualify for one. I am now almost finished residency and have moved my debt relief prospects away to a distant hope of paying the whole thing off over my first 5 years of work at normal medphys pay. Itố been horrible and stressful, but manageable. Iôm not impoverished or anything.

3. YES. I went to a recently-accredited graduate program at first before I knew what the heck I was doing. An MS from that program officially qualified me for a residency, and my research / GPA were pretty good, but the program was littleknown, I didnâ get an interview, and none of my classmates obtained a residency position. This was in __. I transferred into a $\mathrm{PhD}$ program at a better-known school and obtained the in-house residency after 4 years of additional debt and interest accrual. I was lucky not to have to navigate interviewing in the match.

4. Amazing. Getting the residency was harder than getting a job will be on the other side. Being a resident is stressful. It feels like a well-paid internship with a high salary waiting for me.

5. Hours are about 55/week and salary is average for a residency.

6. The field as currently designed is a mess for students trying to enter the profession in the MS + Residency track. My overall experience turned out alright but I feel for the students that paid for a degree that they ended up not being able to use in a clinic.

\section{Respondent 7}

1. I graduated with about $\$ 12,000$, but have paid the debt within 5 years of graduation.

2. Debt added significant pressure to find any sort of employment after my education. I worked in industry directly after graduation, instead of going to residency. Acceptance into residency did not occur until 4 years after graduation.

3. Yes. I had graduated in from a program which was at the time not CAMPEP accredited. Furthermore, was about the commensurate year for when the 
current rules specify that an individual must have graduated from a CAMPEP graduate program to take part 1 and pass through a CAMPEP residency to take part 2 of the ABR. This produced a great amount of competition to enter into very few residency programs (less than 50 in North America!), and most of which accepted only $\mathrm{Ph} . \mathrm{D}$ graduates. It took years of clinical and industrial experience, as well as time for the number of applicants and number of residency positions to better even out, in order for me to become competitive.

4. Mostly positive. Very friendly and knowledgeable faculty, and a very reputable program.

5. Average weekly workload is about 40 - 50 hours per week. Salary is about $\$ 51,000$ per year.

6. I entered into medical physics somewhat accidentally, and have had a grown passion for it ever since. My opinion is that medical physics is dynamic, multidisciplinary, at the forefront of medical science and fulfilling.

\section{Respondent 8}

1. No.

2. NA

3. Just the competition and arranging my schedule so I could attend the interviews.

4. I am enjoying my experience, in the past year I feel my understanding and confidence have improved tremendously. And I really appreciate starting in a role that is semi-training focused, which allows me to be comfortable asking questions and having my work reviewed by my superiors.

5. I typically work 10-11 hour days ( 8 am - 6/7 pm), and make around 50K per year.

6. I have positive feelings about medical physics. I really enjoyed the MS program at , and have enjoyed my experience working as a resident. I did not enjoy the stress of finding a residency position knowing that there were over 300 students applying for 106 spots, and I often deter people from joining the field by sharing the current fact that only about $30 \%$ of graduates can achieve board certification. 


\section{Respondent 9}

1. No. My tuition was covered through tuition reimbursement from

2. I graduated without any debt.

3. I was fortunate enough to obtain interviews from some good institutions, and matched with my top hospital.

4. I learned a great deal during residency. It was challenging, but not overly so. I never felt overwhelmed.

5. Hours averaged around 50-60 hours a week, with salary of $\$ 45 \mathrm{k} /$ year.

6. I feel very satisfied with my career choice.

\section{Respondent 10}

1. I am still in debt from my medical physics education, but less than $\$ 15 \mathrm{k}$ at this point. I have recently started a junior faculty position post-residency, however, and will paying that amount off in the next 6 months.

2. I did not find that my debt added any pressure to finding a residency position, but more to the overall pressure of finding a job or a residency. (I was grandfathered in on the old training rules, so I sought both types of positions.)

3. I had some personal obstacles in general, but this was related to my previous . Since I was applying to jobs and a single residency position, I was furious that I suddenly had to participate in the Match, because it was not simple, straightforward to get an answer about whether or not I had a position, in order to prove to the . I had to wait until Match Day. I had to pay a lawyer a $\$ 5000$ relocation retainer fee "on faith" that I was going to be matched. I did not appreciate this process, especially because this was the first year the match started. Luckily, it all worked out, but was the most stressful experience of my life. On top of all that, I was waiting to see if I would find a junior physicist position and whether I would even accept the matched position and what that would mean if I had to reject it due to all the match rules.

4. My residency program experience was good in that I received a high-level of training and education. Ultimately, I believe that I got the faculty job that I did 
because of the residency training. I will say that it was tough, even tougher than my $\mathrm{PhD}$ years, raising a child on my own and going through that.

5. My hours and salary were what I would expect from a physics residency/ postdoctoral position. More salary would have always helped. Especially when paying for childcare and babysitters and the high rent in the city I was in.

6. I feel that my overall experience in the medical physics field has been very positive. I came to medical physics after being in an field, and I think our field is drastically better in terms of training, availability of jobs, professionalism, and compensation.

\section{Respondent 11}

1. I am not in debt from my medical physics education. I obtained my MS degree on a fellowship from the NRC which covered all of my tuition and book costs.

2. I did not have any debt, however I was accepted to a number of well known graduate programs with high match rates which I would not have been funded at. I felt somewhat pressured to attend one of these programs for a perceived higher chance of matching at the cost of taking on debt. I ended up choosing my funded program instead and it worked out, but the pressure to pay a lot to go to the "top" schools is real.

3. Having gone through the match experience I am a huge proponent of the current system. The match streamlined the process and eliminated having to make my decision before I had all of my options in front of me. I am open to making changes to the system, but have so far not heard of a better system than the current one. The main obstacle I feel with the current system is the expense of applying to residencies and interviewing. In addition to paying for part 1 of the ABR along with the residency application/interview expense finances became very tight as a graduate student, and it would be even worse for people in unfunded programs. To spend all of that money and to not match would have been devastating.

4. My residency has been an excellent experience. I feel that I am receiving all the training I will need to work independently after residency and to pass my boards. 
The workload is tough, but that is the best way to learn and I feel it is necessary in a field where improper training could lead to significant harm to patients.

5. The hours match my expectations for residency. Particularly during my first year I felt I was constantly working, but it has not been quite as intense my second year. Once again I feel this is a positive, and I have spoken with people in other programs who are working very little hours and are more treated as cheap "QA monkeys" which is quite concerning. As for salary it is fairly standard across the field which is a pro and a con. It is nice that there is not a large discrepancy in salary so I didn't really need to use that as a decision point for my rank list. However, because of cost of living differences I know one resident in New York who can barely scrape by on his salary due to cost of living and his student loans. I know another resident living in Oklahoma and supporting his family of 4 on his salary. This could create an issue for people with families that maybe cannot afford to live in higher expense area which would further restrict where they can apply to residency in a time where it is difficult to obtain one even applying everywhere.

6. I am happy with my experience in the medical physics field. I have enjoyed my residency, and am excited for the next step. That being said I am a little worried about a trend I have noticed in the field where it seems many people are trying to avoid a lot of the work that I think defines our field. Setting aside research (which is critical) it appears that many physicists are trying to avoid doing QA and checking charts which are the bread and butter of medical physicists in therapy and has manifested itself as the medical physics assistant or the previously mentioned QA monkey residencies. I feel that a continuation in this direction will likely lead to depression of salaries and a loss of respect for our field in general.

\section{Respondent 12}

1. Yes.

2. It definitely meant that if I didn't get a residency, I'd have to look for health physics jobs very quickly or move back home; fortunately because we learn about 
residency matches in March I knew I would have a job with a few months to spare.

3. The cost of flying out for interviews was difficult. I'm paying off my student loans slowly on a pay-scaled plan, and I'm doing a small amount of tutoring on the side to help pay things off a little faster, particularly since I have some minor personal debt related in part to the cost of flying out for residency interviews.

4. I am working as a resident in diagnostic (imaging) medical physics.

5 .

6. Yes - I've only been the job for a few months, but I'm enjoying it so far and look forward to learning more Overall positive - I had a really great volunteer position during my studies and the break between school and residency, and I'm enjoying my residency.

\section{Group 3- RESIDENTS WITH EMPLOYMENT}

\section{Questions}

8. What is your current job title?

9. Is this your first job post-residency?

10. How many years have you been in your current position?

11. What was your experience for finding your first position post-residency? (Location, salary, hours, etc.)

12. Did you have issues finding a job prior to passing the board exam? If so explain. 13. Are you satisfied with your current position?

14. What do you think about the current job market in medical physics based on your experiences?

\section{Respondent 1}

1. Assistant Professor in the Department of Radiation Oncology

2. No

3. Almost 1 year 
4. I took a temporary physicist assignment in the location where I had done my $\mathrm{PhD}$. This was not an advertised position, but a casual position where I was paid hourly (e.g. non-salary). I was compensated at the level physicist (including raise when received my board certification), but with no benefits (insurance, retirement, vacations, travel, relocation, etc...). Otherwise, the main opportunities offered to me before receiving my boards were clinical positions in smaller non-academic centers.

5. No, but the quality of the job offers I received improved after I received my boards

6. Moderately so

7. It depends on whether or not you want to work in an academic/teaching center or in a purely clinical site. There are enough jobs that it is not difficult to be employed if you donâ care where you go, but if you want to limit yourself to certain categories/geography, the process becomes more difficult

\section{Respondent 2}

1. Assistant Professor (clinical health sciences track)

2. Yes.

3. $3+$ years

4. I applied to $~ 10-15$ entry-level academic positions, interviewed informally with perhaps half a dozen, and interviewed formally/on-site for two. My ultimate decision was based on location given that salary offers were competitive with each other.

5. No. It was understood (though not contractually) that I would pursue and obtain ABR certification following the typical time cycle, including Part II the year of graduating residency and Part III the following May.

6. Yes.

7. While I am not intimately familiar with the current market, I believe it has improved over the past couple years. I feel like there are more advertised job openings now than in the past years. Also anecdotally I know a few people who 
have switched jobs in the last year or so, indicating more fluidity and therefore openings in the market.

\section{Respondent 3}

1. Medical Physicist

2. No; $2^{\text {nd }}$

3. 1

4. I started looking for a job halfway into my $2 \mathrm{yr}$ residency. There were hardly any positions posted in the city I was living (__ and the city where I grew up (__ ), in addition to other major metropolitan areas my husband and I were willing to move. I did get 3 interviews in but was turned down for 3 of the 4 positions because they took people with more work experience. 1 did not work out due to salary. Over a year later at the end of residency I still did not have a full time position. I got some per diem work through a physician but in the end, I ended up walking up to strangers at the AAPM meeting and that was how I ended up with my first "real" full time position post residency in Salary was lower than the salary survey but I took the job anyway because it was an academic center and would be a great place to get experience for the Oral board exam and it was a full time position in the city where I grew up and was willing to live. Hours were what I expected 45-50 a week.

5. N/A - I passed the board exam during the 1st full time position I had after residency.

6. Overall, yes, however, I wish it was full time. I work part time for 2 different consulting groups.

7. The job market for medical physicists is very poor due to the fact that there are more physicists being churned out than positions available. The heart of this issue is that there is no regulation/limit on the number of students that graduate programs accept. The CAMPEP graduate programs do not get "punished" for accepting too many students for the job market. There are some programs that have more than 20 students per class which is absurd for the demand for physicists. And of course there is now the issue that there aren't enough residency 
spots either, which is all the more reason that these graduate programs shouldn't be allowed to accept so many students. Additionally there is another problem for those with MS degrees - there are several job posting that "require" PhDs despite the position being a solely clinical position which in reality does not *need* a $\mathrm{PhD}$. The other issue relates to specific geographical job markets. Though there are physicist jobs available across the country at any given time, it is not realistic for people, especially those who are married/with families/etc. to be able to just move where a job is. Despite there being several hospitals in all these major metropolitan locations, the physicist job market is terrible in that typically only 12 positions are posted per *year*, with some cities having 0 postings per year: Chicago, Atlanta, DC, Boston, Seattle, Portland, San Francisco \& the Bay Area, San Diego, Denver, Austin, and the list goes on. There have even been years recently where no jobs were posted in the NYC or Boston area at all! I relocated to the Bay Area because of my husband's job last year. I looked for a position for 6 months before I moved . 3 jobs were posted - 1 was a fake posting in that they already had a contractor working there who the job was for and the other required Cyberknife experience which is not a widely held skill. After the move, thankfully I was only unemployed for 2 months. I ended up getting my 2 part time contractor positions after endless networking.

\section{Respondent 4}

1. Medical Physicist

2. Yes

3. 1.5 years

4. I felt lucky to find a job within driving distance of my current residence. I had received the offer around the same time I landed a few interviews out of state. I decided to accept the offer after a short negotiation process- suburban community hospital, solo therapy physicist job- one linac. Good salary offer for board eligible job starting@153k, good hours 8a-5p. I was able to find a job before I finished residency, and start as soon as I finished. 
5. No- however many more opportunities seemed to be available for board-certified physicists. My job offer required that I be certified within 2 years of hire, which I was able to do.

6. Yes

7. I believe there are a reasonable number of openings for board-certified medical physicists, although many require $\mathrm{PhD} /$ management experience or are not in a desirable location. I think the hard part was getting the residency... more or less smooth sailing from there.

\section{Respondent 5}

1. Medical physicist

2. Yes

3. 1.5 years

4. I applied for multiple post-residency positions but only interviewed at one other location. It seemed like the available positions were pretty similar regarding hours and responsibilities within certain categories. For clinical positions, these categories seemed to be academic, hospital-based, or private practice. I primarily applied for academic and regional hospital-based positions.

5. I didnâ have an issue finding a job, but my prospects were limited before passing the board exam. There were a substantial number of positions posted on the AAPM job board (30-40) but many of those positions were looking for experienced candidates.

6. I am satisfied with my current position.

7. There seem to be a large number of open positions in the current job market. However, the majority are looking for experienced (board-certified) candidates and job-seekers will probably have to relocate to find more desirable positions.

\section{Respondent 6}

\section{Assistant Professor}

2. Yes

3. 2 yrs.

4. Good. Happy with location, salary and hours. 
5. Did not try. I had completed board exam (ABR part-3 oral) prior to completion of MP residency.

6. Yes.

7. Donâ know. It should not be very different from when I tried 2 yrs ago.

Probably, loaded in favor of PhDs over MS.

Respondent 7

1. physicist

2. no

3. 1.5

4. $\longrightarrow, 125 \mathrm{k}, 9-5$

5. No

6. Yes

7. competitive 


\title{
APPENDIX 7- EMERITUS MEMBER SURVEY QUESTIONS
}

\author{
A Mixed Methods Evaluation of the Supply and Demand of Radiation Oncology Medical \\ Physicists in the United States
}

IRB Number: 16.0780

Dear Sir or Madame:

You are being invited to participate in a research study by answering the attached survey about understanding perceptions of the current medical physics workforce in the United States. There are no known risks for your participation in this research study. The information collected may not benefit you directly. The information learned in this study may be helpful to others. The information you provide will provide insight to better understand networks and the factors may or may not influence participation. Your completed survey will be stored at Survey Monkey. The survey will take approximately 5-10 minutes of your time to complete.

Individuals from the Department of Health Management and System Sciences at the University of Louisville School of Public Health and Information Sciences, the Institutional Review Board (IRB), the Human Subjects Protection Program Office (HSPPO), and other regulatory agencies may inspect these records. In all other respects, however, the data will be held in confidence to the extent permitted by law. Should the data be published, your identity will not be disclosed.

Taking part in this study is voluntary. By completing this survey you agree to take part in this research study. You do not have to answer any questions that make you uncomfortable. You may choose not to take part at all. If you decide to be in this study you may stop taking part at any time. If you decide not to be in this study or if you stop taking part at any time, you will not lose any benefits for which you may qualify. 
If you have any questions, concerns, or complaints about the research study, please contact: Christine Swanson (502)-299-1353

If you have any questions about your rights as a research subject, you may call the Human Subjects Protection Program Office at (502) 852-5188. You can discuss any questions about your rights as a research subject, in private, with a member of the Institutional Review Board (IRB). You may also call this number if you have other questions about the research, and you cannot reach the research staff, or want to talk to someone else. The IRB is an independent committee made up of people from the University community, staff of the institutions, as well as people from the community not connected with these institutions. The IRB has reviewed this research study.

If you have concerns or complaints about the research or research staff and you do not wish to give your name, you may call 1-877-852-1167. This is a 24 hour hot line answered by people who do not work at the University of Louisville.

Sincerely,

Christine Swanson, MS, DABR, Phd(c).

1. Have you retired in the last 5 years or do you intend to leave the profession within the next 5 years? Yes or No

**If No- Go to end of survey

2. How long were you in the medical physics profession? 0-5 years, 6-10 years, 1115 years, 16-20 years, 21-30 years, 31-40 years, more than 40 years

3. What is the highest position you have held as a medical physicist? Chief, Faculty, Staff, Consultant, Vendor, Other with open response

4. What is the primary reason you chose to leave the medical physics profession? Retirement, Stress, Work Environment, New Career, Salary, New Technology, Workplace Politics, Personality Conflicts, Other with open response 
5. What are you doing now and/or what do you plan to do when you leave the profession? (select all that apply) Part time Consultant, retired, new career, volunteering, serving profession, other

Questions 6- 12 are Likert with the options: Strongly Disagree, Disagree, Agree, Strongly Agree, N/A

6. I enjoyed my career as a medical physicist.

7. I would repeat my decision to enter medical physics profession.

8. I feel the medical physics profession has evolved in a positive way.

9. I felt my compensation was appropriate for my job responsibilities.

10. My hours were unreasonable.

11. I was able to keep up with changes in technology.

12. I would recommend medical physics as a career for a college student or friend.

13. Please provide any additional comments about your experiences in the medical physics profession and any insight into why you chose to leave the profession. Open response

14. May we contact you with further questions? Yes or No

**If Yes, Question 15

** If No, End of Survey

15. If yes, please provide the best email, telephone number, and time to reach you? End of Survey Page: Thank you for taking this survey. 


\section{APPENDIX 8- EMERITUS MEMBER SURVEY RESPONSES}

Q1. Have you retired in the last 5 years or do you intend to leave the profession within the next 5 years?

$\begin{array}{llll}\text { Answer Choices } & \text { Responses } & \\ \text { Yes } & & 91.30 \% & 42 \\ \text { No } & & 8.70 \% & 4 \\ & \text { Answered } & 46 & \\ & \text { Skipped } & 0 & \end{array}$

Q2. How long were you in the medical physics profession?

\begin{tabular}{lll} 
Answer Choices & Responses & \\
0-5 years & $0.00 \%$ & 0 \\
5-10 years & $2.50 \%$ & 1 \\
11-15 years & $2.50 \%$ & 1 \\
16-20 years & $5.00 \%$ & 2 \\
21-30 years & $20.00 \%$ & 8 \\
31-40 years & $45.00 \%$ & 18 \\
more than 40 years & $25.00 \%$ & 10 \\
\multicolumn{1}{c}{ Answered } & 40 &
\end{tabular}

Q3. What is the highest position you have held as a medical physicist?

$\begin{array}{lll}\text { Answer Choices } & \text { Responses } & \\ \text { Chief of Physics } & 50.00 \% & 20 \\ \text { Faculty } & 20.00 \% & 8 \\ \text { Staff } & 15.00 \% & 6\end{array}$

Consultant $\quad 2.50 \% \quad 1$ 


$\begin{array}{lll}\text { Vendor } & 0.00 \% & 0 \\ \text { Other (please specify) } & 12.50 \% & 5 \\ & \text { Answered } & 40 \\ & \text { Skipped } & 6 \\ 1 & \text { Government regulatory- Chief of Physics staff and Sr Advsor } \\ 2 & \text { VP/CTO of two startup interventional oncology companies } \\ 3 & \text { Vice President Research [medical device company] } \\ 4 & \text { Locum Tenens } \\ 5 & \text { Professor and Dept. Vice-Cair }\end{array}$

Q4. What is the primary reason you chose to leave the medical physics profession? (select all that apply)

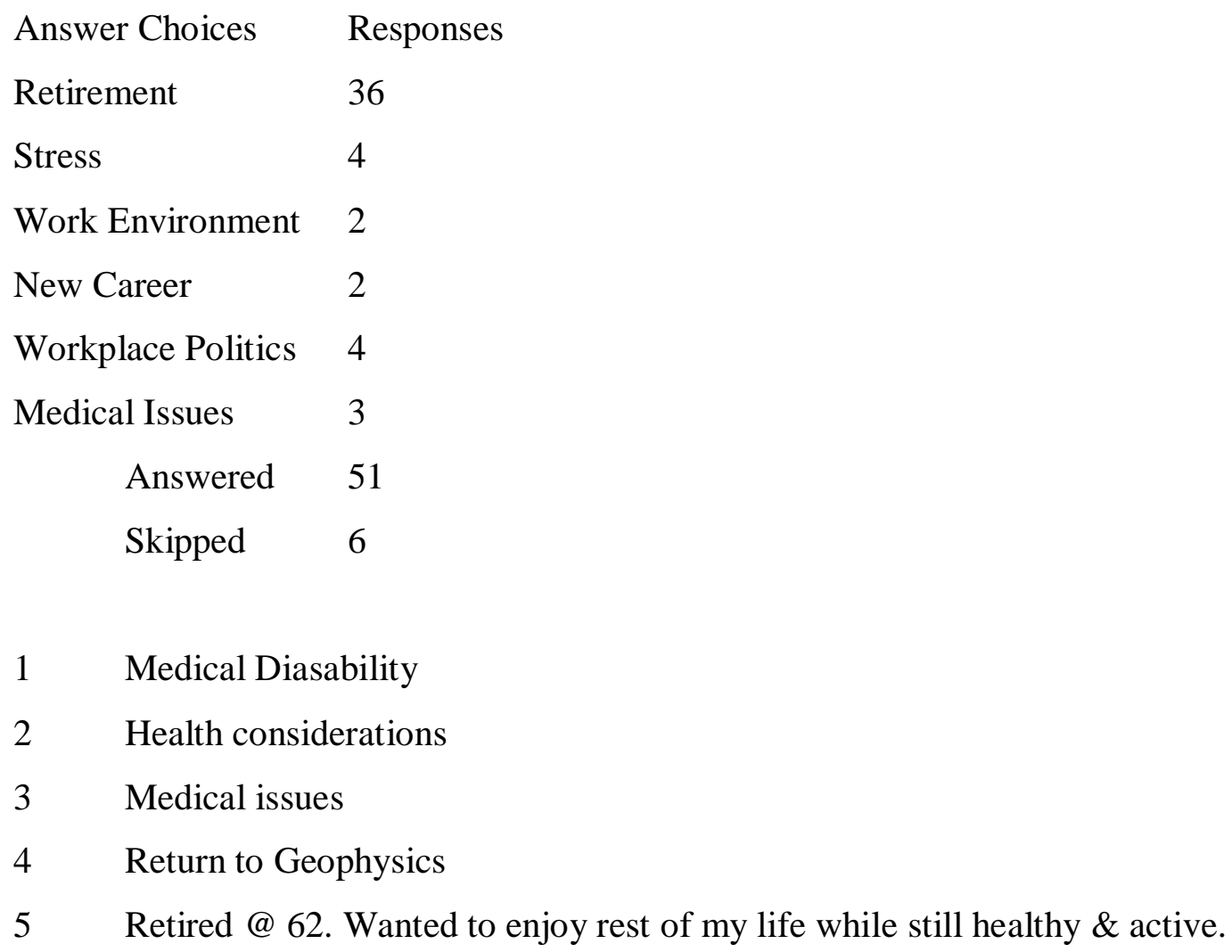


Q5. What are you doing now and/or what do you plan to do when you leave the profession? (select all that apply)

Answer Choices Responses

Part Time Consultant $27.50 \% \quad 11$

Retired $\quad 75.00 \% \quad 30$

New Career $\quad 7.50 \% \quad 4$

Volunteering $\quad 25.00 \% \quad 10$

Serving Profession $\quad 7.50 \% \quad 5$

Answered $\quad 40$

Skipped 6

1 Continuing research and involvement with ACR accreditation programs and governance

$2 \quad$ Full Time Geophysicist

3 travel

4 Involved Medical Physics volunteer organization for the developing world

Q6. I enjoyed my career as a medical physicist.

$\begin{array}{lll}\text { Answer Choices } & \text { Responses } & \\ \text { Strongly Disagree } & 2.50 \% & 1 \\ \text { Disagree } & 0.00 \% & 0 \\ \text { Agree } & 15.00 \% & 6 \\ \text { Strongly Agree } & 82.50 \% & 33 \\ \text { N/A } & 0.00 \% & 0\end{array}$

Answered $\quad 40$

Skipped 6

Q7. I would repeat my decision to enter the medical physics profession.

Answer Choices Responses

Strongly Disagree $\quad 0.00 \% \quad 0$

Disagree $\quad 7.50 \% \quad 3$ 


\begin{tabular}{|c|c|}
\hline Agree & $17.50 \%$ \\
\hline Strongly Agree & $72.50 \%$ \\
\hline N/A & $2.50 \% 1$ \\
\hline Answered & 40 \\
\hline Skipped & 6 \\
\hline
\end{tabular}

Q8. I feel the medical physics profession has evolved in a positive way.

$\begin{array}{lll}\text { Answer Choices } & \text { Responses } & \\ \text { Strongly Disagree } & 0.00 \% & 0 \\ \text { Disagree } & 7.50 \% & 3 \\ \text { Agree } & 42.50 \% & 17 \\ \text { Strongly Agree } & 50.00 \% & 20 \\ \text { N/A } & 0.00 \% & 0 \\ \quad \text { Answered } & 40 & \\ \quad \text { Skipped } & 6 & \end{array}$

Q9. I felt my compensation was appropriate for my job responsibilities.

$\begin{array}{lll}\text { Answer Choices } & \text { Responses } & \\ \text { Strongly Disagree } & 0.00 \% & 0 \\ \text { Disagree } & 12.50 \% & 5 \\ \text { Agree } & 42.50 \% & 17 \\ \text { Strongly Agree } & 45.00 \% & 18 \\ \text { N/A } & 0.00 \% & 0 \\ \quad \text { Answered } & 40 & \\ \quad \text { Skipped } & 6 & \end{array}$

Q10. My hours were unreasonable.

$\begin{array}{lll}\text { Answer Choices } & \text { Responses } & \\ \text { Strongly Disagree } & 5.00 \% & 2 \\ \text { Disagree } & 45.00 \% & 18 \\ \text { Agree } & 50.00 \% & 20\end{array}$




$\begin{array}{llll}\text { Strongly Agree } & 0.00 \% & 0 \\ \text { N/A } & & 0.00 \% & 0 \\ & & \text { Answered } & 40 \\ & \text { Skipped } & 6 & \end{array}$

Q11. I was able to keep up with changes in technology.

$\begin{array}{lll}\text { Answer Choices } & \text { Responses } & \\ \text { Strongly Disagree } & 5.00 \% & 2 \\ \text { Disagree } & 7.50 \% & 3 \\ \text { Agree } & 52.50 \% & 21 \\ \text { Strongly Agree } & 35.00 \% & 14 \\ \text { N/A } & 0.00 \% & 0 \\ \quad \text { Answered } & 40 & \\ \quad \text { Skipped } & 6 & \end{array}$

Q12. I would recommend medical physics as a career for a college student or friend.

$\begin{array}{lll}\text { Answer Choices } & \text { Responses } & \\ \text { Strongly Disagree } & 0.00 \% & 0 \\ \text { Disagree } & 7.50 \% & 3 \\ \text { Agree } & 32.50 \% & 13 \\ \text { Strongly Agree } & 60.00 \% & 24 \\ \text { N/A } \quad 0.00 \% & 0 \\ \quad \text { Answered } & 40 & \\ \quad \text { Skipped } & 6 & \end{array}$

Q13. Please provide any additional comments about your experience in the medical physics profession and any insight into why you chose to leave the profession.

Answered 37

Skipped 9 
$1 \quad$ Although not considered "main stream", since I served in government- I was recognized by by AAPM colleagues professionally as a Fellow, and served on numerous committees. I did practical research, involved in promulgating practical regulations, considered myself a medical physicist, worked clinically and interacted with numeorus clinical scenarios. My only concerns is the "march" to elitism, ignoring the fundamental changes medicine is undergoing today. This march may isolate, and potentially endanger the very profession due to technologies that are replacing some of the very tasks medical physicists prided themselves in doing. Beware.

2 I retired because I wanted to spend more time with my family.

3 Being a Medical Physicist the last 40+ years, and watching the profession develop and mature has been a wonderful and fulfilling experience.

$4 \quad$ I felt that it was time for me to retire.

5 Too complicated to go into, didn't leave the profession other than my age and ability to work long hours

6 Regarding the first question, I actually retired almost 10 years ago.

$7 \quad$ worthwhile partnership to physicians

8 Thoroughly enjoyed my career as a medical physicist.

9 The Association trends to be very exclusive, in the name of maintaining high professional standards. In reality it's basically preserving the supply demand law.

10 I enjoyed contributing to the care of patients. Unfortunately, a large percentage of medical physicists do not, in my experience, make a sincere effort to provide the best care possible to their patients.

11 I found a career in medical physics highly gratifying and professionally rewarding. At age 70, due in large part to health problems, I decided it was time to step back to doing research and consulting on a part-time basis. 
12 Stayed until I was 74. Hired a young, smart, energetic replacement. Satisfaction in this field is strongly dependent on the team you work with. I had a good one.

13 About 3 years ago I left full time employment but continued to consult to my last employer as a key consultant.

14 Saw many changes and improvements in the field. Clinical expertise is imperative. Instituted a MP Residency program in a Consulting Group. Still interested in the Education aspect, but time to retire from the Clinic.

15 I moved into teaching physics and stopped doing medical physics consulting.

16 The opportunities in medical physics are fewer compared to when I entered. I would have preferred keeping the option that "pure" physicists could be trained as med physicists rather than the regs currently in place.

17 AAPM should try to integrate industrial members better. It was time to retire.

18 It was a wonderful profession for someone with my interests and skills $<3$

19 Unfortunate that some academic physicists chose to create major tensions with things like ACMP vs. ACR and were against physicists certifying physicists. -- also peer review publishing article is sometimes a personality conflict rather than scientific endeavor

20 I thoroughly enjoyed Medical Physics during the 1990 through 1996 time frame while the Oil and Gas industry was in a downturn

21 no opportunities to learn new technologies

22 I was teaching in a Medical Science Campus and I enjoyed it. Had to retire after 40 years to care for elderly mother and because my own health conditions.

23 The field lacks protection from the doctors who are not interested in quality. 
24 I retired because I was 69 and wanted freedom to travel. After the death of my younger brother, we decided that I had better retire or I might not have the opportunity.

25 Job satisfaction and security were small or inconsistent. I felt that my career was in the hands of a few people whose behavior was petty and unprofessional. I and my family made many sacrifices in moving many times to different cities to continue my career under better conditions. Over forty years, I never stayed more than eight years with the same employer.

26 Innovative atmospare and newest technologies

27 Great international medical friends and colleagues

28 I found it to be a very challenging and rewarding career. As you mature in the profession you must to embrace the ever changing technologies. When the ride gets too fast you need to know when to get off.

29 I chose the profession to get out of low paying teaching college. Based on advisor in grad school.

30 "It is a very rewarding career, although to be successful in both clinical service and research involves a lot of dedication and a lot of hours.(Note that I am a Canadian working in Canada.)"

31 For 24 out of 29 years hospitals and Doctor groups paid in the lower half of of the salary survey from pervious years and required my presence during patient txt for 8-9 hours. Then I had to do maintenance /calibration after hours. I still enjoyed my career.

32 growth if complexity in Clinical rad therapy made keeping up harder as years go on

33 Concerned that the profession has move away from eclectic background and too focused on rigid and overly complicated credentialing. This has led to practitioners who lack common sense and breadth of knowledge to be clinically relative. 
34 I'm old. I am answering the survey so that you can assess your goal to evaluate the need for future professionals. Also, I came to the profession there was high need. I left to teach as it fit my personal life better even though the salary was less at that time.

35 My wise decision to enter the field early while demand was high.

36 retired to pursue other interests

$37 \quad 38$ years in the field

Q14. May we contact you with further questions?

Answer Choices Responses

Yes

$77.50 \% \quad 31$

No

$22.50 \%$

9

Answered 40

Skipped 6

Q15. Please provide the best email, telephone number, and time to reach you.

Answered 31

Skipped $\quad 15$ 


\section{APPENDIX 9- FOLLOW UP SURVEY EMERITUS MEMBERS ATTRITION/RETIREMENT}

Note- Open response answers with identifiable information have been redacted to protect the privacy of respondents.

Questions:

1. Explain why you retired from the medical physics field and what are you doing now.

2. What changes would you want to see take place in the medical physics profession?

3. If considering a career today, would you repeat your decision to pursue career in medical physics? Why or why not?

4. Do you feel like you have left a legacy? If so how?

5. Did you have an "AHA" moment in your career as a medical physicist? If so what?

6. What do you think about the current state of the medical physics profession? (Salary, job market, technology, residency programs, certification, etc.)

7. What changes, if any, would you like the AAPM to make to better serve the retirement community?

\section{Respondent 1}

1. I worked in industry for a __ manufacturer, which might make the parameters concerning retirement different from other AAPM members. I retired at 66, which was considered late for retirement by the home corporation (I worked for the research center). It was time. I didnâ necessarily agree with the direction theory was taking (there was a gestalt washing over the field, both in academia 
and industry). It was time to make way for otherð youngerð medical physicists to have their time in the sun, to try out their ideas. It was time to go. Outside interests were also a factor, to enjoy them while still healthy. Iôm enjoying retirement, mostly living an active outdoor life of hiking, biking, skiing, and writing family stories. I did go to this yearô AAPM Annual Meeting after missing the last three. It was nice to see former colleagues and to hear how much the technology has changed (or not).

2. I donâ have a strong opinion here. Perhaps a better effort at integrating those of us from industry into the mainstream of the AAPM. But then restrictions placed by companies might make this difficult.

3. I had an interesting career and have no regrets about the path my working life took. It wasnâ a planned to decision to go into medical physics, but rather it was the best of the few job offers I had after my education. My training in medical physics per se was on-the-job.

4. Yes, I do feel that I have left a legacy. Many of the __ systems developed by my employer have my fingerprints all over them, machines that are used every day to better diagnose whatô wrong with patients and help guide interventions. These contributions include overall system design of a few models, the reconstruction methods used by most, and the data corrections used by most. Furthermore, I lead a team of imaging researchers and developers and take pride in improving their skills and in their contributions.

5. Yes, I did have an AHA moment. It was a way to handle that came to me in a flash é after years of mind preparation. This method had several applications including an elegant way to __ that worked well for ___ that dominated the market from around 2000 until today. I published the original kernel of the idea in the journal Medical Physics.

6. I have nothing to add here.

7. When you retire to a community far from a medical physics academic center, itôs hard to see what the AAPM could do.

\section{Respondent 2}


1. I retired from the medical physics field at the age of 75 , after working as a medical physicist for 50 years. I am currently a Professor Emeritus with continuing connectivity to my former full-time work colleagues and spend a busy week as an active volunteer in _ local community non-profit organizations providing a variety of contributed services.

2. Additional formal emphasis put on training for medical physicists in management skills such as strategic planning, team building, financial management, fund raising, and grant application writing can advance the perception of the value of medical physicists by senior management executives to ensure their future support.

3. Absolutely would pursue a career in medical physics again. My education and training provided me with the great satisfaction of having contributed to major technical advances that have had a major positive impact on cancer care throughout the world; and also provided me with many national and international colleagues and friends working in this field.

4. I was fortunate to have participated closely in the pioneering development of new technology with accompanying publications and presentations at meetings that included the now a major international cancer treatment modality. It was also my privilege to serve in senior leadership roles for AAPM, ACMP and ABMP during their period of early development and growth.

5. My ñAHAò moment in medical physics came when I realized the importance of acquiring strong management skills as well as demonstrating scientific, teaching and clinical ability.

6. The current state of our profession is strong; but with senior management increasingly looking to cut costs, their perceptions of highly compensated individuals like medical physicists about which they have only superficial knowledge, poses a definite challenge.

7. The AAPM need make no changes to better serve our retirement community. This is a great organization of which I have been a member since 19_starting as a predoctoral fellow at 


\section{Respondent 3}

1. In 2009, I took a 6 month leave of absence from my position at that time to work as a consultant at the During this period they asked me if I would take another 8 month consultancy. Since I felt that it was not appropriate to be away for such a long time and continue to be the head of a department while I was on leave, I decided to hand in my letter of retirement. I did not really retire from Medical Physics; I retired from my existing position. I worked at the from 2009 to 2011. I then formally retired from Medical Physics in that I was no longer getting paid. In the meantime, I have continued in Medical Physics activities on almost a full time basis but not getting paid for it, i.e., volunteer work. I am the main founder of an organization called an altruistic organization devoted to providing intellectual/mentoring/teaching support to Medical Physicists in less advantaged countries.

2. It would be great if employers would recognize the need for Medical Physics support in Developing Countries and provide some encouragement and paid leave for volunteer work in those environments.

3. Yes, I would make the same decision. Medical Physics has been a very rewarding career and it continues to be rewarding even as a volunteer.

4. Yes! I published multiple papers and 3 books entitled the $\underline{n}$ _. If continues to function successfully after I finish my terms on the board, it will be even more rewarding.

5. Not in particular.

6. The work is great. The pay is great. The entry into new positions is becoming very restrictive. I am concerned that the residency training is becoming too dogmatic and too routine oriented not leaving much room for innovation. Residents are taught very specific techniques and procedures but not much in the way of creative and original thinking.

7. The AAPM should encourage more flexibility and originality in the residency programs. Regarding the retirement community, the AAPM is supportive by giving discounted registration fees for annual meetings. It would be even better if retired members are invited to participate as a speaker in symposia at the annual 
scientific meeting that travel/accommodation support would also be provided. At the present time, there is a considerable cost in my attendance at AAPM meetings even when I organize or participate as a speaker in symposia.

\section{Respondent 4}

1. Medical physics was a good career for me. My final position was more lucrative than I initially expected. My previous positions rarely matched the AAPM salary survey 50th percentile. So, while providing a good living, it wasn't until my kids were grown and my homes paid for that the "medical physics pay-off" occurred. I try not to be greedy, so after $6+$ years of this, I decided that at age 62 , I would enjoy life while my health held out. Six years in and I have no regrets!

2. Since I started in the early 80 's, I've seen a continual creep toward the $\mathrm{PhD}$ requirement. There is a hang up of being on "par" with physicians. Radiation Oncology will always be a team effort, and the problem is not that the physicist is MS or PhD. The problem is that physician training, for all doctors, emphasizes that they are in control and responsible (and rightly so), but it does not train them to respect and use the talents of their physicist colleagues. Less than half of the physicians I've worked with knew what I could do for them, and refused to listen, or entertain any ideas other than their own, (or those of their trainers). The axiom is still true, that the $\mathrm{PhD}$ is just the Union Card to teach at the University level. It is not necessary to deliver quality medical physics care.

3. I would hope that today I would not be daunted by the many additional hoops necessary to become and remain a medical physicist. I would probably seek a hands-on clinical training program offering a DMP. While not necessary, the doctorate will probably soon be required.

4. I think my primary legacy resides unseen in the lives of thousands of patients I've had a small part in treating. Some "hands-on" and a lot of "behind-the-scenes" hard work made a difference in a lot of lives. At least I like to think so, though I'll never know. I was also able to give an occasional hand up to younger physicists, and one in particular has done great work I could never have done myself. 
5. My biggest "AHA" was discovering medical physics itself. It married my love of biology and my early health physics training and I knew I'd found a home!

6. I think many are pursuing medical physics as a job choice with good benefits, not because they really love the work. But I also suppose that it has always been that way, at least to some extent. I'm amazed by the technological advances. I think the residency issues could be handled in a wiser and more humane method. Certification seems to be a bit over-the-top, but that may just be the perspective of advanced years.

7. When I was first retired, I did locums work, so I was still fully involved in medical physics. While I try to keep up with what's going on, since I'm not now involved, I no longer identify as a medical physicist, only as a former medical physicist. AAPM has its hands full with current MPs, I'll take care of myself.

\section{Respondent 5}

1. I retired from medical physics after for almost 39 years, just before I reached my 70th birthday. It was time to start the next book in my life.

2. I think that the changes to the path to a career in medical physics that have take place this past decade are not necessarily for the good of the profession. I believe more serious discussions need to be pursued. It is very confusing to the aspiring physicist, and very unorganized on a general level.

3. I had particular reasons for going into medical physics at the time that I did. Given the new requirements and restrictions, I would not do it today. It was the right choice, and a good choice for me in 19

4. Not really an important issue to me. I'm not an academic, I did not publish. But I did participate to a high level in the politics, organizational politics of both the AAPM and the ACR. That I am very proud of.

5. My AHA moment probably was when I sat in on my first AAPM committee meeting, I realized that I had a lot more experience and more to offer in the organizational aspects. I was always proud to sit on the AAPM board and participate at that level. 
6. I feel that the state of AAPM residency programs, certifications, education, etc. are in tremendous flux and makes it very difficult and unfair to prospective physicists. Not sure about the job market, it is very difficult for a young physicist to get started. The increased complexity of the technology has a lot to do with that, I didn't have to face that with my first position.

7. Maybe the AAPM could hold a "retirees" luncheon at the annual meeting.

\section{Respondent 6}

1. I reached my retirement age and can afford retirement. I still do a little consulting work when asked to help.

2. Two track emphases with equal representation: Research \& development for the future and clinical to secure our footing in medical field. If you are in a clinical setting, jump in and do clinical works. Understand the whole treatment process and be able to complete the treatment process if dosimetrist is not available.

3. Yes. It is interesting and rewarding.

4. Yes. I worked hard and smart and earned the respect from my colleague (MDs, Dosimetrists, Therapists, nurses and administrators)

5. I was so involved in the SRS case with neurosurgeons and radiation oncologists, a patient thought I was in charge for the case (I may be in charge of the treatment process, but certainly I am not in charge)

6. Salary is high, job market is good, technology changes rapidly, residency program is in right direction but give up on certification now.

7. AAPM should focus on the future. I am happy with the treatment of Emeritus member now with no annual fee and reduced registration for annual meeting.

\section{Respondent 7}

1. I retired in 1999 to take a job in teaching treatment planning to therapy students. I retired again in 2005 and returned to our family farm.

2. I see the Medical Physicist working themselves out of jobs (with dosimetrists, qc people, junior physicist and thinking they are to high up to do work)

3. No I would not, I would go into IT 
4. I am not sure, I left technologists, dosimetrists that I trained, but is that a legacy, I don't know.

5. My AHA moment came while teaching in Ireland and trying to explain physics to students

6. see answer 2

7. I think it is really to late to change

\section{Respondent 8}

1. My wife got a 2 year job in , so I retired to accompany her. Now I'm figuring out what to do.

2. There is great pressure on clinical physicists to perform technical tasks, which can ease them away from the actual science of physics in medicine. Integrating more in the medical process or in research can help expand the mind of the physicist and increase their enjoyment of the career.

3. Probably, although it would require a substantially increased commitment. When I started out students didn't incur a lifetime school debt to get a job in a desired career.

4. A small one, through the people I've helped train and the text books I have cowritten

5. Many. You can never stop learning; and in my career, the technology changed so drastically, there was always something significant to relearn or replace.

6. I fear for the profession because of the cost of education before on the job training opportunities.

7. Can't suggest any. The emeritus status is a welcome act. 


\section{APPENDIX- IRB APPROVAL}

\section{UNIVERSITY OF LOUISVILLE}

DATE:

TO:

FROM:

IRB NUMBER:

STUDY TITLE:

REFERENCE $\mathbf{~ : ~}$

IRB STAFF CONTACT:
October 05, 2016

Robert J Esterhay, M.D.

The University of Louisville Institutional Review Board

16.0790

A Mixed Methods Evaluation of the Supply and Demand of Radiation Oncology Medical Physicists in the United States

610060

Barbara Dearinger, BS, CIP

(502) $852-5987$

badear01@louisville.edu

This study was reviewed on 09/29/2016 by the Chair/Vice Chair of the Institutional Review Board snd spproved through the Expedited Review Procedure, according to 45 CFR $46.110(0)$, since this study falle under Category 7: Resesrch on individual or group characteristice or behavior [including, but not limited to, research on perception, cognition, motivation, identity, language, communication, cultural beliefs or prsctices, and social behavior) or research employing survey, interview, oral history, focus group, program evaluation, human factors evaluation, or quality sszursnce methodologies. This study now has final IRB approval from 09/29/2016 through 09/28/2017.

This study was also approved through 49 CFR 46.116 (C), which means that an IRB may waive the requirement for the investigator to obtain a signed informed consent form for some or all subjects if it finds either:

- That the only record linking the subject and the resesrch would be the consent document and the principsl risk would be potential harm resulting from a breach of confidentiality. Esch subject will be asked whether the subject wants documentation linking the subject with the research, and the subject's wishes will govern; or

- That the research presents no more than minimal risk of harm to subjects and involves no procedures for which written consent is normally required outside of the research context.

The following items have been approved:

\begin{tabular}{|l|l|l|}
\hline Title & Verzion Date & Outcome \\
\hline Methods & $09 / 14 / 2016$ & Approved \\
\hline survey and interview questions & $09 / 14 / 2016$ & Approved \\
\hline Preamble & $09 / 14 / 2016$ & Approved \\
\hline
\end{tabular}

For guidsnce on using iRIS, including finding your approved stamped documents, plesse follow the instructions st

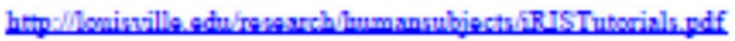

Site Approval

If this study will take place at an affiliated resesrch institution, such as KentuckyOne Heaith, Norton Hearthcare or University of Louisville Hospital, permission to use the site of the affiliated institution is necessary before the research may begin. If this study will take place outside of the University of Louisville Campuses, permission from the organization must be obtained before the research may begin (eg. Jefferson County Public Schools). Failure to obtain this permission may result in a delay in the start of your research. 
Privecy s. Encryption statement

The University of Louisville's Privacy and Encryption Policy requires such information as identifiable medical and hesith records: credit card, bsnk account and other personal financial informstion; socisl security numbers; proprietary research data; dates of birth (when combined with name, address and/or phone numbers) to be encrypted. For sdditional information: http///security.louisville.edu/Polstds/150/pso18.htm.

Implementation of Changes to Previously Approved Research Prior to the implementation of any changes in the approved research, the investigator will submit any modifications to the IRB and await spproval before implementing the changes, unless the change is being mode to ensure the safety and welfare of the subjects enrolied in the research. If such occurs, a Frotocol Deviation/Violation should be submitted within five days of the occurrence indicsting what safety measures were taken, slong with an smendment to revise the protocol.

Unsnticipated Problems Involving Risks to Subjects or Others [UPIRTSOs]

In general, these may include sny incident, experience, or outcome, which has been associsted with sn unexpected event/s), related or possibly related to participstion in the research, and suggests that the resesrch places subjects or others at a greater risk of harm than was previously known or suspected. UPIRTSOs may or may not require suspension of the research. Esch incident is evalusted on a case by case bssis to make this determinstion. The IRB may require remedial sction or education ss deemed necessary for the investigator or sny other key personnel. The investigator is responsible for reporting UPIRTSOs to the IRB within 5 working days. Use the UPIRTSO form located within the iRIS system to report any UPIRTSOs.

\section{Continustion Review Requirements}

You sre responsible for submitting a continuation review 30 dsys prior to the expirstion dste of your research study. Investigators who allow their study approval to expire have committed significant non-compliance with federal regulations. Such lapses may require reporting to federal sgencies, a program audit by compliance auditors to ensure that subjects were not enrolled during the expired period, and may lead to findings of serious snd continuing noncomplisnce if expiration were to occur a second time.

The committee will be advised of this action at a regularly scheduled meeting.

If you have any questions, please contact the IRB analyst listed above or the Humsn Subjects Protection Program office st happofileicuiaville.edu.

Sincerely,

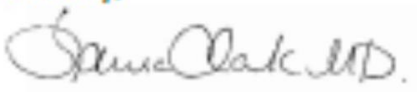

Laura Clark, M.D. Chair

Biomedicsl Institutionsl Review Bosrd 


\section{CURRICULUM VITA}

Name: Christine Marie Swanson

Address: $\quad 704$ Rudy Lane

Louisville, Ky 40207

DOB: $\quad$ Louisville, Kentucky ï February 6, 1987

\section{Education}

\& Training: B.A., Physics

Transylvania University

2005-09

M.S., Radiation Sciences

University of Kentucky

2009-11

Ph.D. Public Health- Management Systems Sciences

University of Louiville

2011-19

Awards:

Presidentô Scholarship

2005

Transylvania University

Transylvania Scholarship 2007

Transylvania University

Cralle Fellowship

2009

University of Kentucky

Daniel Reedy Quality Achievement 2009

University of Kentucky

\section{Employments:}

Clinical Physicist

Baptist Health Louisville

Radiation Oncology Clinical Coordinator

Louisville, KY

December 2013- Present 
Clinical Physicist

October 2012-December 2013

Physics Assistant/Resident

December 2010-October 2012

Diagnostic Physicist Assistant

May 2009-2011

AAPM Summer Fellow

Summer 2008
University of Louisville

Louisville, KY

University of Louisville

Louisville, KY

Bluegrass Physics

Lexington, $\mathrm{KY}$

University of Kentucky

Lexington, $\mathrm{KY}$

\section{Professional Societies}

Member of the Health Physics Society

2009 ï Present

Member of American Association of Physicists in Medicine

2009 ï Present

Member of AAPM Workforce Committee

2012- Present

Member of American Brachytherapy Society

$2011-2015$

Member of American Society of Therapeutic Radiation Oncology

2011 ї 2015

\section{Publications/Presentations}

Swanson, CM, Mills, M, ñFuture Trends in Demand and Supply for Radiation Oncology Physicistsò Presentation AAPM ORVC Chapter Meeting, Cincinatti, OH November 2018

Swanson, CM, Mills, M, ñFuture Trends in Demand and Supply for Radaition Oncology Physicists- 2018 Revisionò Presentation at AAPM Annual Meeting, Nashville, TN July 2018 
James, JA, Lynch, B, Swanson, CM, Wang, B, Dunalp, NE. ñQuantification of PTV Margin When Using Robotic Radiosurgery System to Treat Lung Tumors With Spine Tracking.ò Practical Radiation Oncology. Published online November 2014. Currently in Press.

Ram, N, Shaughnessy, J, Silverman, C, Bumpous, J, Potts, K, Redman, R, Cash, E, Swanson, $C$, Wilson, L, Dunlap, N. ñThe relationship between patterns of failure and human papilloma virus (HPV) status for squamous cell carcinoma of the oropharynx after definitive chemoradiotherapy: what role does elective nodal irradiation play?ò Journal of Radiation Oncology (2014): 1-7, November 22, 2014

Hogue, C, Blackburn, M, Swanson, C, Lynch, B, Wang,B, El-Ghamry,M, ñOptimum Frequency of Cone Beam Computed Tomography (CBCT) for Intact Prostate IMRTò Presentation ASTRO Annual Meeting, San Francisco, CA September 2014

James, JA, Swanson, CM, Lynch, B, Wang, B, Dunlap, NE. ñQuantification of PTV Margin when Using Robotic Radiosurgery System to Treat Lung Tumors With Spine Tracking.òPresentation ASTRO Annual Meeting, San Francisco, CA September 2014.

Sowards, K., Swanson, C., Blackburn, M., and Dragun, A., ñA Dosimetric Analysis of the Field In Field Technique for the Treatment of Breast Cancer: Can Such a Low Dose as Those Used in the Field in Field Technique Actually be Delivered as Planned on the Planning System,ò Presentation ASTRO Annual Meeting, Miami, Florida, October 2 ï 6 , 2011.

Meigooni AS, Luerman CM, Sowards KT. ñEvaluation of the dose distribution for prostate implants using various 125I and 103Pd sources.ò Medical Physics. 2009 April;36(4):1452-8. 